University of Tennessee Health Science Center

UTHSC Digital Commons

$12-2008$

\title{
The Tetraspanin CD9 Localizes to Platelet-Platelet Contacts and Regulates Thrombus Stability
}

\author{
Sarah Kathleen Hill \\ University of Tennessee Health Science Center
}

Follow this and additional works at: https://dc.uthsc.edu/dissertations

Part of the Medical Molecular Biology Commons

\section{Recommended Citation}

Hill, Sarah Kathleen, "The Tetraspanin CD9 Localizes to Platelet-Platelet Contacts and Regulates Thrombus Stability" (2008). Theses and Dissertations (ETD). Paper 350. http://dx.doi.org/10.21007/ etd.cghs.2008.0138.

This Dissertation is brought to you for free and open access by the College of Graduate Health Sciences at UTHSC Digital Commons. It has been accepted for inclusion in Theses and Dissertations (ETD) by an authorized administrator of UTHSC Digital Commons. For more information, please contact jwelch30@uthsc.edu. 


\title{
The Tetraspanin CD9 Localizes to Platelet-Platelet Contacts and Regulates Thrombus Stability
}

\author{
Abstract \\ CD9, a member of the tetraspanin family, is highly expressed on platelets $(50,000-80,000$ copies per \\ platelet). Tetraspanins have been implicated in modulation of integrin function, and it is hypothesized that \\ CD9 will modulate GPIIb-IIla, the major platelet integrin. \\ The association between CD9 and GPIIb-IIla was analyzed using immunoprecipitations and confocal \\ microscopy. These two proteins were found to associate with each other, particularly at areas of platelet- \\ platelet contact and at the periphery. Confocal analysis revealed CD9 localization was most intense at \\ platelet-platelet contact, as well as in platelet filopodia and lamellipodia, but there is a lack of CD9 at \\ areas of platelet-matrix contact. Co-localization with F-actin decreased as platelets progressed through \\ the stages of spreading.
}

In order to analyze CD9 contributions to platelet function, a Fab fragment was generated from mAb7, an antibody which binds with high affinity to the large extracellular loop of CD9. Fab fragments were used to avoid complications of bound antibody crosslinking CD9 with the platelet FcyRII receptor. Confocal analysis of platelet spreading indicated that CD9 perturbation by mFab7 resulted in increased platelet spreading on a variety of matrices, although platelet adhesion was unaffected on all matrices except fibrin. Platelet-platelet interactions, including aggregation and disaggregation, were studied using light transmission aggregometry. CD9 perturbation increased the extent of platelet aggregation in response to threshold levels of agonist, with diminished effect with more potent agonists such as TRAP (Thrombin Receptor Agonist Peptide). CD9 perturbation also diminished, but did not completely inhibit, platelet disaggregation induced by eptifibatide. Interestingly, CD9 perturbation did not alter platelet-mediated clot retraction of platelets in PRP (Platelet rich plasma). In response to CD9 alteration by mFab7, both increased fibrinogen binding and platelet activation (as evidenced by CD63 and P-selectin expression) were elicited in the presence of threshold ADP levels. Both responses were dependent on presence of low-level agonist, as CD9 perturbation in the absence of agonist yielded no effect.

Cytoskeletal isolation revealed that CD9 perturbation results in increased incorporation of actin and other cytoskeletal molecules into the platelet core cytoskeleton. Immunoprecipitations results showed increased CD63 incorporation into the tetraspanin web, although the level of CD9 coprecipitation with GPIIb-IIla was unaffected. A preliminary analysis of tyrosine phosphorylation, particularly Akt, did not reveal alterations on tyrosine phosphorylation of signaling molecules.

These results suggest that CD9 functions as a scaffold, organizing molecules into specific domains on the platelet surface. It appears to function as a "gatekeeper" for GPIIb-IIla activation, particularly modulating activation and aggregate stability at low levels of agonist.

\author{
Document Type \\ Dissertation \\ Degree Name \\ Doctor of Philosophy (PhD) \\ Program \\ Molecular Sciences
}




\section{Research Advisor}

Lisa K. Jennings, Ph.D.

\section{Keywords}

platelets, CD9, tetraspanin, integrin, aggregations, confocal

\section{Subject Categories}

Medical Molecular Biology | Medical Sciences | Medicine and Health Sciences 
THE TETRASPANIN CD9 LOCALIZES TO PLATELET-PLATELET CONTACTS AND REGULATES THROMBUS STABILITY

\author{
A Dissertation \\ Presented for \\ The Graduate Studies Council \\ The University of Tennessee \\ Health Science Center
}

\author{
In Partial Fulfillment \\ Of the Requirements for the Degree \\ Doctor of Philosophy \\ From The University of Tennessee
}

By

Sarah Kathleen Hill

December 2008 
Copyright $(92008$ by Sarah Kathleen Hil All rights reservedl 


\section{DEDICATION}

I gratefully dedicate this manuscript to my family, especially my husband, Michael Hill, for his endless patience and encouragement; our daughter Norah, for her motivation; and my parents, Kieth and Dianne Norris, for raising me to value education and enjoy scientific discovery. 


\section{ACKNOWLEDGEMENTS}

I would like to acknowledge the insights, direction, and support of my research advisor, Lisa K. Jennings, Ph.D. I also thank my committee members, Marshall Elam, MD, Ph.D., Eldon Geisert, Ph.D., Rod Hori, Ph.D., and Susan Senogles, Ph.D for their generosity with their talents and time.

I thank members of the Jennings laboratory, both past and present: Svetozar Grgurevich, Ph.D., Jayaprakash Kotha, Ph.D., Celia Longhurst, Ph.D., Melanie White, Shila Cholera, Henry Speich, Ph.D., Charlett Golden, and Mary Holmes for support and assistance.

I thank Michael Whitt, Ph.D. and Carolyn Matthews for their training and advice with using the confocal microscope and John Cox, Ph.D. for his knowledge and assistance in quantifying the confocal data.

I thank Patrick Ryan, Ph.D. for generously sharing his laboratory space and supplies while the Coleman Building was inaccessible.

Finally, thanks to Shirley Hancock, Deanna Delffs, Larry Tague, and David Armbruster, Ph.D., for formatting review; David M. Trayer, M.S., Myralin A.

Trayer, M.A., Siobhan Pehrson, and Michael Hill for proofreading; and the staff at the UT Help Desk for technical assistance.

This research was funded through the NIH Training grant 5T32HL00764119 from the National Heart, Lung and Blood Institute. The Zeiss LSM 510 was obtained through a Shared Instrumentation Grant (S10 RR13725) from the NIH. 


\section{ABSTRACT}

$\mathrm{CD9}$, a member of the tetraspanin family, is highly expressed on platelets (50,000-80,000 copies per platelet). Tetraspanins have been implicated in modulation of integrin function, and it is hypothesized that CD9 will modulate GPIIb-IIla, the major platelet integrin.

The association between CD9 and GPIIb-IIla was analyzed using immunoprecipitations and confocal microscopy. These two proteins were found to associate with each other, particularly at areas of platelet-platelet contact and at the periphery. Confocal analysis revealed CD9 localization was most intense at platelet-platelet contact, as well as in platelet filopodia and lamellipodia, but there is a lack of CD9 at areas of platelet-matrix contact. Co-localization with Factin decreased as platelets progressed through the stages of spreading.

In order to analyze CD9 contributions to platelet function, a Fab fragment was generated from $\mathrm{mAb7}$, an antibody which binds with high affinity to the large extracellular loop of CD9. Fab fragments were used to avoid complications of bound antibody crosslinking CD9 with the platelet FcyRII receptor. Confocal analysis of platelet spreading indicated that CD9 perturbation by $\mathrm{mFab} 7$ resulted in increased platelet spreading on a variety of matrices, although platelet adhesion was unaffected on all matrices except fibrin. Platelet-platelet interactions, including aggregation and disaggregation, were studied using light transmission aggregometry. CD9 perturbation increased the extent of platelet aggregation in response to threshold levels of agonist, with diminished effect with more potent agonists such as TRAP (Thrombin Receptor Agonist Peptide). CD9 perturbation also diminished, but did not completely inhibit, platelet disaggregation induced by eptifibatide. Interestingly, CD9 perturbation did not alter platelet-mediated clot retraction of platelets in PRP (Platelet rich plasma). In response to CD9 alteration by $\mathrm{mFab7}$, both increased fibrinogen binding and platelet activation (as evidenced by CD63 and P-selectin expression) were elicited in the presence of threshold ADP levels. Both responses were dependent on presence of low-level agonist, as CD9 perturbation in the absence of agonist yielded no effect.

Cytoskeletal isolation revealed that CD9 perturbation results in increased incorporation of actin and other cytoskeletal molecules into the platelet core cytoskeleton. Immunoprecipitations results showed increased CD63 incorporation into the tetraspanin web, although the level of CD9 coprecipitation with GPIlb-Illa was unaffected. A preliminary analysis of tyrosine phosphorylation, particularly Akt, did not reveal alterations on tyrosine phosphorylation of signaling molecules.

These results suggest that CD9 functions as a scaffold, organizing molecules into specific domains on the platelet surface. It appears to function as 
a "gatekeeper" for GPIIb-IIla activation, particularly modulating activation and aggregate stability at low levels of agonist. 


\section{TABLE OF CONTENTS}

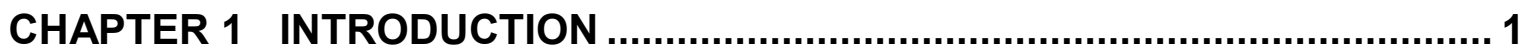

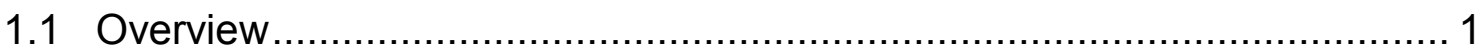

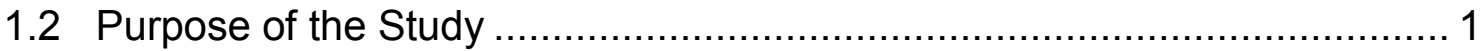

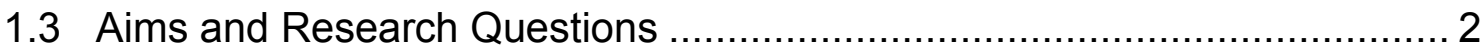

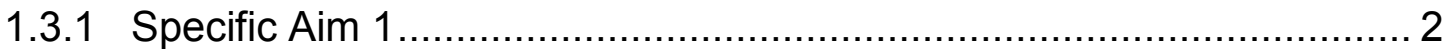

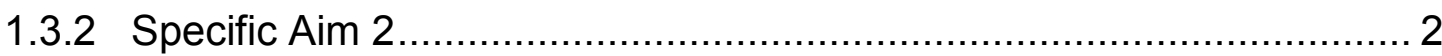

1.3.3 Specific Aim 3

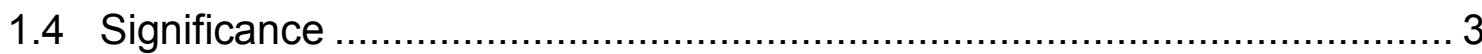

CHAPTER 2 REVIEW OF LITERATURE ................................................... 5

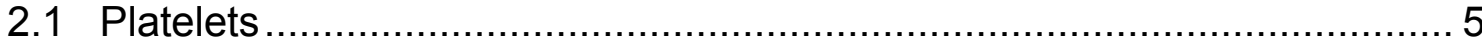

2.1.1 Platelet Formation and Function ..................................................... 5

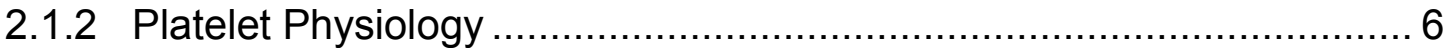

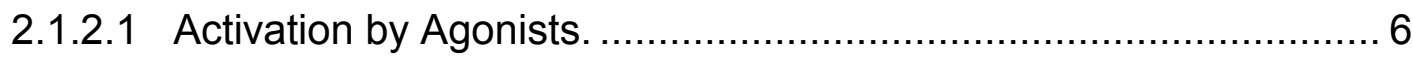

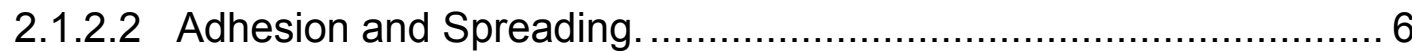

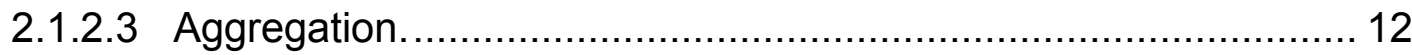

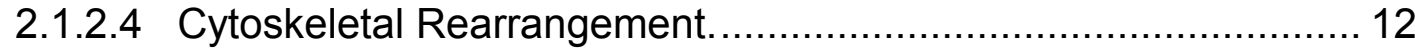

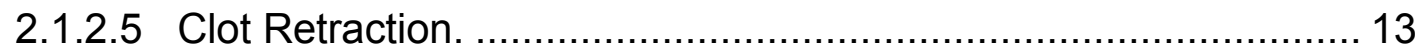

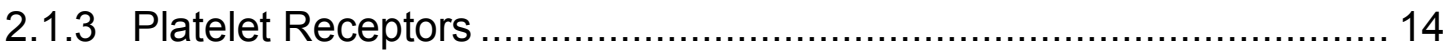

2.1.3.1 G Protein-Coupled Receptors ................................................ 14

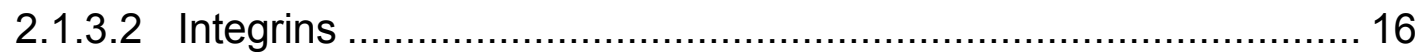

2.1.3.3 Leucine-Rich Repeat Proteins.................................................... 18

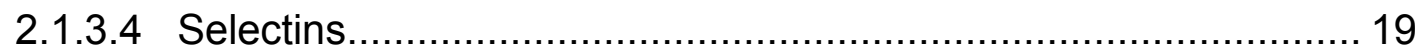

2.1.3.5 Immunoglobulin Receptors...................................................... 19

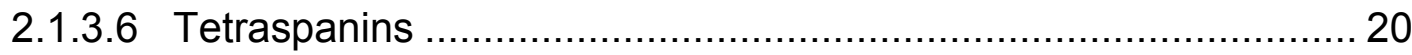

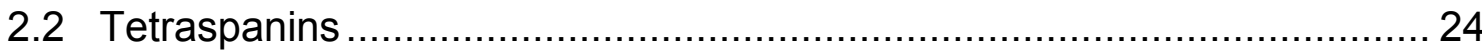

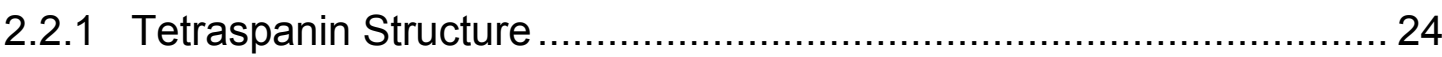

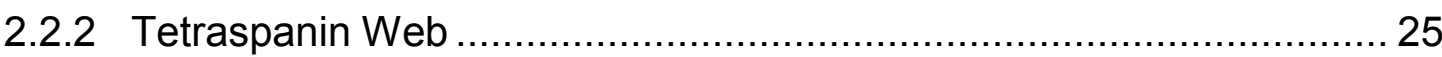

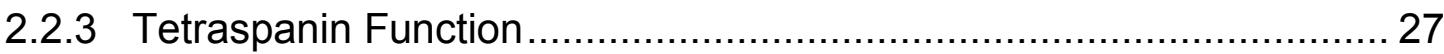

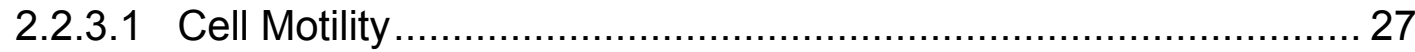

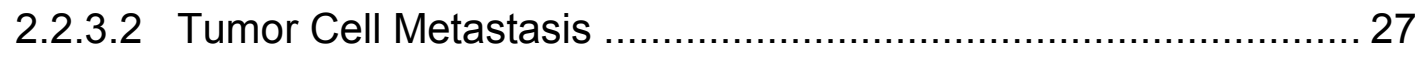

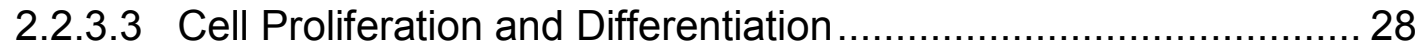

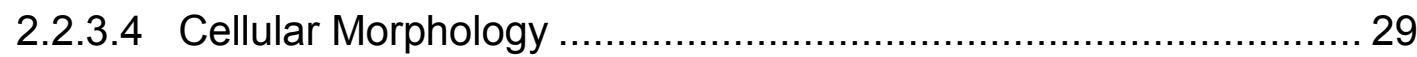

2.2.3.5 Virus-Induced Syncitia Formation ............................................ 29

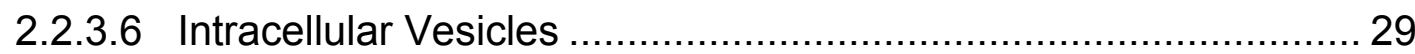

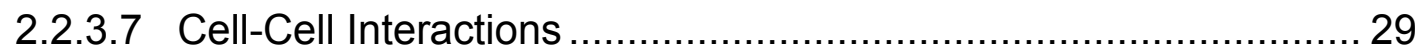

2.2.4 Tetraspanin CD9 ….......................................................... 30 


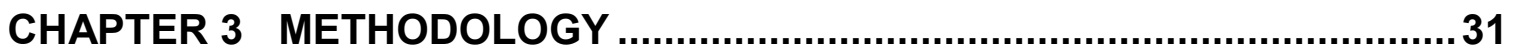

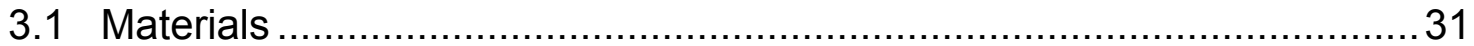

3.2 Tetraspanin Expression on Resting and Activated Platelets....................31

3.3 Association of CD9 and GPIIb-IIla in Resting and Activated Platelets.....34

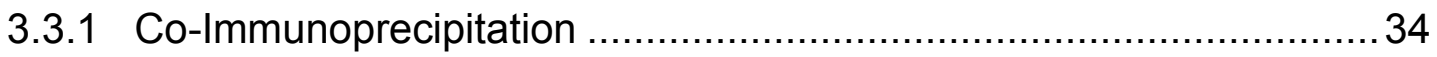

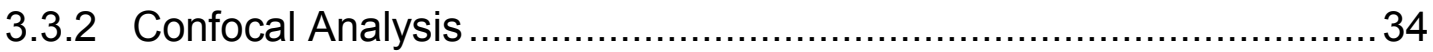

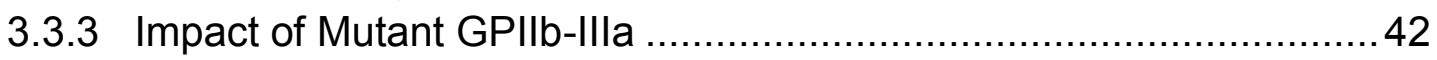

3.4 Localization of CD9 during Platelet Spreading ................................... 42

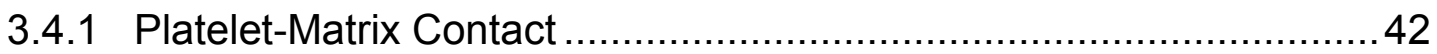

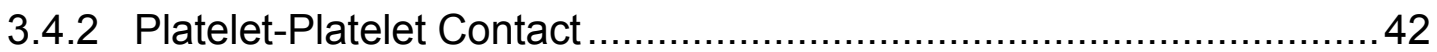

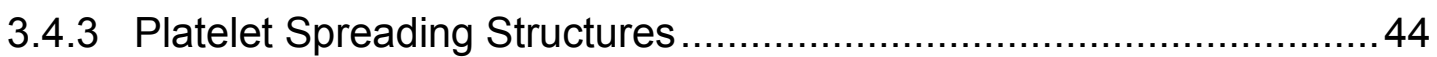

3.5 Generation and Purification of mAb7 Fab (mFab7) Fragments ............. 44

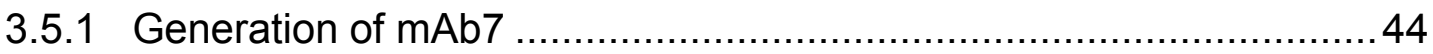

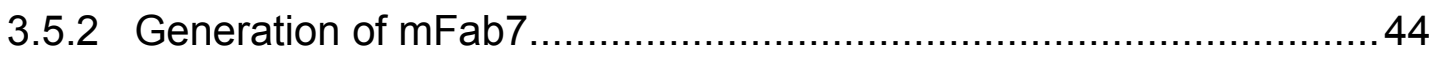

3.5.3 Determination of Purity and Function of mFab7 …............................4 44

3.5.3.1 Flow Cytometry ….......................................................... 44

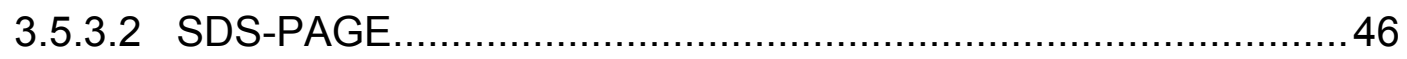

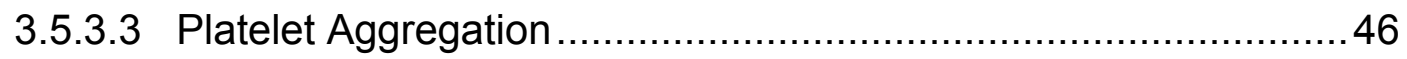

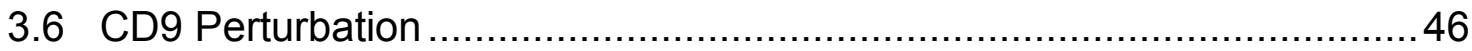

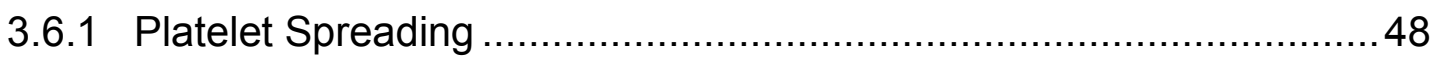

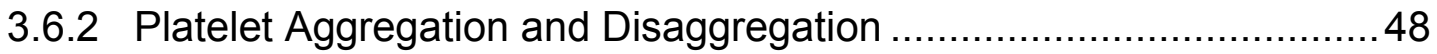

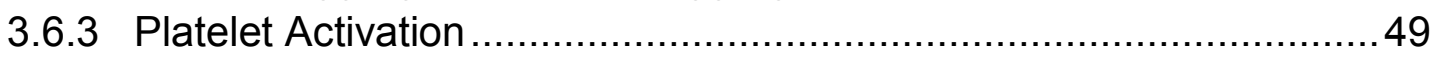

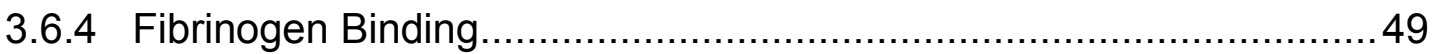

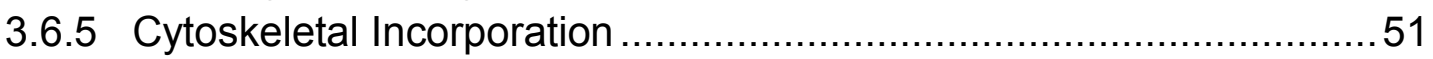

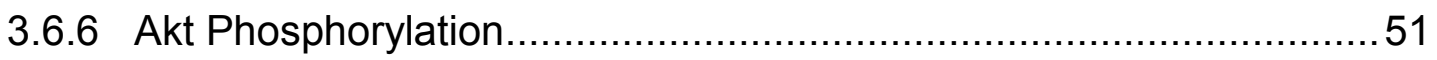

3.6.6.1 During Platelet Aggregation ............................................... 51

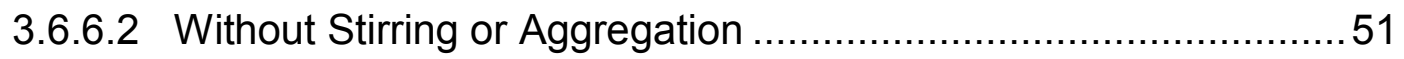

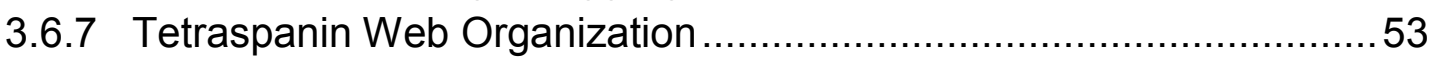

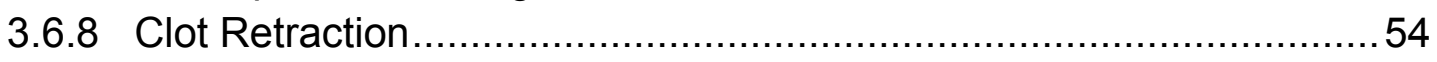

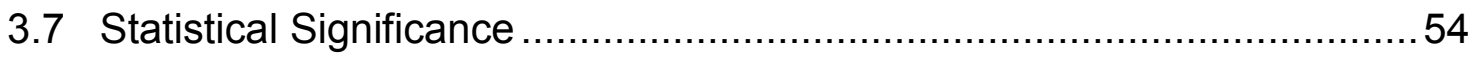

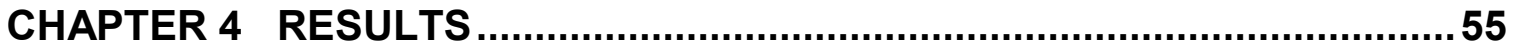

4.1 Tetraspanin Expression on Resting and Activated Platelets ...................55

4.2 Association of CD9 and GPIIb-IIla in Resting and Activated Platelets.....57

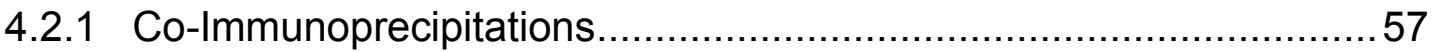

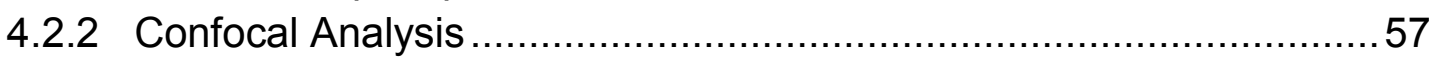

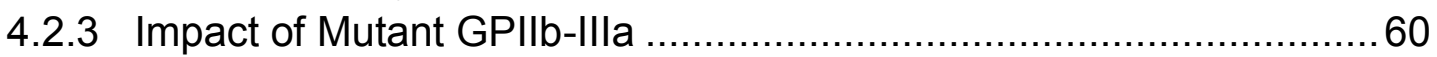

4.3 Localization of CD9 during Platelet Spreading......................................60

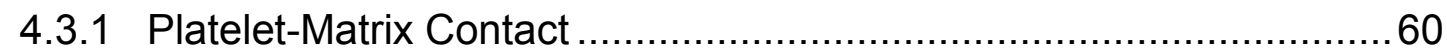

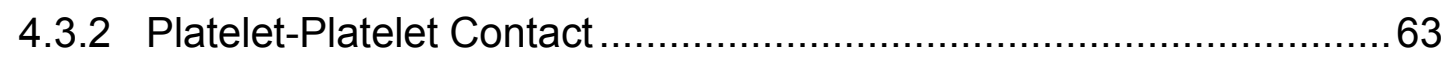

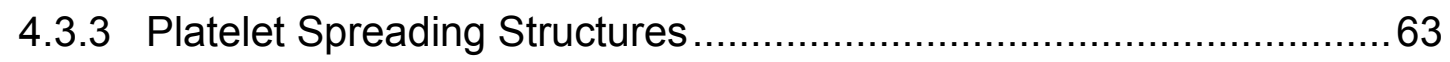


4.4 Generation and Purification of mAb7 Fab (mFab7) Fragments ..............66

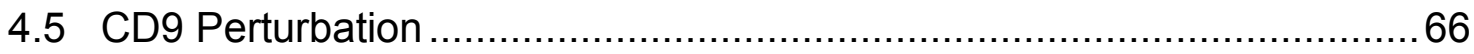

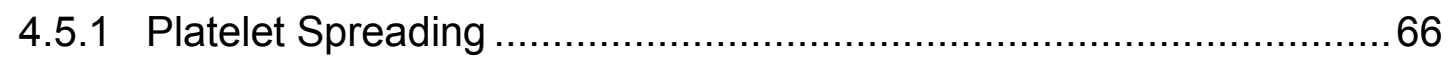

4.5.2 Platelet Aggregation and Disaggregation ................................... 70

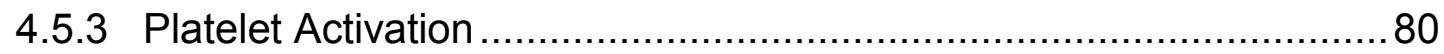

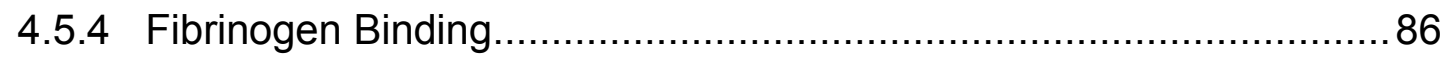

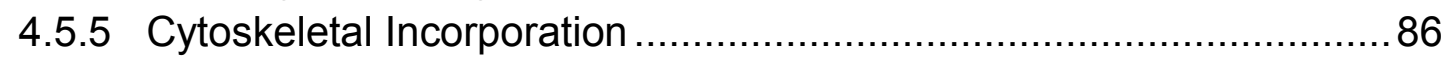

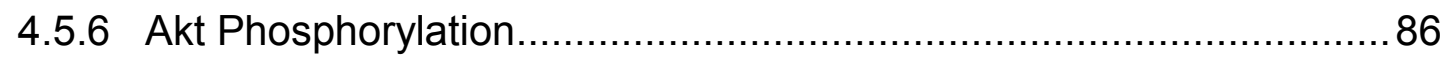

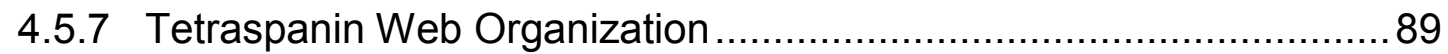

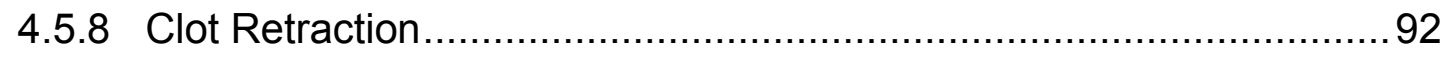

CHAPTER 5 CONCLUSIONS AND RECOMMENDATIONS ….....................94

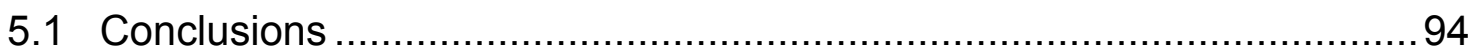

5.1.1 Localization and Protein Partners of CD9........................................ 94

5.1.2 Platelet Functions Affected by CD9 Perturbation ............................95

5.1.3 Mechanisms Involved in Contribution of CD9 to Platelet Function ....97

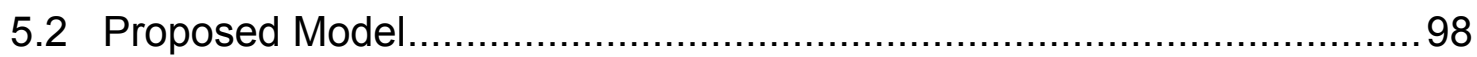

5.3 Recommendations for Future Study ............................................ 102

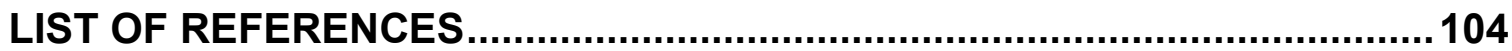

VITA 


\section{LIST OF TABLES}

Table 2.1 Comparison of Platelet Agonists …...................................... 7

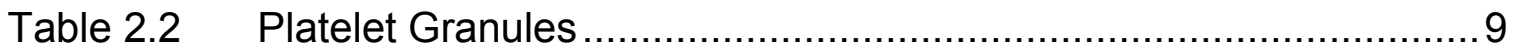

Table 2.3 Summary of Tetraspanins in Platelet Function ...........................21

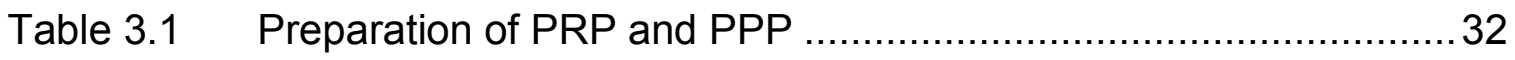

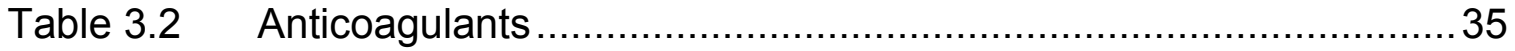

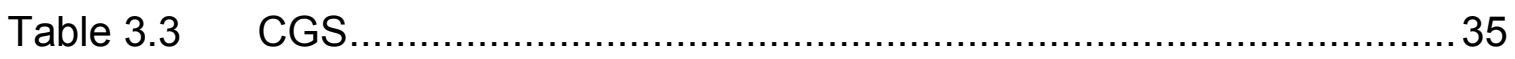

Table 3.4 Lysis Buffer for Immunoprecipitations........................................36

Table $3.5 \quad$ Formula for 1/3x NR Sample Buffer........................................... 37

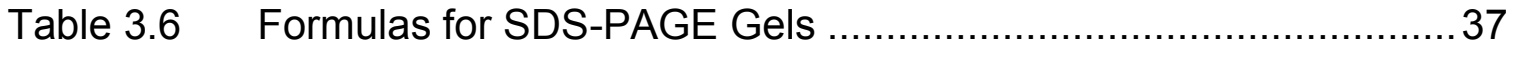

Table 3.7 Formula for Western Blot Buffers …........................................ 38

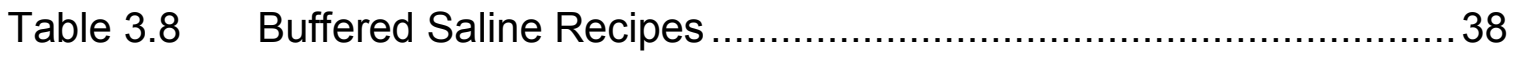

Table 3.9 Fibrin and Fibrin-Fibronectin Matrix Components.........................39

Table 3.10 Preparation of Washed Platelets ............................................ 40

Table 3.11 Modified Tyrode's Buffer (HEPES-Tyrode Buffer) ...................... 41

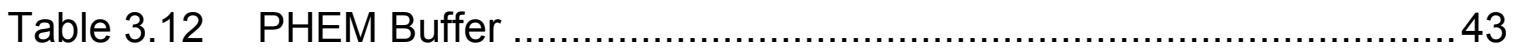

Table 3.13 Cytoskeletal Extraction Buffers, pH $7.4 \ldots \ldots \ldots \ldots \ldots \ldots \ldots \ldots \ldots \ldots \ldots \ldots \ldots . . .52$

Table 4.1 Perturbation of CD9 Affects Percent Platelet Aggregation ............79

Table 4.2 Perturbation of CD9 Affects Eptifibatide-Induced Platelet Disaggregation .................................................................. 84 


\section{LIST OF FIGURES}

Figure 2.1 Platelet Spreading Structures ............................................ 10

Figure 2.2 Platelet Activation Leading to Adhesion and Spreading or

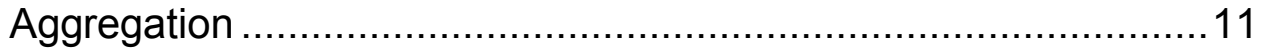

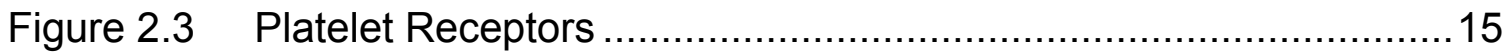

Figure 2.4 Schematic of Tetraspanin CD9 ..........................................22

Figure 2.5 Tetraspanin Web in Platelets...............................................23

Figure 3.1 Measurement of Surface Proteins by Flow Cytometry..................32

Figure 3.2 Antibody Cleavage and Purification of Fab Fragment .................45

Figure 3.3 Light Transmission Aggregometry ….....................................4

Figure 3.4 Eptifibatide-Induced Platelet Disaggregation .............................50

Figure 4.1 Expression of Tetraspanins on the Platelet Surface ....................56

Figure 4.2 Co-Immunoprecipitation of CD9 and GPIIb-IIla .........................58

Figure 4.3 Localization of CD9 and GPIlb-IIla in Spread Platelets ...............59

Figure 4.4 CD9 Localization in Glanzmann Thrombasthenia .......................61

Figure 4.5 Analysis of CD9 Localization in Platelet Sections with or without

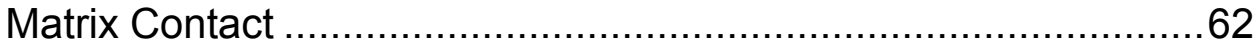

Figure 4.6 Localization of CD9 at Platelet-Platelet Contacts ........................64

Figure 4.7 Localization of CD9 and Actin during Platelet Spreading .............65

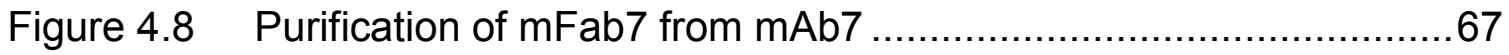

Figure 4.9 CD9 Affects Platelet Spreading on Fibronectin (FN), Fibrin (Fb), Fibrin-Fibronectin Matrix (Fb-FN), or Fibrinogen (FG) ..................71

Figure 4.10 Impact of CD9 Perturbation on Colocalization with F-actin............75

Figure 4.11 CD9 Affects Platelet Aggregation ..........................................76

Figure 4.12 CD9 Affects Eptifibatide-Induced Platelet Disaggregation .............81 


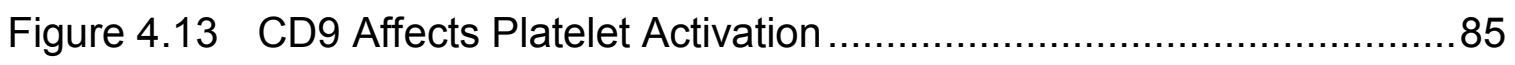

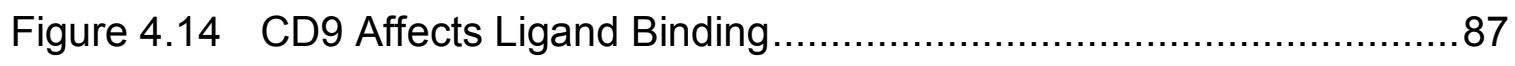

Figure 4.15 CD9 Alters the Platelet Core Cytoskeleton ................................88

Figure 4.16 CD9 Perturbation Does Not Appear to Alter the Phosphorylation

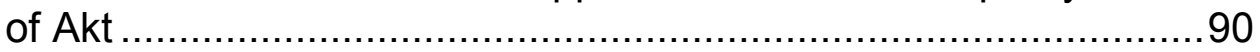

Figure 4.17 CD9 Perturbation Alters Tetraspanin Web Associations ...............91

Figure 4.18 mFab7 Interaction with CD9 Does Not Alter Clot Retraction .........93

Figure 5.1 Proposed Model of CD9 Function in Platelets ............................99 


\section{LIST OF ABBREVIATIONS}

$\begin{array}{ll}\text { ABP } & \text { Actin binding protein } \\ \text { ACD } & \text { Acid-citrate-dextrose } \\ \text { ADP } & \text { Adenosine diphosphate } \\ \text { Akt } & \text { Cellular signaling molecule } \\ \text { Arp } & \text { Actin-related protein } \\ \text { ATP } & \text { Adenosine triphosphate } \\ \text { BFU } & \text { Burst forming unit } \\ \text { BiP } & \text { Binding protein } \\ \text { BME } & \text { Beta-mercaptoethanol } \\ \text { BSA } & \text { Bovine serum albumin } \\ \text { CAMP } & \text { Cyclic adenosine monophosphate } \\ \text { CapZ } & \text { Capping protein } \\ \text { CD } & \text { Clusters of differentiation } \\ \text { CFU } & \text { Colony forming unit } \\ \text { CGS } & \text { Citrate-Glucose-Salt } \\ \text { CHO } & \text { Chinese hamster ovary cell line } \\ \text { CLEC } & \text { C-type lectin receptor } \\ \text { CMP } & \text { Common myeloid progenitor } \\ \text { Csk } & \text { C-terminal Src kinase } \\ \text { DAG } & \text { Diacylglycerol } \\ \text { EC } & \text { Extracellular } \\ \text { ECM } & \text { Extracellular matrix } \\ \text { EGF } & \text { Epidermal growth factor } \\ \text { EGTA } & \text { Ethylene glycol tetraacetic acid } \\ \text { ERK } & \text { Extracellular signal-regulated kinase } \\ \text { EWI-2 } & \text { Glu-Trp-lle (EWI) motif-containing protein 2 } \\ \text { Fab } & \text { Antigen-binding fragment of an antibody } \\ \text { Fak } & \text { Focal adhesion kinase } \\ \text { Fb } & \text { Fibrin } \\ \text { FbFN } & \text { Fibrin-fibronectin cross-linked matrix } \\ \text { FC } & \text { Constant fragment of an antibody } \\ \text { FG } & \text { Fibrinogen } \\ \text { FITC } & \text { Fluorescein isothiocyanate } \\ \text { FN } & \text { Fibronectin } \\ \text { GEMM } & \text { Granulocyte, erythrocyte, megakaryocyte, monocyte } \\ \text { GP } & \text { Glycoprotein } \\ \text { GTP } & \text { Guanosine triphosphate } \\ \text { HBEGF } & \text { Heparin binding EGF-like growth factor } \\ \text { HRP } & \text { Horseradish peroxidase } \\ \text { HSC } & \text { Hematopoietic stem cell } \\ \text { HT-1080 } & \text { Human fibrosarcoma tumor cells } \\ \text { ILK } & \text { Integrin-linked kinase } \\ \text { IBP } & \text { Integrin binding protein } \\ \end{array}$




$\begin{array}{ll}\text { IP3 } & \text { Inositol 3-phosphate } \\ \text { ITAM } & \text { Immunoreceptor tyrosine-based activation motif } \\ \text { ITIM } & \text { Immunoreceptor tyrosine-based inhibitory motif } \\ \text { KAI1 } & \text { Tetraspanin CD82 } \\ \text { kDa } & \text { Kilodalton } \\ \text { KO } & \text { Knock-out } \\ \text { LIBS } & \text { Ligand induced binding site } \\ \text { LSM } & \text { Laser scanning microscope } \\ \text { mAb } & \text { Monoclonal murine antibody } \\ \text { MAPK } & \text { Mitogen-activated protein kinase } \\ \text { MEP } & \text { Megakaryocyte-erythroid progenitor } \\ \text { MFI } & \text { Mean fluorescence intensity } \\ \text { MK } & \text { Megakaryocyte } \\ \text { NR } & \text { Nonreduced } \\ \text { P2Y } & \text { Purinergic receptor } \\ \text { PAR } & \text { Protease activated receptor } \\ \text { PBS } & \text { Phosphate-buffered saline } \\ \text { PETA } & \text { Platelet-endothelial cell tetraspan antigen } \\ \text { PHEM } & \text { Buffer containing PIPES, HEPES, EGTA, MgCl } 2 \\ \text { PI3K } & \text { Phosphoinositol 3-kinase } \\ \text { PIP2 } & \text { Phosphatidylinositol bisphosphate } \\ \text { PLC } & \text { Phospholipase C } \\ \text { PKB } & \text { Protein kinase B, also known as Akt1 } \\ \text { PKC } & \text { Protein kinase C } \\ \text { PP1c } & \text { Protein phosphatase 1 } \\ \text { PPP } & \text { Platelet-poor plasma } \\ \text { PRP } & \text { Platelet-rich plasma } \\ \text { PSG17 } & \text { Pregnancy specific glycoprotein 17 } \\ \text { PSGL } & \text { P-selectin glycoprotein ligand } \\ \text { PVDF } & \text { Polyvinyldifluoride } \\ \text { Rac } & \text { A small guanosine triphosphate, member of Ras family } \\ \text { RANKL } & \text { Receptor Activator of Nuclear factor-kB Ligand } \\ \text { rds } & \text { Retinal degeneration slow } \\ \text { Rho } & \text { A small guanosine triphosphate, member of Ras family } \\ \text { ROM-1 } & \text { Retinal outer segment membrane protein 1 } \\ \text { SDS-PAGE } & \text { Sodium dodecyl sulfate-polyacrylamide gel electrophoresis } \\ \text { SLP-76 } & \text { Adapter signaling protein } \\ \text { Src } & \text { A cytoplasmic tyrosine kinase } \\ \text { Syk } & \text { Spleen tyrosine kinase } \\ \text { TBS } & \text { Tris-buffered saline } \\ \text { TGF } & \text { Transforming growth factor } \\ \text { TM } & \text { Transmembrane } \\ \text { TM4SF } & \text { Tetraspanin super family } \\ \text { TP } & \text { Thromboxane A2 receptor } \\ \text { TRAP } & \text { Thrombin receptor agonist peptide } \\ \text { TRITC } & \text { Tetramethyl rhodamine isothiocyanate } \\ & \end{array}$


TSSC Tumor-suppressing subchromosomal transferable fragment cDNA

VASP Vasodilator-stimulated phosphoprotein

Vav

Signaling protein

vWF

WASP

von Willebrand factor

$\%$ PA

Wiskott-Aldrich Syndrome protein

Percent platelet aggregation

$\%$ PD

Percent platelet disaggregation 


\section{CHAPTER 1 INTRODUCTION}

\subsection{Overview}

Platelets are anucleate, disc-shaped cell fragments generated from megakaryocytes. They circulate through the vasculature and play a dual role in that they are critical for regulating hemostasis and wound healing (constituting a primary defense against bleeding) and thrombosis (which can lead to thrombotic disorders under pathological conditions). Platelets express a wide array of adhesion receptors that mediate adhesion, spreading, and cell-cell interactions. Tetraspanins are one family of proteins that modulate cell adhesion events in concert with integrins. Platelets express several tetraspanins-most prominently CD9-at 50,000-80,000 copies per platelet.

Tetraspanins constitute a unique class of integral membrane-spanning proteins. Four transmembrane domains, intracellular carboxy and amino termini, two extracellular loops, and unique motifs in the large extracellular loop characterize this family of proteins. Tetraspanins have been implicated in regulation of platelet integrin function, such as platelet adhesion, activation, and aggregation, yet the exact role of CD9 in human platelets has remained unclear. Based upon data in other cell model systems, it is hypothesized that CD9 may regulate platelet adhesive functions by regulating integrin activation and postreceptor occupancy events, such as thrombus stability.

\subsection{Purpose of the Study}

The purpose of this study is to determine the role of CD9 in human platelets. For the first time, the functional activity of CD9 in platelets will be defined by using a well-characterized anti-CD9 Fab fragment generated from an antibody (mAb7) that has been shown in other studies to modulate cell adhesive events. These data are critical for understanding which aspects of platelet function tetraspanins most influence and how tetraspanins, specifically CD9, may regulate platelet response to vascular injury. It is also hypothesized that CD9 function likely occurs on the platelet surface-such as adhesive functions or interaction with the integrin GPIIb-IIla-mediated through its extracellular loops. This is because specific motifs in its cytoplasmic domains known to interact with platelet signaling molecules or adaptor proteins have not been identified. Thus, CD9 through its extracellular loop regions may function at threshold levels of activation, with a role in regulating the extent of integrin activation.

Through understanding the function of CD9, the influences of platelet pathophysiological responses can be further appreciated. These findings may lead to advances in wound healing, hemostasis and thrombosis, and vascular 
bed diseases such as acute coronary syndromes by targeting CD9 and its function for pharmacological intervention.

\subsection{Aims and Research Questions}

\subsubsection{Specific Aim 1}

Determine the localization and protein partners of CD9 in human platelets. Flow cytometry will be performed to analyze CD9 expression in resting and activated platelets, which will shed insight if CD9 is primarily important in platelet activation or activated platelets, or if it primarily regulates other proteins during platelet events. Flow cytometry will also reveal relative surface expression of other members of the tetraspanin web in resting and activated platelets.

Immunoprecipitation and confocal microscopy will be used to determine the association and localization of CD9 and GPIIb-IIla, the primary platelet integrin. It is anticipated that CD9 might exert its effect through regulating the extent of GPIlb-IIla activation. These results will yield insight into the effect of platelet activation and integrin ligand binding on the CD9-GPIIb-IIla association by platelets spread on substrate and in suspension. Experiments with platelets expressing a mutant GPIIb-IIla will provide preliminary insight into possible areas of GPIlb-Illa critical to its association with CD9.

Confocal microscopy will also be used to analyze the localization of CD9 into platelet spreading structures such as filopodia, lamellipodia, and plateletplatelet contact sites to initially determine if CD9 is involved in platelet adhesive events. Co-localization with F-actin will yield insight into CD9's linkage with the cytoskeleton, although this could occur directly or indirectly through other members of the tetraspanin web.

\subsubsection{Specific Aim 2}

Determine platelet functions affected by CD9 perturbation. The effect of CD9 on platelet events will be determined by creating a Fab fragment which binds to the extracellular region of CD9. The full-length antibody has been shown to have a functional effect in smooth muscle cells and Chinese hamster ovary cells. A Fab fragment is used here to ensure that results are due to CD9 ligation without involvement of the receptor FcyRII.

Major platelet functions involved in this study include platelet aggregation and disaggregation, platelet adhesion and spreading on four substrate matrices-all of which are ligands for GPIIb-IIla, ligand binding and platelet activation (via flow cytometry), and platelet-mediated clot retraction. These 
events are mediated by GPIIb-IIla, and it is anticipated that CD9, by regulating this integrin, will alter these events.

Aggregation and disaggregation, ligand binding, and platelet activation will be analyzed using low concentrations of platelet agonists. It is anticipated that CD9 will function as a gatekeeper for integrin activation, and that its impact will be most pronounced at threshold levels of platelet activation. Stronger levels of agonist would be expected to overwhelmingly activate the integrin, regardless of CD9 signaling.

\subsubsection{Specific Aim 3}

Determine mechanisms involved in the contribution of CD9 to platelet function. This includes examination of the tetraspanin web, incorporation of cytoskeletal proteins into the core cytoskeleton, phosphorylation of key signaling molecules, and the effect of CD9 perturbation on each.

CD9 may function as a membrane protein scaffold, and may be critical in recruiting cell surface molecules and organizing signaling complexes in the tetraspanin web. In this role, CD9 may function to keep proteins in contact with or away from GPIIb-IIla or to maintain a desirable (active or inactive) conformation of GPIIb-IIla. Flow cytometry will analyze the impact of CD9 perturbation on association of CD9, GPIlb-IIla, and CD63 in resting and activated platelets. Platelet core cytoskeletons will be isolated and analyzed to determine the role of CD9 on the incorporation of cytoskeletal proteins. Platelet signaling molecules will also be evaluated, primarily phosphorylation of Akt. Research in our lab has shown the Akt pathway to be the primary CD9 signaling pathway (Kotha 2008). However, total tyrosine phosphorylation will also be analyzed to examine a possible involvement of another pathway.

It is anticipated that the linkage of CD9 to the cytoskeleton or signaling molecules is indirect, through GPIlb-Illa, due to the short intracellular regions of CD9, although a novel CD9 binding partner may be discovered. Since CD9 is likely involved in mediating activation of GPIlb-IIla, its cytosolic partners could also be altered.

\subsection{Significance}

Genetic research shows a biological significance for tetraspanins in mammalian systems. Inactivation of the tetraspanin TALLA-1 causes X-linked mental retardation (Zemni 2000); CD9 and CD81 knock-out mice have reduced fertility, with double knock-out mice being completely infertile (Kaji 2000, LaNaour 2000, Miyado 2000, Rubinstein 2006); and CD37 knock-out mice have reduced 
immune response. In the platelet system, CD151 or TSSC-6 knock-out mice have impaired integrin outside-in signaling (Goschnick 2006, Lau 2004).

Currently available studies of CD9 functions in platelets have yielded limited information. At present, there have been no published studies showing defects or abnormalities in platelet function in the CD9 knock-out mice; however, there is no information regarding expression levels of (and possible compensation by) other tetraspanins or integrins. Use of anti-CD9 antibodies have consistently activated signaling mechanisms through the receptor FcyRII, making interpretation of results difficult. In this study, Fab fragments will be used in place of antibodies; thus, CD9 ligation can still be achieved without the involvement of the FcyRII.

The results of this project will lead to better understanding of the basic biology of CD9 and its role in platelet function. This will add to the knowledge of platelet function that could lead to the development of pharmacological agents that target CD9 and arrest thrombosis.

These results will also lead to a broader understanding of cell adhesive function and better define a family of molecules that regulate integrins, key receptors in cell adhesion, differentiation, and proliferation of cells. The functional role of the CD9-GPIIb-IIla interaction is, at present, poorly defined. The ability of tetraspanins to modulate integrin conformation, as well as membrane complexes, ligand binding, and integrin-associated cell signaling pathways, will be more clearly defined, and our understanding of communication through platelet-platelet and platelet-matrix interactions will be advanced. 


\section{CHAPTER 2 REVIEW OF LITERATURE}

\subsection{Platelets}

\subsubsection{Platelet Formation and Function}

Platelets are small cell fragments released from megakaryocytes, composed of a membrane, cytoplasm, granules, and organelles. Approximately $10^{11}$ platelets are produced in the human body on a daily basis; once released from the bone marrow megakaryocytes, they circulate in the blood for seven to ten days (Harker 1969). Their function is to maintain vascular integrity by regulating hemostasis and thrombosis.

Megakaryocytes are derived from hematopoietic stem cells (HSCs), which evolve from the multipotent haemangioblast, the precursor for all blood and blood vessel cells. The HSC yields the early Common Myeloid Progenitor (CMP), which is cloned as the (Granulocyte, Erythrocyte, Megakaryocyte and Monocyte) Colony-Forming Unit (CFU-GEMM). The CMP differentiates into the Megakaryocyte-Erythroid Progenitor (MEP), which yields both the erythroid and megakaryocytic lineages, controlled by GATA-1 (which regulates granulocyte and monocyte precursors). Cytokines and chemokines, in response to environmental factors, allow differentiation of MEP into the highly proliferative BFU-MK (Megakaryocyte Burst-Forming Unit) or the more mature CFU-MK (megakaryocyte colony-forming unit). These cells progress into megakaryoblasts, which are incapable of cell division but able to replicate DNA (Deutsch 2006). This yields the immature, polyploid (up to $128 \mathrm{~N}$ ) megakaryocyte (Tomer 1988), containing elevated RNA levels, prominent ribosomes and rough endoplasmic reticulum, alpha and dense granules, and a primitive demarcation membrane. The maturing megakaryocyte develops a horseshoe-shaped nucleus and an expanded cytoplasm and amplifies platelet organelles and the demarcation membrane, which is continuous with the plasma membrane (Breton-Gorius 1976). The cell surface expresses GPIIb-IIla ( $\alpha$ llb $\beta 3$ ), GPIX, and GPIb, and the granules contain von Willebrand factor (VWF), platelet factor $4, \beta$ thromboglobulin, fibrinogen, coagulation factor VIII, and factor V (Breton-Gorius 1976). Megakaryocytes occur in about one in 2000 nucleated bone marrow cells, although this number may increase ten-fold in response to thrombocytopenia (Branehog 1975).

The megakaryocyte can extend long proplatelet projections; the demarcation membrane serves primarily as a membrane reservoir for proplatelet formation. These are filled with the proper specific organelles and granule contents, which migrate from the cell body to the proplatelet ends, to give rise to new circulating platelets (Italiano 1999, Italiano 2003). A single megakaryocyte may give rise to $2000-5000$ new platelets (Long 1988). Two models suggest how 
platelets arise: platelets may arise and bud off the tip of proplatelet (Choi 1995, Patel 2005), or there may be preformed territories with internal membranes that are released by fragmenting from the membrane (Mori 1993, Zucker-Franklin 1984).

Resting platelets circulate as small discs, approximately $0.5 \times 3.0 \mu \mathrm{m}$ in humans. An internal microtubule beneath the plasma membrane, composed of 13 stacks of tubulin subunits arranged head-to-tail in protofilaments, maintains the disc shape (Lecine 2000). It remains unclear whether the microtubule coil has any other function, as well as any advantage of a disc-shape (Hartwig 2006).

An internal actin filament cytoskeleton maintains platelet integrity. The two main components of the actin filament cytoskeleton are the membrane skeleton and the cytoplasmic actin scaffold.

Upon platelet activation, the microtubule reorganizes into multiple short microtubules that run from the platelet center toward outward protrusions, as well as a forming a compressed coil in the center of a spread platelet. Microtubule kinetics is controlled by dynein, a minus-end-directed motor, and kinesins, which are mainly plus-end-directed motors (Hartwig 2006).

\subsubsection{Platelet Physiology}

2.1.2.1 Activation by Agonists. Platelets express a number of agonist receptors: GPVI (collagen) (Clemetson 2001), PAR-1 and PAR-4 (thrombin) (Coughlin 2005), $\mathrm{P}_{2} \mathrm{Y}_{1}$ and $\mathrm{P}_{2} \mathrm{Y}_{12}$ (ADP) (Gachet 2006), and receptors for thromboxane A2 (Thomas 1998) and epinephrine (Pozgajova 2006). A summary of platelet agonists can be found in Table 2.1.

Platelet agonists can be found in increased concentrations at sites of vascular injury. They lead to platelet activation, causing shape change, integrin activation via inside-out signaling, and granule secretion (see $\underline{\text { Table 2.2). }}$.

2.1.2.2 Adhesion and Spreading. Immediately upon vascular injury, platelets tether to the exposed subendothelium and become activated by the agonists present at the site of injury (collagen and thrombin). Once activated, platelets become firmly adherent and will release their storage granules, which contain ADP and other substances (see Table 2.2). This in turn promotes additional platelet recruitment and platelet aggregation (Denis 2007) (see Fig 2.1 and Fig 2.2).

Initial platelet tethering is mainly carried out by the GPIb-IX-IV complex binding to exposed von Willebrand factor (VWF) (see Fig 2.2), which undergoes a conformational change when bound to the matrix or exposed to high shear conditions (Bergmeier 2000, Berndt 2001, Ruggeri 2003). The interaction 
Table 2.1 Comparison of Platelet Agonists

\begin{tabular}{|c|c|c|c|c|c|c|}
\hline Agonist & Receptor & $\begin{array}{l}\text { G } \\
\text { Protein }\end{array}$ & $\begin{array}{l}\text { Signaling } \\
\text { Molecules }\end{array}$ & Effect & Importance & $\begin{array}{l}\text { Medical } \\
\text { Targets }\end{array}$ \\
\hline \multirow[t]{2}{*}{ ADP } & $\mathrm{P} \mathrm{Y}_{1}$ & $\mathrm{Gq}$ & $\begin{array}{l}\text { PLC } 32 \text {, } \\
\text { RhoA, Rac, } \\
\text { Src kinase, } \\
\text { PKC }\end{array}$ & $\begin{array}{l}\text { Weak, } \\
\text { transient } \\
\text { activation } \\
\text { of GPIlb- } \\
\text { Illa }\end{array}$ & $\begin{array}{l}\text { Shape change, } \\
\text { initiation of } \\
\text { aggregation }\end{array}$ & \\
\hline & $\mathrm{P} 2 \mathrm{Y}_{12}$ & Gi2 & $\begin{array}{l}\text { Inhibit } \\
\text { adenylyl } \\
\text { cyclase } \\
\text { and } \\
\text { cytosolic } \\
\text { cAMP; } \\
\text { activate } \\
\text { PI3K, } \\
\text { Akt/PKB, } \\
\text { Rap1b, src } \\
\text { family } \\
\text { kinases }\end{array}$ & $\begin{array}{l}\text { GPIlb-IIla } \\
\text { activation, } \\
\text { dense } \\
\text { granule } \\
\text { release }\end{array}$ & $\begin{array}{l}\text { Sustained } \\
\text { aggregation } \\
\text { response, } \\
\text { leading to } \\
\text { thrombus } \\
\text { growth and } \\
\text { stabilization }\end{array}$ & $\begin{array}{l}\text { Ticlopidine } \\
\text { Clopidigrel }\end{array}$ \\
\hline \multirow[t]{2}{*}{ Thrombin } & PAR1 & $\begin{array}{l}\mathrm{Gq} \\
\mathrm{G} 12 / 13, \\
\mathrm{Gi}\end{array}$ & $\begin{array}{l}\text { PLC } \beta, \text { IP3, } \\
\text { DAG, PKC, } \\
\text { Rho/Rho } \\
\text { kinase, } \\
\text { inhibition of } \\
\text { adenylyl } \\
\text { cyclase }\end{array}$ & $\begin{array}{l}\text { Strong } \\
\text { activation } \\
\text { of GPIlb- } \\
\text { Illa in } \\
\text { response } \\
\text { to low } \\
\text { thrombin } \\
\text { levels }\end{array}$ & $\begin{array}{l}\text { Cytoskeletal } \\
\text { rearrange- } \\
\text { ment, shape } \\
\text { change, } \\
\text { degranulation, } \\
\text { adhesion }\end{array}$ & \\
\hline & PAR4 & $\begin{array}{l}\mathrm{Gq} \\
\mathrm{G} 12 / 13\end{array}$ & $\begin{array}{l}\text { PLC } \beta, \text { IP3, } \\
\text { DAG, PKC, } \\
\text { Rho/Rho } \\
\text { kinase, }\end{array}$ & $\begin{array}{l}\text { Strong } \\
\text { activation } \\
\text { of } \\
\text { GPIlb-IIla } \\
\text { in } \\
\text { response } \\
\text { to high } \\
\text { thrombin } \\
\text { levels }\end{array}$ & $\begin{array}{l}\text { Cytoskeletal } \\
\text { rearrangement, } \\
\text { shape change, } \\
\text { degranulation, } \\
\text { adhesion }\end{array}$ & \\
\hline \multirow[t]{2}{*}{ Collagen } & $\alpha 2 \beta$ I & ---- & $\begin{array}{l}\text { Syk, SLP- } \\
76, \text { PLC }\end{array}$ & $\begin{array}{l}\text { Activation } \\
\text { of GPIlb- } \\
\text { Illa }\end{array}$ & $\begin{array}{l}\text { Outside-in } \\
\text { platelet } \\
\text { activation }\end{array}$ & \\
\hline & $\begin{array}{l}\text { GPVI, } \\
\text { GPIV }\end{array}$ & ---- & $\begin{array}{l}\text { Src, Fyn, } \\
\text { Lyn, Syk, } \\
\text { PI3K }\end{array}$ & $\begin{array}{l}\text { Activation } \\
\text { of GPIlb- } \\
\text { Illa }\end{array}$ & $\begin{array}{l}\text { Calcium } \\
\text { release }\end{array}$ & \\
\hline
\end{tabular}


Table 2.1 (continued)

\begin{tabular}{lllllll}
\hline Agonist & Receptor & $\begin{array}{l}\text { G } \\
\text { Protein }\end{array}$ & $\begin{array}{l}\text { Signaling } \\
\text { Molecules }\end{array}$ & Effect & Importance & $\begin{array}{l}\text { Medical } \\
\text { Targets }\end{array}$ \\
\hline $\begin{array}{llllll}\text { Epin- } \\
\text { ephrine }\end{array}$ & $\begin{array}{l}\alpha 2- \\
\text { adrenergic } \\
\text { receptors }\end{array}$ & ---- & IP3, DAG, & $\begin{array}{l}\text { Activation } \\
\text { of GPIlb- } \\
\text { IIla }\end{array}$ & $\begin{array}{l}\text { Granule } \\
\text { secretion, } \\
\text { aggregation }\end{array}$ & $\begin{array}{l}\text { Aspirin, } \\
\text { others }\end{array}$ \\
\hline
\end{tabular}

Source:

Bennett JS. Structure and function of the platelet integrin allbb3. J Clin Invest. 2005; 115: 3363-3369.

Gachet C. Regulation of platelet functions by P2 receptors. Ann Rev Pharmacol Toxicol. 2006; 26: 277-300.

Kahner BN, Shankar H, Murugappan S, Prasad GL, Kunapuli SP. Nucleotide receptor signaling in platelets. J Thromb Haemost. 2006; 4 (11): 23172326.

Offermans S. Activation of platelet function through $\mathrm{G}$ protein-coupled receptors. Circ Research. 2006; 99: 1293-1304.

Samaha FF, Kahn ML. Novel platelet and vascular roles for immunoreceptor signaling. Arterioscler Thromb Vasc Biol. 2006; 26: 2588-2593.

Voss B, McLaughlin JN, Holinstat M, Zent R, Hamm HE. PAR1, but not PAR4, activates human platelets through a Gi/o/phosphoinosite-3 kinase signaling axis. Molec Pharmacol. 2007; 71 (5): 1399-1406.

Watson SP, Auger JM, McCarty OJT, Pearce AC. GPVI and integrin allbß3 signaling in platelets. J Thromb Haemost. 2005; 3 (8): 1752-1762. 
Table 2.2 Platelet Granules

\begin{tabular}{|c|c|c|c|}
\hline Granule & Alpha Granules & Dense Granules & Lysosomes \\
\hline \# per platelet & 80 & 7 & $2-4$ \\
\hline Contents & $\begin{array}{l}\text { Growth factors, } \\
\text { coagulation proteins, } \\
\text { adhesion molecules, } \\
\text { cytokines, cell- } \\
\text { activating agents, } \\
\text { angiogenic factors, } \\
\text { platelet-specific } \\
\text { molecules } \\
\text { (coagulation factor V, } \\
\text { thrombospondin, P- } \\
\text { selectin, von } \\
\text { Willebrand factor), } \\
\text { endocytosed } \\
\text { molecules (FG); } \\
\text { some contain } \\
\text { exosomes }\end{array}$ & $\begin{array}{l}\text { High concentrations } \\
\text { of small molecules } \\
\text { important to cell } \\
\text { activation (ADP, } \\
\text { serotonin, calcium, } \\
\text { magnesium, } \\
\text { pyrophosphate, } \\
\text { nucleotides) }\end{array}$ & $\begin{array}{l}\text { Components of } \\
\text { endosomal- } \\
\text { lysosomal } \\
\text { degradative } \\
\text { pathway (acid } \\
\text { hydrolases, } \\
\text { cathepsins D and } \\
\text { E) }\end{array}$ \\
\hline Development & $\begin{array}{l}\text { Fusion of vesicles } \\
\text { budding from trans- } \\
\text { Golgi apparatus in } \\
\text { megakaryocytes, or } \\
\text { fusion of vesicles } \\
\text { endocytosed from } \\
\text { the plasma } \\
\text { membrane }\end{array}$ & $\begin{array}{l}\text { Endogenous } \\
\text { synthesis in } \\
\text { megakaryocytes; } \\
\text { may develop from } \\
\text { fusion with endocytic } \\
\text { vesicles }\end{array}$ & $\begin{array}{l}\text { Different } \\
\text { ontogeny than } \\
\text { alpha or dense } \\
\text { granules, yet } \\
\text { share common } \\
\text { antecedents }\end{array}$ \\
\hline Disorders & $\begin{array}{l}\text { Gray platelet } \\
\text { syndrome (variable } \\
\text { bleeding diathesis; } \\
\text { small abnormal } \\
\text { vesicles; defect in } \\
\text { formation or packing } \\
\text { of alpha granule) }\end{array}$ & $\begin{array}{l}\text { Dense Storage Pool } \\
\text { Deficiency } \\
\text { (decreased thrombus } \\
\text { formation, varying } \\
\text { hemostatic defect) }\end{array}$ & \\
\hline
\end{tabular}




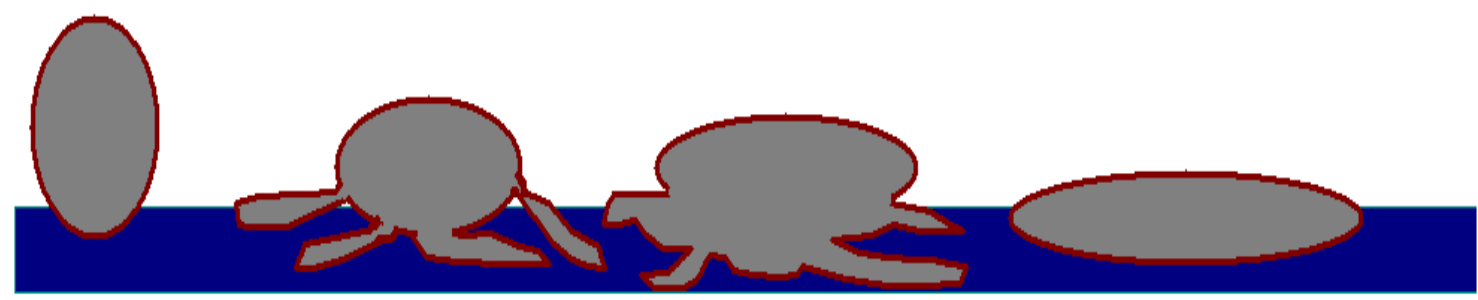

$\begin{array}{llll}\text { Newly } & \text { Filopodia } & \text { Gaps } & \text { Fully spread } \\ \text { adherent } & \text { are } & \text { between } & \text { platelets cover a } \\ \text { platelets } & \text { extended } & \text { filopodia are } & \text { wide surface area } \\ \text { have a round } & & \text { filled in with } & \\ \text { morphology } & & \text { lamellipodia } & \end{array}$

\section{Figure 2.1 Platelet Spreading Structures}

Platelets adhering to a matrix initially have a round morphology, but immediately extend fingerlike projections termed filopodia. Then lamellipodia are extended, which have been compared to webbing between a duck's toes. Finally, the membrane fully extends to allow the platelet to cover a large surface area. 


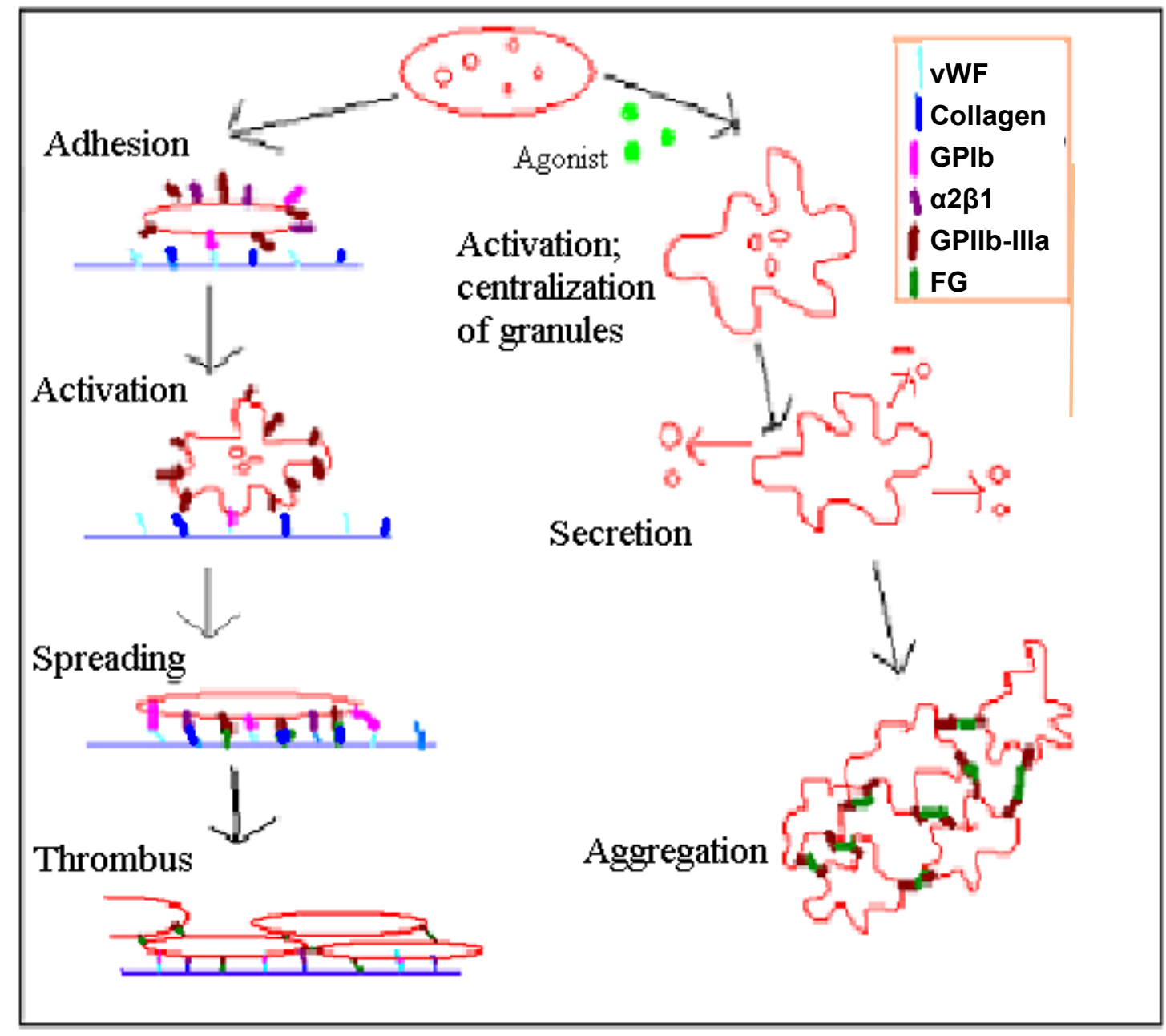

Figure 2.2 Platelet Activation Leading to Adhesion and Spreading or Aggregation

Interaction of the platelet receptors GPIb and $\alpha 2 \beta 1$ with vWF or collagen on the exposed subendothelium leads to platelet activation and spreading on the subendothelium. Nearby platelets are recruited to form a thrombus and maintain hemostasis. Platelets can also be activated by soluble agonists (such as ADP), leading to platelet activation, granule secretion, and aggregation via binding and crosslinking GPIIb-IIla on adjacent platelets. 
between GPIb and VWF can withstand very high shear rates, yet is characterized by fast association and dissociation rates, allowing slow platelet translocation along the vessel wall (Savage 1998). In the absence of VWF, GPIb can still initiate platelet tethering through other ligands, possibly thrombospondin-1 (Bergmeier 2006, Jurk 2003). Under cases of low shear, a direct interaction between exposed collagen in the subendothelium and the platelet receptors $\alpha 2 \beta 1$ and GPVI can support adhesion (Clemetson 2001).

Collagen and thrombin at the site of injury lead to platelet activation and inside-out signaling. As platelets then become activated, platelet integrinsparticularly GPIIb-IIla - transition from their inactive conformation to an active conformation capable of binding agonists and transmitting intracellular signals. Activated integrins then bind their ligand on the vessel wall, develop filopodia and lamellipodia and become fully spread, and release the contents of their granules (see also Table 2.2). ADP and thromboxane A2 are among the granule contents released, promoting activation, and leading to the formation of a platelet plug and arrest of bleeding (Coleman 2004).

2.1.2.3 Aggregation. The major platelet protein involved in aggregation is GPIlb-IIla (Fig 2.2), which is present in the platelet membrane and alpha granules, providing an extra pool of the integrin on the platelet surface upon platelet activation and granule release (Bennett 2005). Absent or dysfunctional GPIIb-IIla leads to the bleeding defect Glanzmann thrombasthenia, characterized by platelets that are unable to form stable aggregates (Nurden 2005). Fibrinogen is the major GPIIb-IIla ligand, capable of causing platelet aggregation by crosslinking GPIlb-IIla on adjacent platelets. Fibrinogen can also be converted to fibrin by thrombin; the resulting fibrin can cross-link with fibronectin, contributing to thrombus stability by anchoring the thrombi to the vessel wall.

Thrombus formation is not abolished in fibrinogen-deficient mice, and other ligands for GPIlb-IIla include vWF and FN (Ni 2000). vWF plays an essential role in occlusive thrombi formation at both arterial and venous shear rates (Nanda 2005, Ni 2000). Absence of VWF prevents additional thrombus growth and occlusion (Ni 2000). Additionally, in mice with reduced plasma FN levels, thrombus formation is highly defective, with increased emboli and delayed vessel occlusion (Ni 2003). However, this defect is specific to arteries, as no defect is found at venous shear (Matsukova 2006).

2.1.2.4 Cytoskeletal Rearrangement. In order for the platelet to be able to extend filopodia and lamellipodia, release its granules, and form stable aggregates, it must be able to rearrange its cytoskeleton.

Upon agonist exposure, platelets lose their discoid shape, becoming spherical and then rapidly extending filopodia and spreading on a surface. Shape change is driven by reorganization of the cytoskeleton and a doubling of the actin filament content (converted from globular actin) (Hartwig 2006). 
The membrane skeleton is first disassembled. It is released from actin and becomes centered in spread platelets. This is partly mediated by adducin, which is dissociated from spectrin and the barbed ends of actin. Adducin is inactivated by PKC-mediated phosphorylation, phosphatidylinositides, or calciumcalmodulin-binding (Matsuoka 2000).

The cortical actin network is then disrupted. Gelsolin (20,000 per platelet) and cofilin (100,000 per platelet) function to fragment actin filaments, resulting in F-actin disassembly: gelsolin severs and caps barbed ends, while cofilin promotes the disassembly of actin from pointed ends. Increasing cytosolic concentrations of calcium triggers a conformational change in gelsolin, allowing it to bind and fragment actin. Gelsolin remains bound to the barbed end of actin until it is removed by polyphosphoinositides. Cofilin must be dephosphorylated to become active, requiring 15 to 60 seconds for maximal activation (Falet 2005). Gelsolin and cofilin, combined with the release of adducin from spectin-actin, remodel the membrane and actin cytoskeletons.

New actin filament assembly is initiated from the ends of actin filaments adjacent to the plasma membrane. Formation of lamellipodia, required for circumferential platelet spreading on the surface, requires a large amount of Factin. This need is met as platelets double their cellular F-actin content as filaments form and grow through barbed-end growth, via uncapping and fragmentation of barbed filament ends and activation of actin-related protein 2/3 (Arp 2/3) (Hartwig 2006). Approximately 50\% of gelsolin is dissociated from barbed ends of actin filaments, and the Arp $2 / 3$ complex binds to actin near the barbed ends and nucleates a second filament. Upstream proteins and phospholipids, including Wiskott-Aldrich syndrome protein (WASP) family members and cortactin, regulate Arp 2/3 nucleation activity. Actin filament assembly is terminated via CapZ constitutively capping exposed barbed filaments; filopodial growth in cells can be promoted by modulating the activity of CapZ via proteins such as VASP/Mena (Gertler 1996, Mejillano 2004).

2.1.2.5 Clot Retraction. Platelet-mediated clot retraction is a necessary step for consolidation of a platelet thrombus. Retraction keeps the thrombus from falling apart by making it less susceptible to fibrinolysis (Denis 2007) and aids in wound closure, as the damaged edges are drawn together (Parise 1999).

Interactions between GPIIb-IIla and fibrin (which is cleaved from fibrinogen by thrombin) results in outside-in signaling. Clot retraction is brought about as tyrosine residues on the cytoplasmic tail of GPIlb are phosphorylated (Phillips 2001, Shattil 2004), and cytoskeletal assembly and molecular translocations occur (Parise 1999). Clot retraction appears to be regulated through multiple pathways, including activation of PLCß and Rho kinase, which activate MLC kinase and inhibit MLC phosphatase, and PLCY2 downstream of Src kinase (Suzuki-Inoue 2007). This process is dependent on the contractile 
protein thrombasthenin, as well as the interaction between actin and myosin (Suzuki-Inoue 2007).

\subsubsection{Platelet Receptors}

2.1.3.1 G Protein-Coupled Receptors. G-protein coupled receptors are one family of surface receptors involved in platelet activation (see Fig 2.3). These receptors contain seven membrane-spanning domains, and an intracellular and an extracellular terminus, and are also referred to as "seven transmembrane receptors" or serpentine receptors. The intracellular domain of each of these receptors is coupled to a distinct heterotrimeric $\mathrm{G}$ protein, belonging to either the $\mathrm{Gi}, \mathrm{Gq}, \mathrm{G} 12 / 13$, or $\mathrm{Gs}$ families. Upon activation, the $\mathrm{G}$ protein triggers an intracellular signaling cascade resulting in platelet shape change, granule secretion, and platelet aggregation via integrin activation.

G-protein coupled receptors in human platelets include the ADP receptors $\mathrm{P}_{2} \mathrm{Y}_{1}$ and $\mathrm{P}_{2} \mathrm{Y}_{12}$, the thrombin receptors PAR-1 and PAR-4, and the thromboxane A2 receptors TPa and TP $\beta$.

The $\mathrm{P} 2 \mathrm{Y}_{1}$ receptor is coupled to $\mathrm{Gq}$ and phospholipase $\mathrm{C} \beta$, which leads to activation of the small G proteins RhoA and Rac and Src kinases (Kahner 2006). Activation of PLC $\beta$ leads to hydrolysis of phosphatidylinositol 4,5-bisphosphate (PIP2) to inositol triphosphate (IP3) and diacyl glycerol (DAG), leading to calcium release, PKC activation, and weak, transient activation of GPIlb-IIla (Gachet 2006, Kahner 2006). $\mathrm{P}_{2 Y_{1}}$ is important for platelet shape change, the initial wave of reversible aggregation, thromboxane A2 generation, procoagulant activity, adhesion to immobilized fibrinogen, and thrombus formation under shear (Cattaneo 2005, Murugappan 2006).

$\mathrm{P}_{2} \mathrm{Y}_{12}$ is coupled to $\mathrm{Gi} 2$ (Gachet 2006). Activation leads to inhibition of adenylyl cyclase and inhibition of cytosolic cAMP concentration via the Ga subunit, and activation of phosphoinositide 3-kinase (PI3K), Akt/PKB, Rap1b, and src family kinases (Gachet 2006, Kahner 2006). This receptor is important for stable platelet aggregation, in addition to sharing many of the same functions as $\mathrm{P}_{2} \mathrm{Y}_{1}$ (Cattaneo 2005, Murugappan 2006). The combined action of both receptors is needed for full platelet aggregation in response to ADP (Cataneo 2005). P2Y 12 -blocking drugs such as clopidigrel and ticlopidine are clinically being used in the treatment of thrombotic disorders.

PAR1, which responds to low thrombin concentrations, and PAR4, which responds to higher thrombin concentrations, are activated by cleavage of an extracellular portion of the receptor. PAR4 is coupled to $\mathrm{Gq}$ and $\mathrm{G} 12 / 13$, and PAR1 is coupled to $\mathrm{G} 1, \mathrm{G} 12 / 13$, and $\mathrm{Gi}$ (Offermans 2006). Gq is coupled to PLC $\beta$, especially $\beta 2$ (leading to activation of PKC). G12/13 regulates the Rho/Rho kinase pathway, and Gi inhibits adenylyl cyclase (Offermans 2006). 


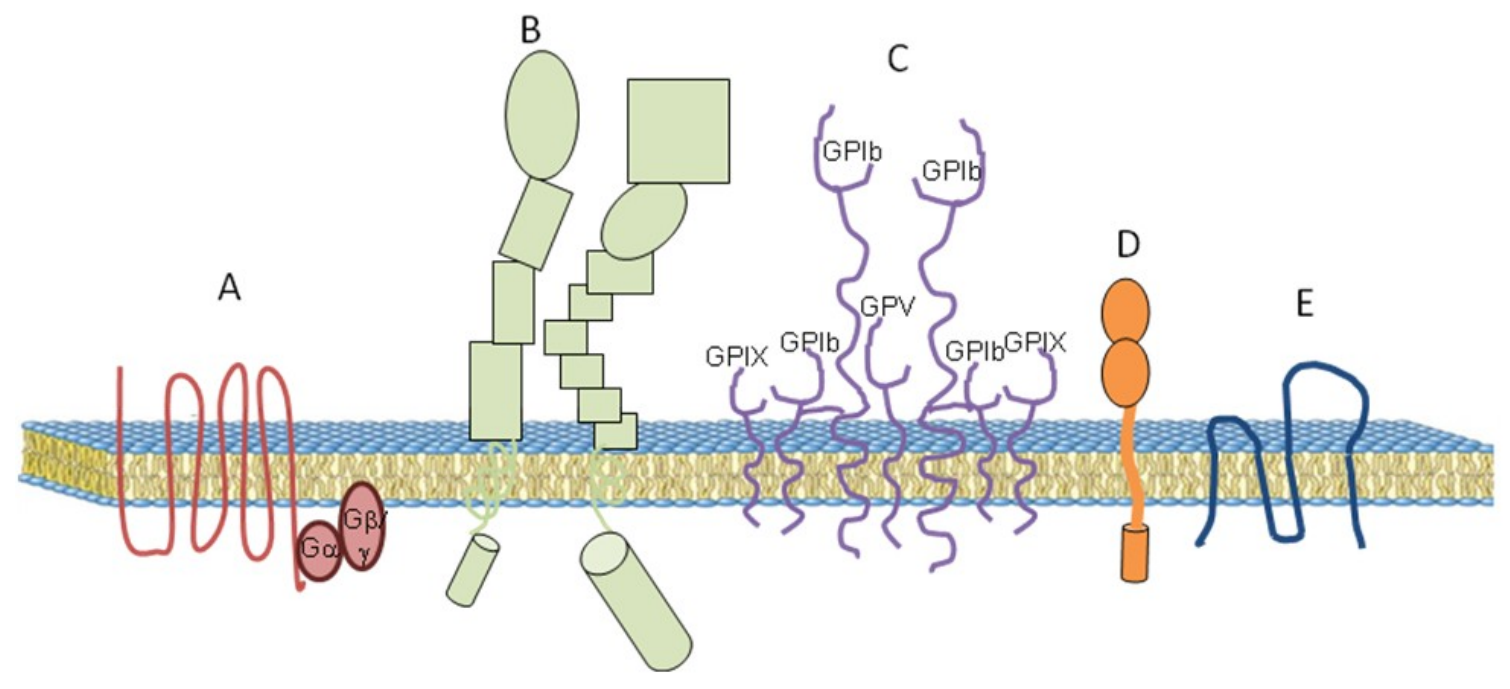

Figure 2.3 Platelet Receptors

$A$, G protein-coupled receptor; $B$, Integrin; $C$, Leucine-rich repeat protein; $D$, Immunoglobulin receptor; $E$, Tetraspanin. 
These steps lead to platelet cytoskeletal rearrangement, resulting in platelet shape change and platelet degranulation and adhesion (Offermans 2006).

TP $\alpha$ and TP $\beta$ are coupled to $\mathrm{G} 13$ and $\mathrm{Gq}$, resulting in activation of RhoGEF and PLC $\beta$. Both are important in platelet activation and shape change, and blockade of these receptors results in increased bleeding times and protection from thromboembolism (Murugappan 2004).

2.1.3.2 Integrins. Integrins are a family of integral cell-surface receptors made up of an alpha and a beta chain. Each chain consists of a large extracellular domain, a single transmembrane domain, and a short cytoplasmic domain (Fig 2.3). In mammals, 19 alpha and eight beta subunits combine to form 24 integrins (Humphries 2000). They mediate contact between a cell and its environment and transmit signals across the plasma membrane.

Integrins undergo a highly regulated structural change, providing a transition from a bent state with a low affinity for ligand binding (inactive) to an extended, open state with a high affinity for ligand binding (active) (Adair 2002, Takagi 2002, Vinogradova 2002). Conformational changes resulting from ligand binding may result in the unmasking of specific epitopes, separate from the ligand-binding domain, on the integrin. These "ligand-induced binding sites", or LIBS, offer a means to study integrin activation and ligand binding without occupying the ligand-binding domain.

Integrin signaling can be grouped into "inside-out" signals, which control activation of the integrin, and "outside-in" signals, resulting from ligand binding. Inside-out signaling results from a stimulus from another cell receptor (such as G Protein-Coupled Receptors), which leads to a stimulus acting on the cytoplasmic portion of the integrin and modifying the contacts between the cytoplasmic tails, leading to a change in the transmembrane domains and altering integrin affinity for ligand and integrin avidity (via integrin clustering on the cell surface). Outsidein signals lead to recruitment of intracellular signaling molecules and cytoskeletal proteins, resulting in changes in platelet cytoskeleton and morphology (AriasSalgado 2005; Han 2006; Tadokoro 2003).

Platelets express several integrins, including allb $\beta 3$, which binds fibrinogen, fibrin, fibronectin, and von Willebrand factor; $\alpha \mathrm{v} \beta 3$, which binds vitronectin; $\alpha 2 \beta 1$, which binds collagen and laminin; $\alpha 5 \beta 1$, which binds fibronectin; and $\alpha 6 \beta 1$, which binds laminin. Of these, $\alpha$ llb $\beta 3$, or GPIlb-Illa, has the highest expression level, at 50,000-80,000 per platelet, and has been the most extensively characterized.

allb is composed of 1008 amino acids. The extracellular domain is composed of an $\mathrm{N}$-terminal $\beta$-propeller domain, thigh domain, and two calf domains. $\beta 3$ is composed of 762 amino acids, with an extracellular domain consisting of an A domain, plexin/semaphorin/integrin domain, four EGF 
domains, and a membrane-proximal $\beta$ TD domain (Xiong 2001). The extracellular domains of the $\alpha$ and $\beta$ subunits combine to form an ellipsoid "head" consisting of the $\beta$-propeller and A-domain, and two tails (Ma 2007). The transmembrane domains of each subunit form alpha helices that are believed to interact when the integrin is in a resting conformation (Adair 2002, Gottschalk 2005). The cytoplasmic tails form a complex between the membrane-proximal helices that is maintained by electrostatic and hydrophobic interactions; disruption of both these interactions leads to integrin activation (Ma 2006, Vinogradova 2002, Weljie 2002). The membrane-distal regions of the cytoplasmic tails include a divalent ion-binding site, although the significance of this feature is uncertain (Haas 1996). There is also a phosphotyrosine binding domain critical to integrin activation (Chen 1994, O'Toole 1995, Van der Geer 1995). More than 20 proteins have been identified as binding partners, most prominently talin (which links the integrin to the actin cytoskeleton and is critical in integrin-mediated focal adhesion formation) (Burridge 1996, Rees 1990). The cytoplasmic domains can also directly interact with the cytoskeletal proteins myosin, skelemin, filamin, $\alpha$ actinin, and F-actin; the adaptor/signaling proteins paxillin, Shc, and Grb 2; the protein kinases/phosphatases Src, Csk, Syk, ILK, FAK, and PP1c; and BiP, Calreticulin, and $\beta 3$-endonexin (Ma 2007). allbß3 can also bind with the transmembrane proteins CD36, CD47/IAP, CD98, and CD31, as well as the tetraspanins CD9, CD63, and CD151, although these interactions likely involve interactions with the transmembrane and extracellular domains (Ma 2007).

Inside-out signaling of GPIIb-IIla is initiated by various platelet agonists, including thrombin, ADP, and collagen; each is capable of initiating inside-out signaling events, but they likely act cooperatively in a physiological environment. Agonist signaling leads to activated PKC, which regulates serine/threonine phosphorylation of GPIIb-IIla. DAG, calcium, and PI3K regulate GPIIb-IIla activation through Rab1b (a small GTPase of the Ras family), thus affecting binding of proteins, particularly talin, to the cytoplasmic domain of GPIIb-IIla (Focosi 2007). The head domain of talin activates GPIlb-IIla by binding to actin directly or indirectly through vinculin and $\alpha$-actinin. The binding of $\beta 3$-endonexin can also activate GPIIb-IIla by binding to the $\beta 3$ NITY motif. Integrin binding protein (IBP) binds to allb and appears to be involved in integrin activation (Platelets 2007).

Following inside-out signaling, the integrin GPIIb-IIla becomes competent to bind ligands (fibrinogen, fibronectin, fibrin, etc). Ligand binding alters the conformation of the integrin, as well as inducing integrin clustering. This further encourages binding of cytoskeletal proteins leading to outside-in signaling. Src kinases, which are constitutively bound to $\beta 3$, become activated through autophosphorylation. This leads to recruitment of Syk and tyrosine phosphorylation of PLCY2, which is necessary for lamellipodial formation. SLP-76 and Vav are also involved in regulation of PLCY2. GPIlb-IIla can also signal through Syk-independent cascades (Watson 2005). 
av $\beta 3$ is structurally similar to GPIIb-IIla, although its alpha chain has a slightly longer cytoplasmic tail (Suzuki 1986). Vitronectin, not fibrinogen, is the preferred ligand, although it can bind several RGD-containing ligands (including osteopontin and adenovirus penton base) (DiGiovine 2001). ADP appears to induce the high-affinity conformation (Bennett 1997, Helluin 2000).

$\alpha 2 \beta 1$ is the only platelet integrin to contain an I domain, which usually constitutes the primary ligand-binding interface (Emsley 1997). This integrin binds collagen types I-VI and XI (Kehrel 1995), leading to ADP release (Atkinson 2003, Jung 2000) and phosphorylation of Src kinases, SLP-76, Syk, and PLC (Inoue 2003). Its absence leads to a bleeding disorder and reduced platelet response to collagen, although GPVI appears to be most important in collagenmediated platelet activation (Kehrel 1995, Nieuwenhuis 1985).

a5 $\beta 1$ is important for platelet interaction with the fibronectin matrix. Unlike the $\beta 3$ integrins, it can support adhesion under static conditions in the absence of platelet activation (McCarty 2004), although adhesion strength may be increased upon activation (Garcia 1998). Ligand interaction is unable to promote tyrosine phosphorylation, calcium release, or shape change (McCarty 2004), limiting the role of this integrin to initiating the interaction of resting platelets with the extracellular matrix (Kasirer-Friede 2007).

$\alpha 6 \beta 1$ is a receptor for laminins, a component of basement membranes and the extracellular matrix (Sonnenberg 1988). Platelet activation is not necessary for ligand binding (Sonnenberg 1991), and binding to laminin does not appear to induce granule release or aggregation (Nigatu 2006), although it does induce filopodial formation (Chang 2005).

2.1.3.3 Leucine-Rich Repeat Proteins. GPIb-IX-V is a platelet adhesion receptor in the Leucine-rich repeat family. Its major function is initiating thrombus formation at high shear stress in flowing blood (Andrews 2003). It binds to VWF in the subendothelial matrix or plasma, as well as Mac-1 on neutrophils and Pselectin on activated platelets and endothelial cells (Andrews 2003). Its absence or dysfunction leads to Bernard-Soulier syndrome, a rare but often severe bleeding disorder (Andrews 1997, Berndt 2001, Lopez 1998).

GPIb-IX-V consists of GPIba disulfide-linked to GPIb $\beta$, noncovalently complexed with GPIX and GPV in a 2:2:2:1 ratio (Fig 2.3) (Andrews 1997, Berndt 2001, Lopez 1998). All components are members of the leucine-rich repeat family. The N-terminal portion of GPIba, consisting of eight leucine-rich repeats, contains binding sites for VWF, Mac-1, P-selectin, $\alpha$-thrombin, clotting factors $\mathrm{XI} / \mathrm{XIla}$, and high-molecular-weight kininogen (Berndt 2001).

High shear results in GPIb-IX-V binding von Willebrand factor, which is rapidly secreted following platelet activation. Following binding, platelets become activated, leading to shape change, spreading, and granule secretion caused by cytoskeletal rearrangement, recruiting additional platelets to the developing 
thrombus. GPIb-IX-V signal transduction, involving PI-3-kinase, Syk, Src, and ERK-1/2, leads to activation of GPIlb-Illa, mediating platelet aggregation (Andrews 2003, Berndt 2001).

In order to be competent to adhere and signal, GPIb-IX-V undergoes multiple post-translational modifications. GPIb sulfation within the ligand-binding domain regulates adhesion to VWF (Dong 2001, Huizinga 2002, Shen 2000, Tait 2002, Uff 2002) and thrombin (Berndt 2001); glycosylation of GPIb extends the ligand-binding domain and allows adhesion (Lopez 1998); cytoplasmic palmitoylation of GPIb and GPIX may regulate surface localization and association with other membrane proteins (Lopez 1998), and phosphorylation allows association with the signaling protein 14-3-3 (Bodnar 1999, Gu 1999).

2.1.3.4 Selectins. Selectins are proteins that bind glycoproteins and glycolipids in a calcium-dependent manner. They consist of an extracellular $\mathrm{N}$ terminal lectin domain adjacent to a domain homologous to epidermal growth factor, a variable number of short consensus repeats, a single transmembrane domain, and a C-terminal cytoplasmic domain (Sperandion 2006, Thomas 2006).

Platelets express the P-selectin, also known as CD62P. P-selectin is found in alpha granules of platelets and is rapidly mobilized to the cell surface upon platelet activation, where it binds to P-selectin glycoprotein ligand 1 (PSGL1) and Sialyl Lewis $X$-bearing glycoproteins (Smith 2007). The interaction between P-selectin and PSGL-1 allows platelet tethering to leukocytes under shear conditions and may contribute to leukocyte activation (Pitchford 2005, Zarbock 2006).

2.1.3.5 Immunoglobulin Receptors. Platelet Fc receptors mediate immune responses to IgG-containing complexes, implicating platelets in the adaptive immune response. These receptors contain immunoreceptor tyrosinebased activation motifs (ITAMS) (Fig 2.3) (Reth 1989), and upon ligand binding, Src-family kinases phosphorylate tyrosine residues within the ITAM sequence, leading to recruitment and activation of Syk or ZAP-70 tyrosine kinase, initiating downstream signaling events (Fodor 2006). These responses seem to be regulated by the phosphoinositides $\mathrm{PI}_{4,5} \mathrm{P} 2$ and $\mathrm{Pl}_{3,4,5} \mathrm{P} 3$ (Booth 2006). The activation pathways are inhibited by immunoreceptor tyrosine-based inhibitory motifs (ITIMs), which bind to the downstream tyrosine phosphatases (Jackson 1997). In platelets, ITAM/ITIM signaling may be involved in hemostatic regulation as well as immune responses (Kasirer-Friede 2007).

Fc receptors are of particular importance in this study due to a localization and association of $\mathrm{Fc}$ receptors with tetraspanins. Anti-CD9 monoclonal antibodies crosslink CD9 to FcyRII, eliciting a potent activation response. While the functional relevance of this interaction has yet to be elucidated, tetraspanins have been shown to negatively regulate FcR signaling independently of coligation, possibly through interactions within the tetraspanin web (Moseley 2005). 
Other receptors coupled to $\mathrm{Fc}$ receptors include GPVI, a collagen receptor (Berlanga 2000, Nieswandt 2000); GPIb-IX-V, a vWF receptor (Wu 2001, Arthur 2005); and potentially C-type lectin receptor-2 (CLEC-2), which has an as-yet unknown function in platelets (Gross 2006).

2.1.3.6 Tetraspanins. The structure and function of tetraspanins is discussed more fully in the following sections. Tetraspanin function in platelets is summarized in Table 2.3.

Platelets express several tetraspanins, among them CD9, CD63, CD151, and TSSC-6 (Fig 2.3, Fig 2.4, and Fig 2.5). They are believed to modulate integrin function, and indeed, both antibody-blocking and knockout studies yield platelets with incomplete GPIlb-Illa functioning. Megakaryocytes have been shown to contain the transcripts for the tetraspanins NET5 (TSPAN9) and TSPAN33, and these may also be expressed at the protein level in platelets (Senis 2007).

The tetraspanin CD63, with an apparent molecular mass of $30-60 \mathrm{kDa}$, is expressed on platelet lysosomes in resting platelets and is expressed on the platelet surface upon exocytosis triggered by platelet activation. CD63 has been studied by blocking with a monoclonal antibody. These platelets retained normal adhesion to fibrinogen, but platelet spreading, F-actin reorganization, redistribution of vinculin, extensive tyrosine phosphorylation, and phosphorylation of Focal Adhesion Kinase (FAK) were diminished. CD63 was also shown to be linked to PI 4-kinase type II (Israels 2005).

The impacts of TSSC- 6 and CD151 in platelet function have been studied using knock-out mice. It is important to note that expression levels of integrin GPIlb-IIla is unaffected in these knock-outs (Goschnick 2006, Lau 2004).

TSSC-6 (Tumor-suppressing subchromosomal transferable fragment cDNA 6) is localized to the cell surface and in intracellular pools in murine platelets. Mice that are deficient for TSSC- 6 exhibit increased tail bleeding time, increased blood loss, and more rebleeds in a tail-bleeding assay, all features of unstable hemostasis. They also exhibit secondary instability in a ferric chloride oxidative injury model, showing greater time to vessel occlusion and a greater number of emboli forming during the observation period. Impaired "outside-in" signaling of GPIlb-IIla was evident, as these platelets had delayed clot retraction, defective spreading, and reduced aggregation at low concentrations of agonist ( $\leq 150 \mu$ M PAR-4, $5 \mu \mathrm{g} / \mathrm{ml}$ collagen). However, "inside-out" signaling was unaffected, as knockout mice showed normal fibrinogen binding, normal binding of an activation-dependent antibody to GPIIb-IIla, and normal alpha granule release (Goschnick 2006). 


\section{Table 2.3 Summary of Tetraspanins in Platelet Function}

\begin{tabular}{|c|c|c|c|c|c|}
\hline Tetraspanin & CD9 & CD9 & CD151 & CD63 & TSSC- 6 \\
\hline $\begin{array}{l}\text { Method } \\
\text { Studied }\end{array}$ & knock-out & $\begin{array}{l}\text { antibody } \\
\text { blocking }\end{array}$ & knock-out & $\begin{array}{l}\text { antibody } \\
\text { blocking }\end{array}$ & knock-out \\
\hline Species & Mouse & human & mouse & human & mouse \\
\hline Aggregation & Unknown & unknown & $\begin{array}{l}\text { reduced in } \\
\text { response to } \\
\text { PAR4, } \\
\text { collagen, } \\
\text { ADP }\end{array}$ & & $\begin{array}{l}\text { reduced in } \\
\text { response to } \\
\text { PAR4 } \\
<150 \text { uM, } \\
\text { Collagen } 5 \\
\mathrm{ug} / \mathrm{ml} \text {. }\end{array}$ \\
\hline Adhesion & Unknown & unknown & unaffected & unaffected & unaffected \\
\hline Spreading & Unknown & unknown & impaired & Impaired & impaired \\
\hline Ligand Binding & Unknown & unknown & $\begin{array}{l}\text { normal } \\
\text { soluble FG } \\
\text { binding }\end{array}$ & unknown & $\begin{array}{l}\text { normal } \\
\text { soluble FG } \\
\text { binding }\end{array}$ \\
\hline Activation & Unknown & unknown & unaffected & unaffected & $\begin{array}{l}\text { unaffected/ } \\
\text { similar P- } \\
\text { selectin } \\
\text { expression }\end{array}$ \\
\hline Cytoskeleton & Unknown & unknown & unknown & $\begin{array}{l}\text { impaired F- } \\
\text { actin } \\
\text { reorganiz- } \\
\text { ation, vinculin } \\
\text { distribution }\end{array}$ & unknown \\
\hline $\begin{array}{l}\text { Signaling } \\
\text { Molecules }\end{array}$ & Unknown & unknown & $\begin{array}{l}\text { normal } \\
\text { levels of } \\
\text { calcium and } \\
\text { IP3 }\end{array}$ & $\begin{array}{l}\text { reduced } \\
\text { phosphoryl- } \\
\text { ation of FAK. } \\
\text { IP's PI4- } \\
\text { kinase type II. }\end{array}$ & unknown \\
\hline Clot Retraction & Unknown & unknown & impaired & unknown & impaired \\
\hline Other insight & $\begin{array}{l}\text { possible } \\
\text { compen- } \\
\text { sation by } \\
\text { another } \\
\text { tetraspanin } \\
\text { or integrins } \\
\text { is unknown }\end{array}$ & $\begin{array}{l}\text { activation } \\
\text { of Fc } \gamma \text { RII } \\
\text { makes } \\
\text { interpret- } \\
\text { ation of } \\
\text { data } \\
\text { difficult }\end{array}$ & & & $\begin{array}{l}\text { increased } \\
\text { tail bleeding } \\
\text { time/ } \\
\text { rebleeding, } \\
\text { unstable } \\
\text { platelet } \\
\text { thrombi/ } \\
\text { more emboli }\end{array}$ \\
\hline
\end{tabular}




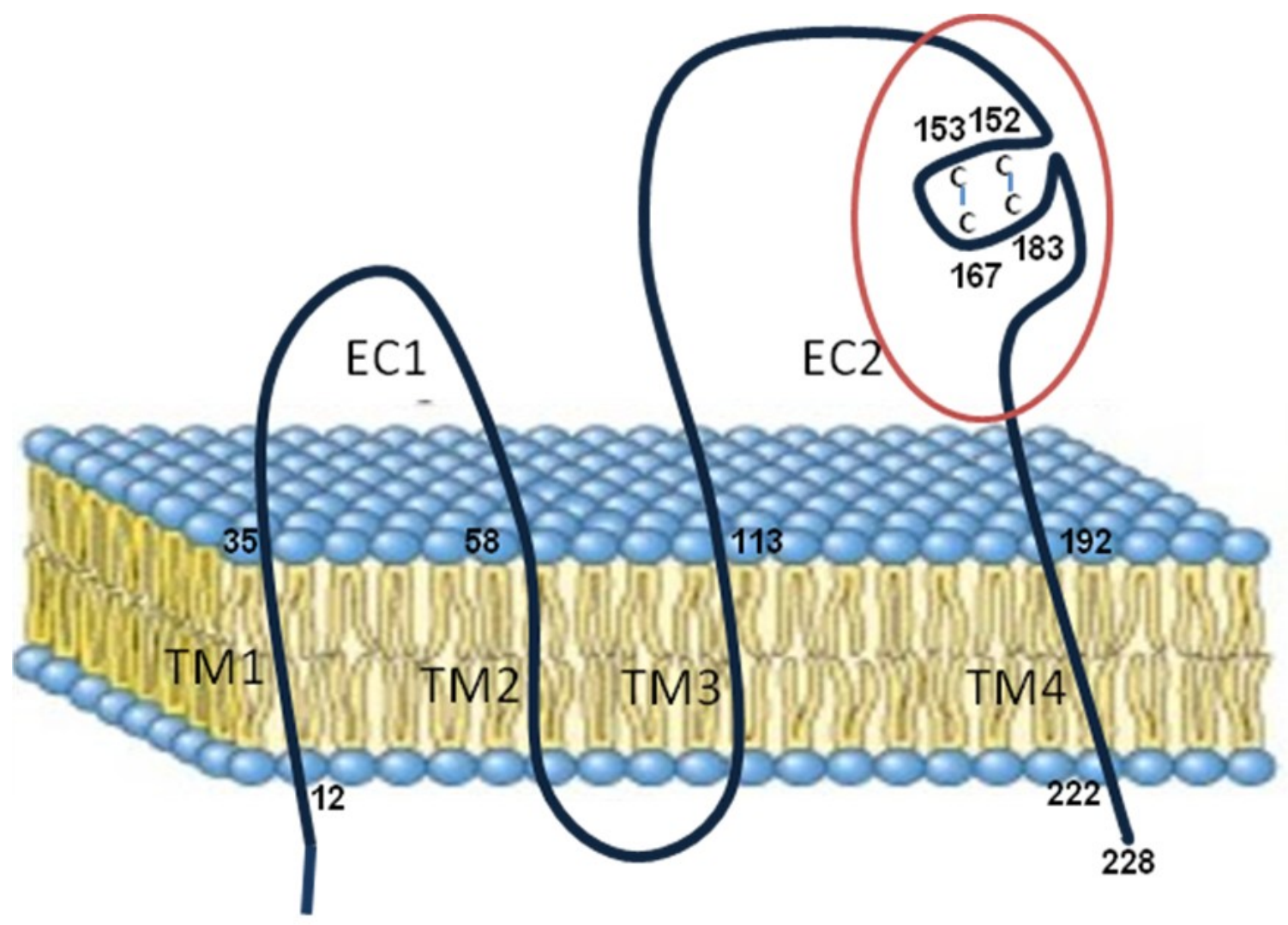

Figure 2.4 Schematic of Tetraspanin CD9

$T M$, Transmembrane domain; $E C$, extracellular loop. Numbers refer to amino acid residues. C-C, disulfide bond between cysteine residues. The area circled in red corresponds to the binding site for $\mathrm{mAb} 7 / \mathrm{mFab} 7$. 
A

allb $\quad \beta 3$

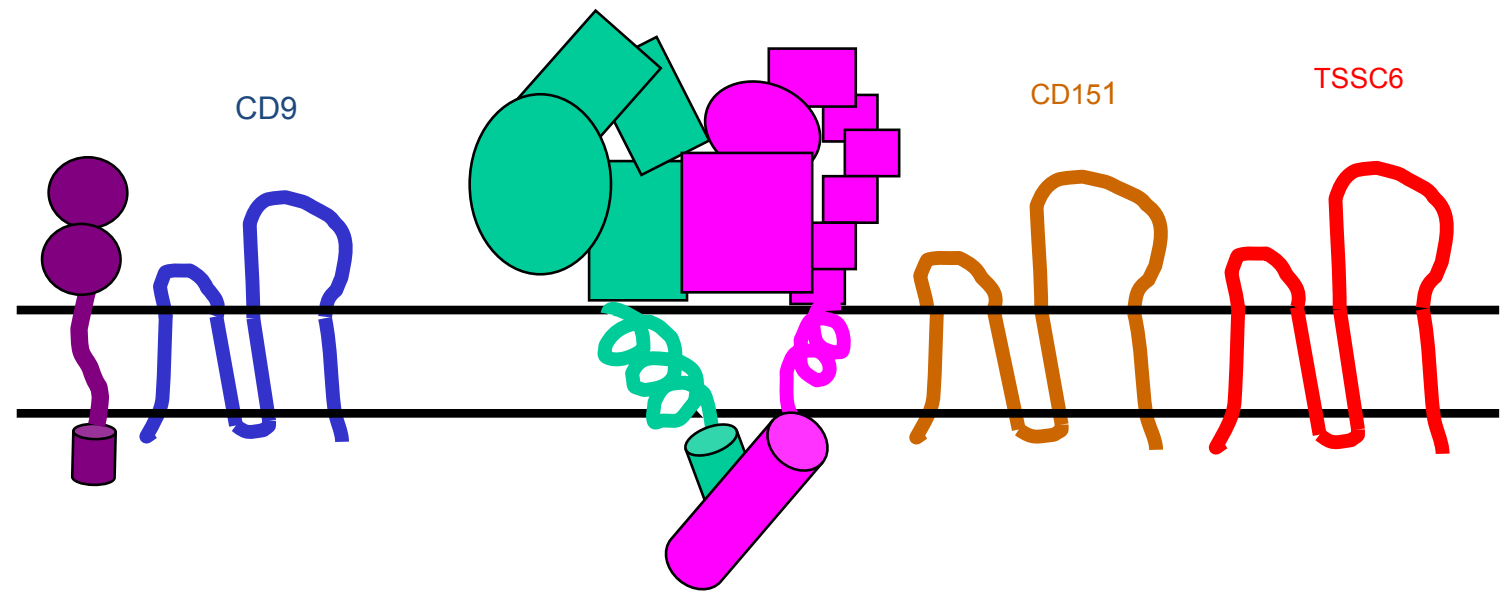

B

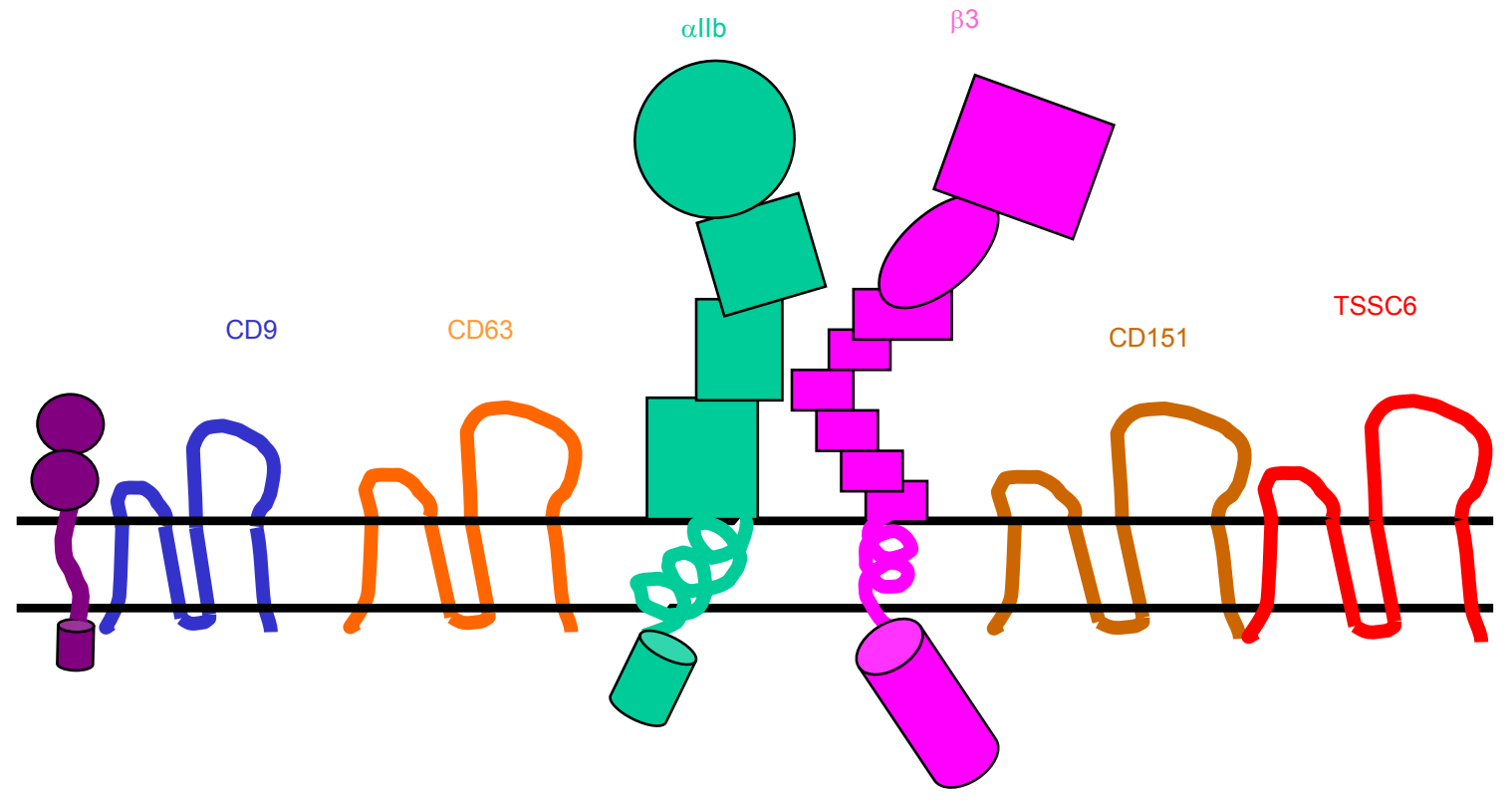

Figure 2.5 Tetraspanin Web in Platelets

$A$, Resting platelet membrane, expressing FcR, CD9, a bent (inactive) GPIIb-IIla, CD151, and TSCC6. B, Activated platelet membrane. GPIlb-Illa now assumes an extended conformation, capable of ligand binding. CD63 is also brought to the surface, in association with CD9 and GPIIb-IIla. 
CD151, also known as PETA-3 (platelet endothelial tetraspan antigen-3), is physically and functionally associated with GPIlb-Illa and modulates its "outside-in" signaling. CD151-deficient mice have delayed clot retraction; reduced aggregation to $500 \mu \mathrm{M}$ PAR $-4,20 \mu \mathrm{g} / \mathrm{ml}$ collagen, and $10 \mu \mathrm{M}$ ADP; and normal adhesion but incomplete spreading on fibrinogen, including reduced number of filopodia per platelet. Inside-out GPIlb-Illa signaling was normal, as these platelets had normal FG binding, normal binding of an activationdependent antibody to GPIIb-IIla, normal alpha and dense granule secretion, and normal increases in cytosolic-free calcium and IP3 levels (Lau 2004).

In spite of CD9 expression on the platelet surface being greater than other tetraspanins, and being greatly studied, it is still poorly understood. It is localized to the platelet surface membrane and alpha granules (Cramer 1994). Studies with antibody ligation to CD9 have been inconclusive due to the linkage to the low-affinity immunoglobulin $\mathrm{G}$ receptor, FcyRlla, in human platelets (Kuruda 1995, Qi 1996), although one study suggests that CD9 regulates platelet function independently of FcyRlla (Wu 2000).

CD9 knock-out mice have not shown any critical platelet defects; however, expression levels of other tetraspanins, integrins, and surface proteins have not been characterized, allowing the possibility of compensation. Additionally, studies involving CD9 knock-out platelets have not utilized low concentrations of agonists, which would be suggested based on studies with TSSC-6 knockout platelets.

CD9 (see Fig 2.4 and Fig 2.5) is proposed to have roles in platelet aggregation and spreading. It may facilitate platelet functions via its association with GPIlb-IIla or through direct ligand binding, as fibronectin has been shown to be a ligand for CD9 (Longhurst 2002).

\subsection{Tetraspanins}

\subsubsection{Tetraspanin Structure}

Tetraspanins are integral membrane proteins containing four transmembrane alpha-helices (TM1, TM2, TM3, and TM4), two extracellular loops (EC1 and EC2), and short intracellular amino and carboxy termini (Berditchevski 2001, Boucheix 2001, Hemler 2001). EC1, also known as the small extracellular loop, is flanked by TM1 and TM2, while EC2, also known as the large extracellular loop, is flanked by TM3 and TM4.

Proteins are identified as tetraspanins based on a shared overall structure distinct from other proteins with four transmembrane domains and the conservation of specific amino acid residues in their transmembrane domains 
and the second extracellular loop (Hemler 2001, Maecker 1997). These characteristic motifs include the conserved cysteine-cysteine-glycine (CCG) sequence in EC2, which is involved in two of the two to four disulfide bridges observed in EC2 of all tetraspanins (Seigneuret, 2001). TM1, TM2, and TM3 consist of heptad repeat motifs, containing highly conserved asparagine and glycine in TM1 and TM2, and conserved leucine and glutamate/glutamine in TM3. Heptad repeat motifs are noticeably absent in TM4, although it contains conserved polar amino acids (Kovalenko 2005). There is a highly conserved asparagine-glycine-glycine motif in EC1 (Kovalenko 2005).

$\mathrm{EC} 2$, and rarely EC1, are glycosylated at one or more $\mathrm{N}$-glycosylation sites, contributing to the overall tetraspanin size that ranges from 20 to $70 \mathrm{kDa}$ (Yunta 2002).

Crystal structures of full-length tetraspanin proteins have not been generated, owing to inherent properties of membrane proteins; however, the crystal structure of the EC2 loop of CD81 has been solved (Kitadokoro 2001). This showed five alpha-helices arranged in "stalk" and "head" domains, and it is believed that these structural features are consistent among all tetraspanins (Kitadokoro 2001).

Tetraspanins are evolutionarily conserved. In addition to mammals, they have been found in Schistosomes (Wright 1990), early metazoans (Adell 2004), fungi (Gourgues 2002), and nematodes (Moribe 2004). Currently, more than 30 tetraspanins have been identified.

Tetraspanins are expressed in all human cell types, and most cells generally express multiple tetraspanins (Levy 2005). Tetraspanins may be expressed on both the cell surface and on granular membranes (Israels 2005). Some tetraspanins-such as CD9 and CD81—are expressed in almost all cell types, while others are more restricted-CD37 in B cells (Schwartz-Albeiz 1988), RDS/peripherin in retina (Travis 1991), uroplakins in bladder epithelium (Walz 1995), and CD53 in lymphoid-myeloid cells (Maeker 1997).

\subsubsection{Tetraspanin Web}

Tetraspanins have been implicated in a wide variety of cell processes. This is likely the result of interactions between tetraspanins and other associated proteins within tetraspanin webs (which is also known as tetraspanin microdomains, tetraspanin enriched microdomains, or tetraspanin complexes) (see also Fig 2.5).

Tetraspanins have the ability to associate with a wide variety of membrane proteins. Generally, the extracellular domains-mainly EC2-interact with laterally associated proteins or soluble ligands, the cytosolic regions associate 
with cytoskeletal or signaling molecules, and the transmembrane domains interact with other proteins necessary for maintenance of the tetraspanin web (Levy 2005). Thus, the tetraspanin web acts as a molecular facilitator, organizing membrane proteins and coupling receptors to signaling pathways (Levy 2005).

In differing cell types, the tetraspanin web is composed of different tetraspanins and partner proteins. It is unclear whether all the tetraspanins in a certain cell are associated with each other.

Within the tetraspanin web, specific tetraspanins directly associate with a partner membrane protein (frequently a member of the integrin or immunoglobulin superfamilies) and other tetraspanin proteins. These tetraspanins also directly associate with a particular partner protein. Primary interactions between tetraspanins and partner proteins are believed to be mediated through extracellular domains, in particular EC2, due to resistance to Triton-X 100 disruption. The majority of tetraspanin interactions with other membrane proteins cannot withstand Triton-X 100 treatment, but can withstand milder detergents and are termed secondary interactions (Serru 1999).

Palmitoylation of intracellular cysteine residues plays an important role in tetraspanin-tetraspanin interactions; abolishment of this palmitoylation reduces a tetraspanin's interaction with other tetraspanins (Charrin 2002, Yang and Claas 2002). Palmitoylation of partner proteins also contributes to their incorporation into the tetraspanin web (Yang and Kovalenko 2004). Palmitoylation provides a regulatory mechanism to rearrange the tetraspanin web in response to stimulation (Dempsey 1996).

The tetraspanin web also includes interactions with cytoskeletal and signaling molecules. These signaling molecules include Rho GTP-binding proteins (Schwartz 2000), G protein-coupled receptors and their intracellular associated heterotrimeric G-proteins (Little 2004), phosphatidylinositol 4-kinase (Berditchevski 1997, Yauch 1998), and PKC isozymes (Zhang 2001). The tetraspanin web is linked to the actin cytoskeleton via EWI-2 and EWI-F (SalaValdes 2006).

Tetraspanin-enriched membrane domains are physically and functionally separate from lipid rafts, although they share some characteristics (Claas 2001, Hemler 2003). Both can associate with cholesterol and gangliosides and can be recovered from low-density membrane fractions of sucrose gradients. However, tetraspanin webs and lipid rafts exhibit differences in membrane solubility and have different protein content (lipid rafts often contain GPI-linked proteins and caveolin, which are rarely found in tetraspanin webs) (Berditchevski 2002, Foster 2003, Hemler 2005, Yauch 2000). Lipid rafts may associate with the tetraspanin web under certain conditions, thereby facilitating signal transduction (Israels 2007). 
With specific regard to the tetraspanin CD9, interactions have been shown with the integrins $\alpha 3 \beta 1$ (Yanez-Mo 1998), $\alpha 4 \beta 1, \alpha 6 \beta 1, \alpha 5 \beta 1$, $\alpha$ llb $\beta 3$ (GPIlb-Illa), and precursor $\beta 1$ (Yunta 2002); the growth factor receptors TGF- $\alpha$ and HB-EGF (Lagaudriere-Gesbert 1997); immunoglobulin superfamily members FRPP and EWI-2 (Stipp 2001); CD36 and CD9P-1 (Miao 2001), CD19 (Horvath 1998), and CD46 (Yunta 2002); the signaling molecules PKC and PI4K (Boucheix 2001); and the soluble ligands FN (Longhurst 2002), and PSG 17 (Waterhouse 2002). Many more protein partners will likely be identified in the future.

\subsubsection{Tetraspanin Function}

It is unknown whether tetraspanins alter integrin conformation or affinity for ligand. In addition, for the most part, tetraspanins do not affect static cell adhesion. However, other integrin-dependent events-migration, spreading, and cell morphology, among others-can be greatly affected by tetraspanins.

2.2.3.1 Cell Motility. Tetraspanins have been found to be expressed in motility-related structures, such as lamellipodia, and involved in cell motility.

In keratinocytes, the tetraspanins CD9 and CD81 are highly expressed in filopodia at lateral and apical surfaces, as well as in the footprints and rippings of motile keratinocytes, suggesting a role in keratinocyte motility. In a wound healing assay, cell migration was inhibited with antibodies to CD9 and CD81, and to a lesser extent, to CD151, perhaps via involvement in integrin recycling during keratinocyte migration (Penas 2000).

When HT-1080 cells are transfected with CD9, lamellipodia formation is significantly decreased, and this effect was reversed upon antibody ligation. CD9 was able to influence lamellipodial formation by downregulating WAVE2 (Huang 2006).

In Chinese hamster ovary cells, expression of CD9 enhances cell motility on fibronectin. This is likely via a direct interaction between CD9 EC2 and FN (Longhurst 2002).

2.2.3.2 Tumor Cell Metastasis. Tetraspanins CD9 and CD82 are considered metastasis suppressors in solid tumors (Wright 2004). These tetraspanins are downregulated in progression of several cancers, including nonsmall cell lung, breast, pancreas, colon, and prostate, and decreased expression of these tetraspanins result in poorer prognosis (Boucheix 2001, Saito 2006).

The tetraspanin CD82 (also known as KAl1) tumor metastasis suppressor activity is believed to be through the association of CD82 with the EGF receptor tyrosine kinase, which accelerates ligand-induced clearance of EGF receptor from the cell surface (Bienstock 2001). 
Adenoviral transduction of CD9 or CD82 into lung tumor cells, whether via direct implantation or through intratracheal administration, dramatically reduced metastasis to mediastinal lymph nodes (Takeda 2007). However, overexpression of CD9 in human prostate cancer cell lines did not suppress metastatic properties, suggesting that CD9 partner proteins may be needed for full anti-metastatic effect (Zvieriev 2005).

2.2.3.3 Cell Proliferation and Differentiation. The tetraspanin TSSC-6 colocalizes into domains on T cells containing $\mathrm{T}$ cell molecules involved in $\mathrm{T}$ cell stimulation, such as CD4 and CD8. Deletion of TSSC-6 yields mice with normal lymphoid development, yet $T$ cells showed elevated $T$ cell receptor-dependent proliferation in vitro in response to concanavalin A, anti-CD3, and anti-CD28 (Tarrant 2002).

Proliferation of T lymphocytes from CD81-deleted mice is also enhanced in response to various stimuli. In B cells, deletion of the tetraspanin CD81 results in diminished numbers of a subset of B cells (Miyazaki 1997). CD81 is also involved in driving helper T cells toward polarized Th2 differentiation (Deng 2000, Maecker 1997).

In the brain, deletion of CD81 results in mice with increased numbers of astrocytes and microglia, resulting in greatly enlarged brains (Geisert 2002). CD81 may control astrocyte and microglia proliferation in a cell-cell contactdependent manner; neurons inhibit proliferation by interacting with CD81 on cultured astrocytes (Kelic 2001).

Tetraspanins have been implicated in growth factor signaling as well. CD9 regulates pro-TGFa, pro-HB-EGF, and pro-amphiregulin, all of which are membrane-bound agonists for the EGF receptor (Inui 1997, Shi 2000). CD9 is necessary for HB-EGF mitogenic activity (Nakamura 2000).

During osteoclast differentiation, CD9 expression increases during RANKL-induced osteoclastogenesis. A CD9-neutralizing antibody suppressed RANKL-induced multinucleated osteoclast formation and mRNA expression of osteoclast differentiation marker genes, and this was shown to be through regulating long-term phosphorylation of p44/42 MAPK (Yi 2006).

CD9 is also involved in megakaryocyte differentiation. In hematopoietic stem cells, those with the highest expression of CD9 are committed to the Blymphoid or megakaryocytic lineages, and expression of CD9 is found to precede expression of CD41 in megakaryocyte precursors. Antibody ligation to CD9 inhibited the in vitro terminal differentiation of human $\mathrm{CD} 34^{+}$cells into megakaryocytes. It was observed that antibody ligation deeply altered membrane structures (demarcation membranes and heterogeneous multivesicular body membranes) of these cells (Clay 2001). 
2.2.3.4 Cellular Morphology. The tetraspanins peripherin/RDS and $\mathrm{ROM}-1$ are expressed in the retina and have specialized roles in maintaining the outer segment discs in their characteristic flattened, parallel layers (Kohl 1998). Point mutations in the EC2 domain are associated with various human retinal dystrophies (Kohl 1998) and disruption of the peripherin/RDS tetraspanin gene causes retinal degeneration (Connell 1991).

Mutation of a CD151 site influencing integrin interaction resulted in mutant cells lacking integrin-dependent spreading and cellular cable morphology on Matrigel (Kasarov 2002). Another mutation on CD151, affecting palmitoylation, resulted in cells that could interact with integrins but not with other tetraspanins. This resulted in kidney epithelial cells transitioning from a fibroblastic morphology to an epithelial morphology (Yang 2002). A third mutation in CD151, in the Cterminal tail (abolishing a theoretical linkage to cytoskeletal or cytoplasmic signaling molecules), altered integrin-dependent cell spreading, cellular cable formation functions, and adhesion strengthening (Lammerding 2003, Zhang 2001).

In small cell lung cancer cells, CD9 expression is usually diminished. Increased expression of CD9 suppressed neurite-like process outgrowth and promoted apoptotic death. This was found to be via PI3K/Akt signaling (Saito 2006).

2.2.3.5 Virus-Induced Syncitia Formation. The tetraspanins CD9, CD81, and CD82 have been implicated in virus-induced syncitia formation (Fukudome 1992, Willet 1997).

In human T lymphoblasts, antibody ligation of either CD81 or CD9 enhanced syncitia formation induced by HIV-1 envelope proteins and viral entry into the lymphoblasts. In addition, decreased CD81 and CD9 expression increased syncitia formation and viral entry, while overexpression resulted in decreased susceptibility to syncitia formation (Gordon-Elonso 2006).

2.2.3.6 Intracellular Vesicles. The tetraspanin web may be adapted to facilitate vesicular fusion and fission with the cell membrane (Hemler 2003). Tetraspanin expression is enriched in the endocytic pathway. Exosomes from $\mathrm{B}$ cells are enriched for CD37, CD53, CD63, CD81, and CD82 by 7- to 124-fold (Escola 1998). Jurkat cell activation results in CD81 removal from the cell surface in parallel with release of CD81-containing exosomes (Fritzsching 2002).

2.2.3.7 Cell-Cell Interactions. Investigations into megakaryocyte and proplatelet formation suggest that CD9 is involved in altering membrane structures, suggesting a role in membrane reorganization, especially cell fusion (Clay 2001). 
Fluorescence microscopy has revealed that CD9, while ubiquitously expressed across the cell membrane, is increased at areas of cell-contact, suggesting a role in cell-cell interactions. This phenomena is observed both in cells natively expressing CD9, such as kidney epithelium and breast cancer cells, (Nakamura 1995, Yang 2006) and in cells that have been transfected with CD9 (Yang 2006). Additionally, CD9, CD81, and CD151, along with integrins, accumulate at keratinocyte cell junctions (Penas 2000).

One of the most striking phenotypes of the CD9 knock-out mouse model is the reduced fertility in females. CD9 has been shown to have a crucial role on oocytes during sperm-egg fusion-CD9 knock-out mice oocytes are deficient in their ability to fuse with sperm (Kaji 2000, La Naour 2000, Miyado 2000). Furthermore, anti-CD9 antibodies can inhibit sperm-egg fusion (Chen 1999, La Naour 2000, Miller 2000), and CD9 recombinant proteins corresponding to residues 173-175 in CD9 EC2 partially inhibit fusion when added to the oocyte prior to insemination but not when preincubated with sperm, showing that CD9 is probably not a sperm receptor, but more likely influencing other members of the tetraspanin web (Zhu 2002).

CD9 also appears to be involved in implantation, as CD9 is variably expressed in the murine uterus depending on the stage of implantation, and was upregulated in an ovarian steroid hormone-dependent manner (Weimin 2007).

In human ova, antibody ligation of CD9, prior to zona removal, prevented the clustering of $\alpha 6 \beta 1$ integrin clustering and gamete fusion. Antibody ligation to CD151 is able to partially inhibit sperm-egg fusion. This suggests that these tetraspanins are able to control the redistribution of membrane proteins into the clusters necessary for gamete fusion (Ziyyat 2006).

\subsubsection{Tetraspanin CD9}

CD9 was shown to be localized to the $p$ region of chromosome 12 (Benoit 1991). cDNA from a megakaryocyte library showed that CD9 is comprised of eight exons, producing a protein with 228 amino acids (Lanza 1991).

CD9 expression is most abundant on cells of megakaryocyte lineagemegakaryocytes and platelets (Boucheix 1988, Brisson 1997, Deng 1983, Jennings 1994). It is also expressed on macrophages (Wang 2002), eosinophils (Fernvik 1995), basophils (Fureder 1994), marginal zone B cells (Won 2002), endothelial cells (Barreiro 2005, Klein-Soyer 2000), ectodermal nervous tissue (Banerjee 1997), smooth muscle cells (Scherberich 1998, Scherberich 2002), and oocytes (Ziyyat 2006). 


\section{CHAPTER 3 METHODOLOGY}

\subsection{Materials}

Nonspecific mouse lgG, Fab fragment, and goat anti-mouse Fc specific $\left.\mathrm{F}(\mathrm{ab})_{2}\right)_{2}$ fragment were obtained from Jackson Immunolaboratories (West Grove, PA). Adenosine 5'-diphosphate (ADP), tetramethyl rhodamine isothiocyanate (TRITC)-labeled phalloidin, fluorescein isothiocyanate (FITC)-conjugated goat anti-mouse antibody, fluorescein isothiocyanate (FITC)-conjugated goat antimouse Fab, nonspecific mouse IgG1, $\beta$-octylglucopyranoside, and other general reagents were purchased from Sigma Chemical Company (St. Louis, MO). FITClabeled anti-CD9 antibody, clone ML-13, was purchased from BD Biosciences (San Jose, CA). PE-labeled anti-CD63 and anti-P-selectin were from BD Pharmingen (San Jose, CA). Collagen was purchased from Chronolog Corp (Havertown, PA) and TRAP (thrombin receptor agonist peptide) was purchased from Peninsula Laboratories (San Carlos, CA). Eptifibatide was provided by Schering-Plough (Kenilworth, NJ). Fibrinogen was from Enzyme Research Laboratories (South Bend, IN) and fibronectin was from Gibco (Carlsbad, CA). Gelcode Blue Stain was from Pierce (Rockford, IL) and Coomassie blue was from BioRad (Hercules, CA). mAb7 was obtained from mouse ascites and purified by Affi-gel Protein A column (BioRad, Hercules, CA). mFab7 was generated and purified using Immunopure ${ }^{\circledR}$ Fab Preparation Kit (Pierce, Rockford, IL) and purified Fab underwent buffer exchange into phosphatebuffered saline (PBS), pH 7.4, using Zeba ${ }^{\mathrm{TM}}$ Desalt Spin Columns (Pierce, Rockford, IL). Human coagulation Factor XIII was from Calbiochem (San Diego, CA). Vectashield mounting media was purchased from Vector Laboratories (Burlingame, CA). Superfrost microscope slides and microscope cover glass were from Fisher Scientific (Pittsburgh, PA). Anti-fibrinogen antibody was obtained from The Binding Site (San Diego, CA). Protease inhibitor cocktail tablets were from Roche (Basel, Switzerland).

\subsection{Tetraspanin Expression on Resting and Activated Platelets}

Flow cytometry was used to assay the levels of the tetraspanins CD9, CD63, and CD151; the integrin GPIIb-IIla, and the protein GPIb on the surface of resting and activated platelets (See Fig 3.1). Blood was obtained from healthy adult donors into $0.1 \mathrm{M}$ buffered citrate as an anticoagulant. PRP was prepared (Table 3.1) and diluted with PPP to a final platelet count of 250,000 platelets/ $\mu$ l. Platelets were either allowed to remain resting or were activated with $10 \mu \mathrm{M}$ ADP or $2 \mu \mathrm{M}$ TRAP. Platelets were then incubated with primary antibody for 30 minutes at $37^{\circ} \mathrm{C}$ (R\&D monoclonal anti-human CD151 antibody, catalog \#MAB1884 for CD151; 10E5 and 7E3 for GPIlb-IIla; 6D1 for GPIb; BD Pharmingen Purified mouse anti-human monoclonal antibody, catalog \#3556019 for CD63; mAb7 for CD9; and mlgG, Sigma MOPC-21, as a negative control). 
110

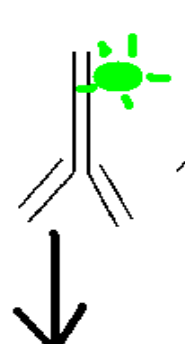

(1)

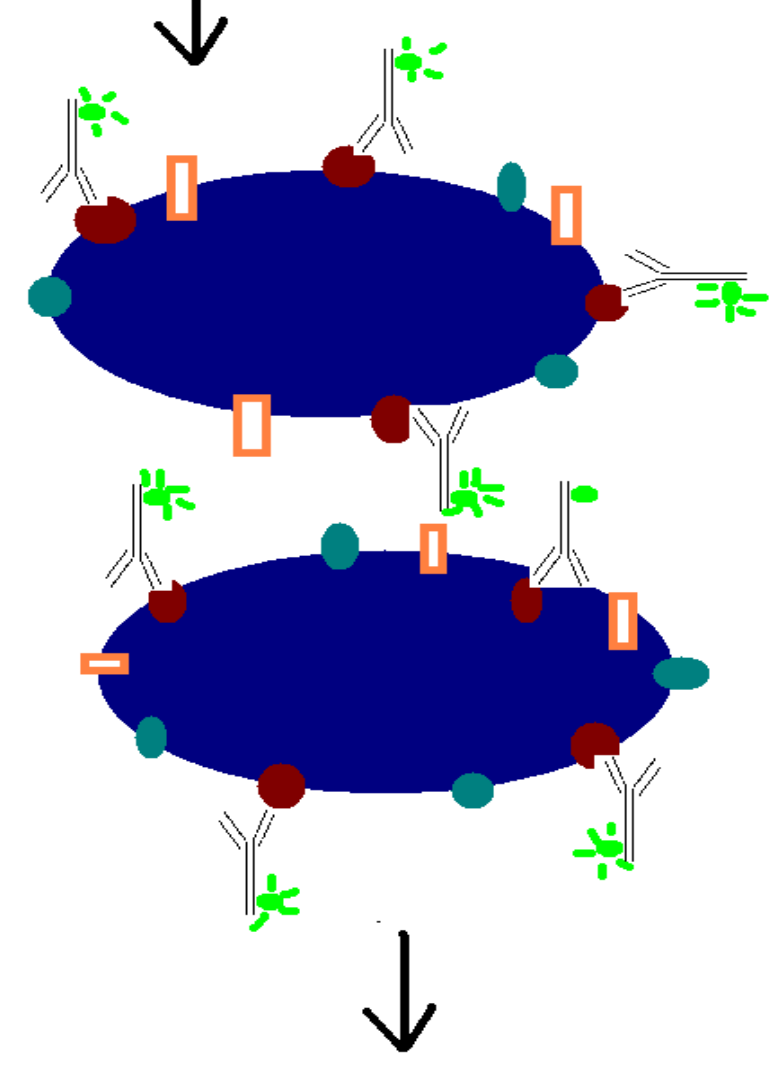

10

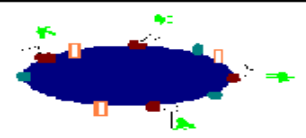

Antibodies are

fluorescently

labelled
Labelled antibodies are incubated with platelets and bind to a specific protein on the surface of the platelet. Greater surface expression results in greater levels of antibody binding.
Level of fluorescence of each platelet is measured with a flow cytometer. Thousands of platelets are measured and a mean fluorescence intensity is recorded.

Figure 3.1 Measurement of Surface Proteins by Flow Cytometry Platelets are incubated with fluorescently-labeled antibodies which bind a specific surface protein. Platelets are incubated with the antibody, and level of fluorescence is measured by a flow cytometer. 


\section{Table 3.1 Preparation of PRP and PPP}

\section{Step Instructions}

$1 \quad$ Whole blood is obtained by venipuncture into $0.1 \mathrm{M}$ buffered citrate. Other anticoagulants may be used as indicated. $10 \mathrm{ml}$ total volume is used per $15 \mathrm{ml}$ tube.

$2 \quad$ Tubes are centrifuged at $135 \times g$ for 15 minutes. Platelet-rich plasma (PRP), the top layer, is removed and set into a clean $15 \mathrm{ml}$ tube. PRP must be carefully removed to avoid contamination with white blood cells in the buffy coat.

$3 \quad$ The remaining blood is centrifuged at 2,500 $\mathrm{x} g$ for 15 minutes. Platelet-poor plasma (PPP), the top layer, is carefully removed and set into a clean $15 \mathrm{ml}$ tube.

$4 \quad$ PRP is counted with a Coulter Counter, and diluted with PPP to the desired concentration. 
Ten microliters of each sample were transferred to a microfuge tube with $500 \mu \mathrm{l}$ filtered PBS $+10 \mu \mathrm{l}$ goat anti-mouse FITC-labeled antibody, and samples were incubated for ten minutes at room temperature prior to data collection using the flow cytometer (using the Platelet Green template). This was repeated using ten normal, healthy adult donors.

\subsection{Association of CD9 and GPIlb-Illa in Resting and Activated Platelets}

\subsubsection{Co-Immunoprecipitation}

Whole blood was obtained by venipuncture and mixed with ACD as an anticoagulant (Table 3.2). Platelets were washed twice with CGS (Table 3.3), resuspended in platelet lysis buffer containing 1\% CHAPS (Table 3.4), and lysed for 20 minutes on a rocker at $4^{\circ} \mathrm{C}$. Samples were clarified by centrifugation at $18,300 \times \mathrm{g}$ for $10 \mathrm{~min}$ at $4^{\circ} \mathrm{C}$, discarding the pellet. Protein concentration was measured using Biorad Detergent-Compatible Assay kit and adjusted to 1.5 $\mathrm{mg} / \mathrm{ml}$. One $\mathrm{ml}$ lysate and $75 \mu \mathrm{l}$ Protein A/G beads were added to each of five eppendorf tubes, and samples were incubated for 60 minutes on a rocker at $4^{\circ} \mathrm{C}$ and then precleared by centrifugation at $18,300 \times g$ for one minute. Supernatants were collected and transferred to five new tubes, to which was added either $5 \mu \mathrm{g}$ D3, $5 \mu \mathrm{g} \mathrm{D} 3+3 \mathrm{mM}$ eptifibatide, $5 \mu \mathrm{g} \mathrm{AP} 3,5 \mu \mathrm{g} \mathrm{mAb7}$, or $5 \mu \mathrm{g}$ mlgG (MOPC21 ) as a negative control. Samples were incubated with primary antibody for one hour on a rocker at $4^{\circ} \mathrm{C} .75 \mu \mathrm{l}$ Protein $\mathrm{A} / \mathrm{G}$ beads were added to each tube and incubated for 60 minutes on a rocker at $4^{\circ} \mathrm{C}$. Samples were centrifuged three times at $18,300 \times g$ with cold lysis buffer, discarding the supernatant after each wash. Samples were boiled with fresh non-reduced sample buffer (Table 3.5), separated on a $5 \%-20 \%$ gradient separating gel (Table 3.6 and Table 3.7), and transferred to a PVDF membrane. Membranes were blocked by rocking with $5 \%$ nonfat dry milk in $0.1 \%$ TBS-Tween at room temperature for 60 minutes then incubated with primary antibody in $5 \%$ nonfat dry milk in TBS-Tween overnight at $4^{\circ} \mathrm{C}$ (mAb7 is used to detect CD9, and C3 is used to detect $\alpha$ llb) (Table 3.8). Bound antibodies are labeled with HRP-labeled sheep anti-mouse antibody and detected with ECL-PLUS kit prior to development onto photo paper.

\subsubsection{Confocal Analysis}

Coverslips, in individual wells of a 20 -well tissue culture plate, were coated with $500 \mu \mathrm{g} / \mathrm{ml} \mathrm{FG}, 50 \mu \mathrm{g} / \mathrm{ml}$ plasma $\mathrm{FN}$, fibrin, or fibrin-FN overnight at $4^{\circ} \mathrm{C}$ (Table 3.9). Coverslips were then blocked with $1 \mathrm{ml} 20 \mathrm{mg} / \mathrm{ml} \mathrm{BSA}$ in PBS for 2 hours at $37^{\circ} \mathrm{C}$ and washed $3 x$ with PBS (Table 3.8). $500 \mu$ l of washed platelets (Table 3.10), at $1 \times 10^{7}$ platelets $/ \mathrm{ml}$ in HEPES-Tyrode buffer (Table 3.11), were incubated 1 hour on the coverslips. Non-adherent platelets were removed by washing $3 x$ with HEPES-Tyrode buffer. GPIlb-Illa was stained with D3 for 30 
Table 3.2 Anticoagulants

\begin{tabular}{lll}
\hline Material & ACD & $\mathbf{0 . 1 ~ M ~ B u f f e r e d ~ C i t r a t e ~}$ \\
\hline Sodium citrate & $0.085 \mathrm{M}$ & $0.06 \mathrm{M}$ \\
Dextrose & $0.1 \mathrm{M}$ & -- \\
Citric acid & $0.07 \mathrm{M}$ & $0.04 \mathrm{M}$ \\
\hline
\end{tabular}

Table 3.3 CGS

\begin{tabular}{ll}
\hline Material & Concentration \\
\hline Sodium Citrate & $0.01 \mathrm{M}$ \\
Dextrose & $0.03 \mathrm{M}$ \\
$\mathrm{NaCl}$ & $0.12 \mathrm{M}$ \\
$\mathrm{pH}$ & 6.5 \\
\hline
\end{tabular}


Table 3.4 Lysis Buffer for Immunoprecipitations

\begin{tabular}{ll}
\hline Amount & Material \\
\hline $10 \mathrm{mM}$ & $\mathrm{HEPES}$ \\
$200 \mathrm{mM}$ & $\mathrm{NaCl}$ \\
$1 \%$ & $\mathrm{CHAPS}$ or BRIJ-98, as indicated \\
$5 \mathrm{mM}$ & $\mathrm{MgCl}_{2}$ \\
$2 \mathrm{mM}$ & $\mathrm{NaF}^{2}$ \\
$100 \mathrm{mM}$ & $\mathrm{Na}_{4} \mathrm{P}_{2} \mathrm{O}_{7}$ \\
1 per $10 \mathrm{ml}$ & $\mathrm{Protease}$ inhibitor tablet \\
\hline
\end{tabular}


Table 3.5 Formula for $1 / 3 x$ NR Sample Buffer

Amount

$1.8 \mathrm{ml}$

$1.6 \mathrm{ml}$

$0.32 \mathrm{~g}$

$0.32 \mathrm{ml}$

Q.S. to $4 \mathrm{ml}$
Material

$0.5 \mathrm{M}$ Tris, $\mathrm{pH} 6.8$

Glycerol

SDS

Bromophenol blue

$\mathrm{dH} 2 \mathrm{O}$

Table 3.6 Formulas for SDS-PAGE Gels

\begin{tabular}{|c|c|c|c|}
\hline Material & $\begin{array}{l}5 \% \text { Separating } \\
\text { Gel }\end{array}$ & $\begin{array}{l}20 \% \text { Separating } \\
\text { Gel }\end{array}$ & Stacking Gel \\
\hline Distilled $\mathrm{H}_{2} \mathrm{O}$ & $22.5 \mathrm{ml}$ & $0.301 \mathrm{ml}$ & $6.1 \mathrm{ml}$ \\
\hline Glycerol & $334.4 \mu \mathrm{l}$ & $1.1 \mathrm{ml}$ & ---- \\
\hline 1.5 M Tris, pH 8.8 & $10.0 \mathrm{ml}$ & $5 \mathrm{ml}$ & ---- \\
\hline 0.5 M Tris, pH 6.8 & ---- & ---- & $2.5 \mathrm{ml}$ \\
\hline $10 \%$ SDS & $401.2 \mu \mathrm{l}$ & $200.7 \mu \mathrm{l}$ & $100 \mu l$ \\
\hline $\begin{array}{l}30 \% \\
\text { acrylamide/bis }\end{array}$ & $6.7 \mathrm{ml}$ & $13.4 \mathrm{ml}$ & $1.3 \mathrm{ml}$ \\
\hline TEMED & $10 \mu \mathrm{l}$ & $5 \mu l$ & $10 \mu l$ \\
\hline $10 \%$ APS (fresh) & $120.3 \mu \mathrm{l}$ & $61.5 \mu \mathrm{l}$ & $50 \mu l$ \\
\hline
\end{tabular}


Table 3.7 Formula for Western Blot Buffers

\begin{tabular}{lll}
\hline Material & Running Buffer & Blot (Transfer) Buffer \\
\hline TRIS & $18 \mathrm{~g}$ & $12.2 \mathrm{~g}$ \\
Glycine & $86.4 \mathrm{~g}$ & $57.6 \mathrm{~g}$ \\
SDS & $3.0 \mathrm{~g}$ & $4.0 \mathrm{~g}$ \\
Methanol & ---- & $800 \mathrm{ml}$ \\
Total volume & $3 \mathrm{~L}$ & $4 \mathrm{~L}$ \\
\hline
\end{tabular}

Table 3.8 Buffered Saline Recipes

\begin{tabular}{lll}
\hline Material & $\begin{array}{l}\text { Phosphate-buffered } \\
\text { saline (PBS) }\end{array}$ & $\begin{array}{l}\text { Tris-Buffered Saline } \\
\text { (TBS) }\end{array}$ \\
\hline $\mathrm{Na}_{2} \mathrm{HPO}_{4}$ & $0.14 \mathrm{M}$ & ---- \\
$\mathrm{NaH}_{2} \mathrm{PO}_{4}$ & $0.06 \mathrm{M}$ & ---- \\
$\mathrm{NaCl}$ & $2.87 \mathrm{M}$ & $0.15 \mathrm{M}$ \\
$\mathrm{Tris}$ & ---- & $0.01 \mathrm{M}$ \\
$\mathrm{pH}$ & 7.4 & 7.4 \\
\hline
\end{tabular}


Table 3.9 Fibrin and Fibrin-Fibronectin Matrix Components

\begin{tabular}{lll}
\hline Material & Fb & FbFN \\
\hline Fibrinogen & $2.4 \mathrm{mg} / \mathrm{ml}$ & $2.4 \mathrm{mg} / \mathrm{ml}$ \\
Fibronectin & 0 & $240 \mu \mathrm{g} / \mathrm{ml}$ \\
$\mathrm{CaCl}_{2}$ & $0.02 \mathrm{M}$ & $0.02 \mathrm{M}$ \\
$\mathrm{NaCl}$ & $0.15 \mathrm{M}$ & $0.15 \mathrm{M}$ \\
Tris-HCl, pH 7.5 & $0.05 \mathrm{M}$ & $0.05 \mathrm{M}$ \\
Human coagulation factor XIII & $5 \mu \mathrm{g} / \mathrm{ml}$ & $5 \mu \mathrm{g} / \mathrm{ml}$ \\
$\gamma-$ Thrombin & $2 \mathrm{units} / \mathrm{ml}$ & $2 \mathrm{units} / \mathrm{ml}$ \\
\hline
\end{tabular}




\section{Table 3.10 Preparation of Washed Platelets}

\section{Step Instructions}

$1 \quad$ Whole blood is obtained by venipuncture into ACD, at a ratio of $1.4 \mathrm{ml}$ ACD to $8.6 \mathrm{ml}$ whole blood. $10 \mathrm{ml}$ total volume is used per $15 \mathrm{ml}$ tube.

2 Blood is centrifuged at $135 \times \mathrm{g}$ for 20 minutes. Platelet-rich plasma, the top layer, is removed and set into a clean $15 \mathrm{ml}$ tube. PRP must be carefully removed to avoid contamination with white blood cells in the buffy coat. Red and white blood cells are discarded.

$3 \quad \mathrm{PRP}$ is centrifuged at $800 \mathrm{xg}$ for 10 minutes. The supernatant is removed and the platelet pellet is gently resuspended in $1 \mathrm{ml}$ of CGS. This $1 \mathrm{ml}$ is transferred to a fresh tube, avoiding transfer of any platelets remaining in clumps. CGS is added to the fresh tube to bring the volume up to $5 \mathrm{ml}$.

4 The platelet suspension is centrifuged at $800 \times \mathrm{g}$ for 10 minutes. The platelet pellet is washed with CGS as in step 3 .

5 After 2 washes with CGS, the pellet is resuspended in the appropriate buffer, counted with the Coulter Counter, and diluted to the appropriate concentration. 
Table 3.11 Modified Tyrode's Buffer (HEPES-Tyrode Buffer)

\begin{tabular}{ll}
\hline Material & Amount \\
\hline $\mathrm{CaCl}_{2}$ & $2 \mathrm{mM}$ \\
$\mathrm{BSA}$ & $0.1 \%$ \\
$\mathrm{NaCl}$ & $137 \mathrm{mM}$ \\
$\mathrm{HEPES}$ & $20 \mathrm{mM}$ \\
$\mathrm{Glucose}$ & $5.6 \mathrm{mM}$ \\
$\mathrm{MgCl}_{2}$ & $1 \mathrm{mM}$ \\
$\mathrm{NaH}_{2} \mathrm{PO}_{4}$ & $3.3 \mathrm{mM}$ \\
$\mathrm{KCl}$ & $2.7 \mathrm{mM}$ \\
$\mathrm{pH}$ & 7.4 \\
\hline
\end{tabular}


minutes and with Sigma TRITC-labeled whole molecule goat-anti-mouse antibody, 1:128 in PBS, for 30 minutes at room temperature. After washing with PBS, CD9 was stained for 30 min with FITC-labeled CD9 antibody clone ML-13, diluted 1:40 in PBS. Platelets were fixed for 30 min with $4 \%$ paraformaldehyde in PBS and washed $3 x$ with PBS. Coverslips were mounted with Vectashield mounting media and edges were sealed with clear nail polish. Samples were viewed with the confocal microscope using the $100 x$ objective. Care was taken to observe samples using the same settings.

\subsubsection{Impact of Mutant GPIIb-IIla}

Platelets from patients with Glanzmann Thrombasthenia, featuring a mutant GPIIb-IIla expressed on the platelet surface, were compared with platelets from patients with normal GPIIb-IIla. Platelets were allowed to spread on fibronectin or fibrin-fibronectin, and CD9 and GPIIb-IIla were immunostained as above. Fibronectin and fibrin-fibronectin matrices were selected due to fibronectin being a ligand for CD9 as well as GPIIb-IIla. It is unlikely that platelets from patients with Glanzmann Thrombasthenia would be able to adhere or spread on fibrinogen or fibrin matrices, as the mutated GPIlb-IIla would likely not be able to bind to these ligands.

\subsection{Localization of CD9 during Platelet Spreading}

\subsubsection{Platelet-Matrix Contact}

Platelets were allowed to spread as described previously. During viewing with the confocal microscope, the upper (apical-facing away from matrix) and lower (basal-in contact with matrix) boundaries of the platelet were selected by focusing the microscope just above and below the regions providing a focused view of the platelet. Usually this resulted in a 2-3 nm selection. The LSM 510 then provided slices corresponding to the apical, central, and basal sections of the platelet, which were analyzed for CD9 and GPIIb-IIla localization and colocalization.

\subsubsection{Platelet-Platelet Contact}

Platelets were allowed to spread on $500 \mu \mathrm{g} / \mathrm{ml}$ fibrinogen for 60 minutes in the absence of any Fab molecules to allow maximal spreading. Platelets were then fixed with $4.0 \%$ paraformaldehyde and permeabilized with $0.4 \% \beta$ octylglucopyranoside in PHEM buffer (Table 3.12). CD9 was labeled with FITClabeled anti-CD9 antibody (clone ML-13). Samples were mounted and viewed with a Zeiss Laser Scanning Microscope using the 100x objective. 


\section{Table 3.12 PHEM Buffer}

\begin{tabular}{ll}
\hline Material & Concentration \\
\hline PIPES & $60 \mathrm{mM}$ \\
HEPES & $25 \mathrm{mM}$ \\
EGTA & $10 \mathrm{mM}$ \\
$\mathrm{MgCl}_{2}$ & $2 \mathrm{mM}$ \\
$\mathrm{pH}$ & 6.9 \\
\hline
\end{tabular}


Areas of platelet-platelet contact and corresponding areas of platelet periphery not in contact with adjacent platelets were selected and pixel intensity was quantified using the Zeiss LSM510 software.

\subsubsection{Platelet Spreading Structures}

To observe CD9 localization during the course of platelet spreading, platelets were allowed to spread on $500 \mu \mathrm{g} / \mathrm{ml}$ fibrinogen for 5-60 minutes in the absence of any Fab molecules. At selected time points, platelets were fixed with $4 \%$ paraformaldehyde and permeabilized with $\beta$-octylglucopyranoside in PHEM buffer, as described above.

Platelet F-actin was labeled with TRITC-Phalloidin. CD9 was labeled with FITC-labeled anti-CD9 antibody (clone ML-13). Samples were mounted and viewed with a Zeiss Laser Scanning Microscope using the 100x objective. Care was taken to visualize images using the same settings (See also Fig 2.1).

\subsection{Generation and Purification of mAb7 Fab (mFab7) Fragments}

\subsubsection{Generation of mAb7}

mAb7 was obtained from mouse ascites, purified using an Affi-gel Protein A column, and dialyzed into PBS. Antibody concentration was assessed using an Ultrospec 1000 UV/Visible Spectrophotometer (Pharmacia Biotech) and purity confirmed with both nonreducing and reducing SDS-PAGE.

\subsubsection{Generation of $\mathrm{mFab7}$}

Papain digestion of $\mathrm{mAb} 7$ and Fab purification was carried out using Immunopure ${ }^{\circledR}$ Fab Preparation Kit (Pierce, Rockford, IL) (Fig 3.2). Briefly, mAb7 was incubated with immobilized papain for five hours in a $37^{\circ}$ shaking waterbath. The resulting digest was added to a Protein A column, allowing separation of Fab fragments from $\mathrm{Fc}$ fragments and uncleaved, full-length antibody. The purified Fab underwent buffer exchange into phosphate-buffered saline (PBS), pH 7.4, using Zeba ${ }^{\mathrm{TM}}$ Desalt Spin Columns (Pierce, Rockford, IL). Protein concentration was determined as above.

\subsubsection{Determination of Purity and Function of $\mathrm{mFab7}$}

3.5.3.1 Flow Cytometry. Binding ability of $\mathrm{mFab7}$ was assessed by flow cytometry. Blood was collected by venipuncture through a 21-gauge butterfly 


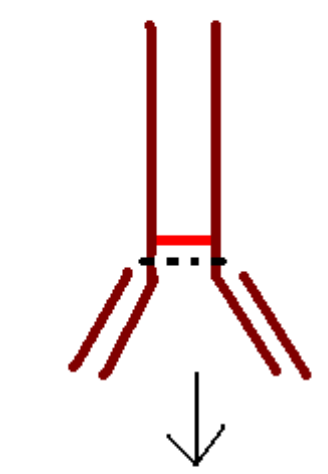

Full-length antibody is

cleaved by

papain

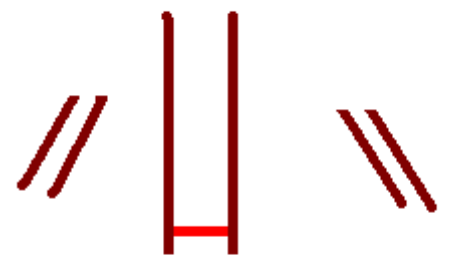

Yielding $\mathrm{Fc}+2$

Fab fragments

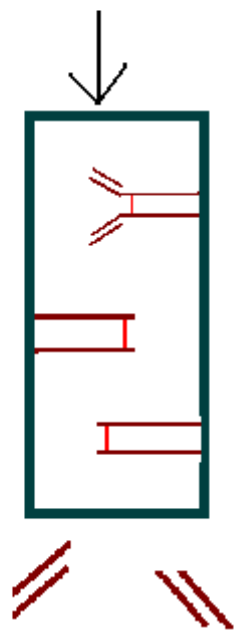

Protein A binds to

$\mathrm{Fc}$ fragments and

full-length antibody

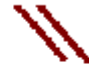

While Fab

fragments pass

through and are

collected

Figure 3.2 Antibody Cleavage and Purification of Fab Fragment

The antibody $\mathrm{mAb7}$ was cleaved by papain, resulting in an Fc and 2 Fab fragments. The resulting digest was poured through a Protein A column, which bound to Fc fragments and any undigested mAb7. Fab fragments (mFab7), which did not interact with Protein A, pass through and are collected. 
needle into $0.1 \mathrm{M}$ buffered citrate. Samples, per established methods, [White 1999] were centrifuged at $135 \times g$ for 15 minutes to obtain platelet-rich plasma (PRP). The remaining blood was centrifuged at $2500 \times g$ for 15 minutes to obtain platelet-poor plasma (PPP). Platelet counts were performed using a Beckman Coulter Z2 Particle Count and Size Analyzer (Beckman Coulter, Miami, FL), and PRP was diluted with autologous PPP to adjust the platelet count to $2.5 \times 10^{8}$ platelets $/ \mathrm{mL}$. Increasing concentrations of nonspecific Fab, mAb7 whole molecule, or mFab7 were added to the adjusted PRP and incubated at $37^{\circ} \mathrm{C}$ for 30 minutes. FITC-conjugated goat-anti-mouse Fab was added and samples were incubated at room temperature for ten minutes. Fluorescence levels were measured using a BD FASCalibur flow cytometer with Cell Quest Pro software (Becton Dickinson, Mountain View, CA) (see Fig 3.1).

Purity of mFab7 samples were also confirmed via flow cytometry. PRP was prepared as above, and incubated with saturating amounts of $\mathrm{mAb} 7$ or $\mathrm{mFab7}$, or corresponding amounts of nonspecific IgG or IgG-Fab at $37^{\circ} \mathrm{C}$ for 30 minutes. FITC-labeled goat anti-mouse Fc was incubated at room temperature for ten minutes to verify the absence of Fc fragments or intact antibody in the $\mathrm{mFab7}$ preparation. Fluorescence levels were measured as above.

3.5.3.2 SDS-PAGE. $50 \mu \mathrm{g}$ of $\mathrm{mFab7}, \mathrm{mAb7}$, $\mathrm{mlgG}$, and nonspecific mlgG-Fab were run on both nonreducing and reducing 12\% SDS-PAGE to determine purity of $\mathrm{mAb} 7$ and $\mathrm{mFab7}$. Gels were evaluated for bands indicating the presence of intact antibody by Coomassie blue staining. An unknown protein of $60 \mathrm{kDa}$ was verified by mass spectrometry to be murine albumin.

3.5.3.3 Platelet Aggregation. To evaluate the ability of antibodies to induce platelet aggregation, mAb7 (up to $20 \mu \mathrm{g} / \mathrm{ml}$ ) or mFab7 (up to $100 \mu \mathrm{g} / \mathrm{ml}$ ) were added to stirring suspensions of platelets and aggregation response was monitored for 15 minutes (Fig 3.3).

Aggregations were also performed using up to $100 \mu \mathrm{g} / \mathrm{ml} \mathrm{mFab} 7$ without inducing aggregation even after 15 minutes, while $\mathrm{mAb} 7$ concentrations $\geq 0.2$ $\mu \mathrm{g} / \mathrm{ml}$ induced an aggregation response, confirming that mFab7 was functionally greater than $98 \%$ pure.

To further ensure that the Fc receptor was not participating in the enhanced aggregatory response, $\mathrm{mFab} 7$ and control Fab were pre-incubated with a goat $F(a b)_{2}$ anti-mouse-Fc before adding to platelets, at a rate of 10 $\mathrm{F}(\mathrm{ab})_{2}{ }_{2}$ per possible intact $\mathrm{mAb7}$, as calculated above.

\subsection{CD9 Perturbation}

Unless otherwise indicated, CD9 perturbation was carried out by preincubating platelets with $20 \mu \mathrm{g} / \mathrm{ml} \mathrm{mFab7}$ for 15 minutes at room temperature 


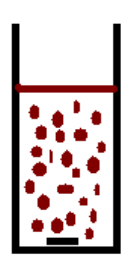

platelets in suspension, little light

transmission

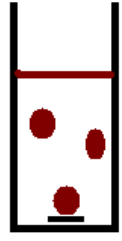

platelet aggregates, more light transmission

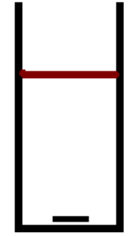

plasma set at

$100 \%$ light

transmission
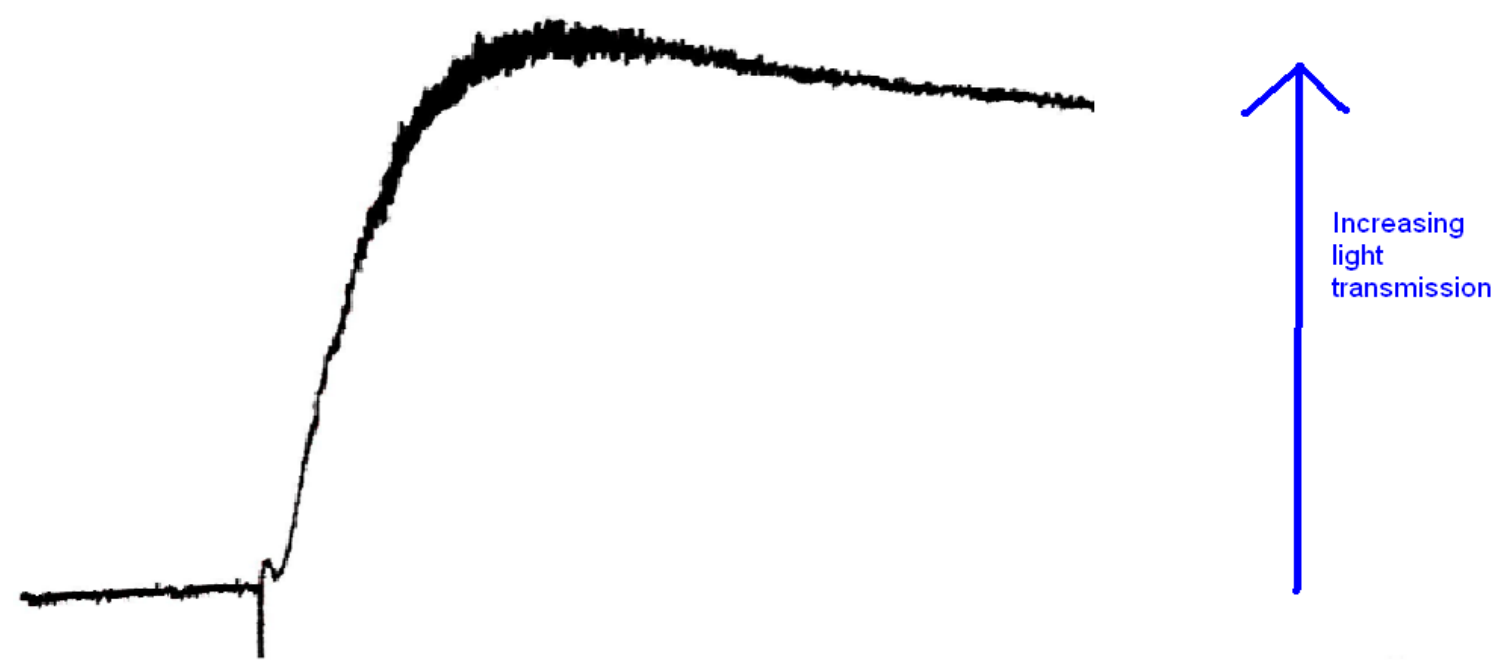

Figure 3.3 Light Transmission Aggregometry

Upon addition of agonist, formation of platelet aggregates is measured by increased light transmission and tracings are recorded on a light transmission aggregometer. 
prior to carrying out the experiment. $20 \mu \mathrm{g} / \mathrm{ml}$ nonspecific murine Fab was used as a control. The control Fab was isotype-matched to mFab7 and both Fab products were handled identically in all experiments.

\subsubsection{Platelet Spreading}

Fibrin-coated coverslips and fibrin-fibronectin matrix-coated coverslips were prepared as previously described [Corbett, 1996]. Additionally, coverslips were covered with $500 \mu \mathrm{g} / \mathrm{ml}$ fibrinogen or $50 \mu \mathrm{g} / \mathrm{ml}$ plasma fibronectin overnight. ACD-anticoagulated blood was washed twice with CGS $(0.01 \mathrm{M}$ sodium citrate, $0.03 \mathrm{M}$ dextrose, $0.12 \mathrm{M} \mathrm{NaCl}$ ), $\mathrm{pH} 6.5$, and resuspended in a modified Tyrode's buffer $\left(2 \mathrm{mM} \mathrm{CaCl}_{2}, 0.1 \%\right.$ bovine serum albumin, $137 \mathrm{mM} \mathrm{NaCl}, 02 \mathrm{mM}$ HEPES, $5.6 \mathrm{mM}$ glucose, $1 \mathrm{mM} \mathrm{MgCl}_{2}, 2.7 \mathrm{mM} \mathrm{KCl}, 3.3 \mathrm{mM} \mathrm{NaH}_{2} \mathrm{PO}_{4}$ ), $\mathrm{pH} 7.4$, at $2 \times 10^{7}$ platelets $/ \mathrm{ml}$. Platelets were incubated with $20 \mu \mathrm{g} / \mathrm{ml} \mathrm{mFab7} \mathrm{or} \mathrm{nonspecific} \mathrm{control}$ Fab and allowed to adhere and spread on coverslips for 30 minutes.

Nonadherent platelets were removed by washing with Tyrode's buffer, and adherent platelets were fixed with $4.0 \%$ paraformaldehyde for 30 minutes. Platelets were permeabilized with $0.4 \% \beta$-ocytlglucopyranoside in PHEM buffer (60 mM PIPES [piperazine-N,N'-bis (2-ethane sulfonic acid)], 25 mM HEPES, 10 mM EGTA, $2 \mathrm{mM} \mathrm{MgCl} 2$ ), pH 6.9, for 5 minutes. Platelet F-actin was labeled with TRITC-labeled phalloidin and CD9 was labeled with FITC-labeled anti-Fab antibody. Coverslips were mounted onto slides with Vectashield Mounting Media and edges were sealed with clear nail polish. Samples were visualized with a Zeiss laser scanning microscope (LSM 510) using the 100x objective. Care was taken to visualize samples using the same settings.

To quantitate pixel intensity, areas of platelet-platelet contact or corresponding areas of the platelet periphery were highlighted and pixel intensity (pixels per $\mu \mathrm{m}$ ) was quantitated by the LSM 510 software.

\subsubsection{Platelet Aggregation and Disaggregation}

Platelet aggregation was measured by light transmission in a dual-channel lumiaggregometer (Payton Scientific, Buffalo, NY) (See Fig 3.3). PRP was preincubated with $20 \mu \mathrm{g} / \mathrm{ml} \mathrm{mFab} 7$ or control Fab for 15 minutes at room temperature. Agonist concentration was calculated as follows: ADP — the highest concentration that would give a biphasic response in the absence of any Fabs (2$3 \mu \mathrm{M})$; Collagen - the concentration that would give a $50 \%$ response in the absence of Fabs $(0.3-1 \mu \mathrm{g} / \mathrm{ml})$; TRAP_the lowest concentration that would give a sustained response in the absence of Fabs (5-12 $\mu \mathrm{M})$. Low concentrations of agonist were chosen as this was the expected range to see an impact of CD9. Following preincubation with $\mathrm{mFab} 7$ or control Fab, the agonist was added to the stirring suspension of platelets, and aggregation response was recorded for 15 
minutes. The maximum aggregation response was determined for each donor, typically at 2.5 minutes after agonist addition.

Percent platelets aggregation (\%PA) was calculated at 5, 10, and 15 minutes after agonist addition. To assess platelet disaggregation, $4000 \mathrm{nM}$ eptifibatide was added to the platelet aggregates $2.5 \mathrm{~min}$ after agonist addition and percent platelet disaggregation (\%PD) was calculated 5, 10, and 15 minutes after antagonist addition (Fig 3.4).

The following were used to calculate \%PA and \%PD:

$$
\% \mathrm{PA}=
$$

(number of chart divisions on the aggregometer tracing from baseline to aggregation response at given time point)/

(total number of chart divisions representing $0 \%$ [PRP] to 100\% aggregation

$$
\begin{gathered}
[\mathrm{PPP}]) \\
\mathrm{x} 100 ; \\
\% \mathrm{\% PD}= \\
\left(\% \mathrm{PA}_{\text {max }} \% \mathrm{PA}_{\text {time point }}\right) /\left(\% \mathrm{PA}_{\max }\right)
\end{gathered}
$$

\subsubsection{Platelet Activation}

PRP in citrate was prepared as described above, at $2.5 \times 10^{8}$ platelets $/ \mathrm{ml}$, and preincubated with $20 \mu \mathrm{g} / \mathrm{ml} \mathrm{mFab} 7$ or control Fab. Selected platelet samples were activated with $2 \mu \mathrm{M}$ ADP or $5 \mu \mathrm{M}$ TRAP and incubated at room temperature for 40 minutes. PE-labeled anti-P-selectin, anti-CD63, or nonspecific mlgG antibodies were added to evaluate expression of P-selectin, a marker of alpha granule release, and CD63, a marker of lysosomal release, indicating platelet degranulation. Platelet fluorescence data, indicating surface protein expression, were acquired using a BD FASCalibur flow cytometer with Cell Quest Pro Software (Becton Dickinson, Mountain View, CA).

\subsubsection{Fibrinogen Binding}

Whole blood was drawn into buffered citrate and PRP was prepared by centrifugation at $135 \mathrm{xg}$ for 15 minutes and supernatant discarded. Pelleted platelets were resuspended in Tyrode's buffer $(138 \mathrm{mM} \mathrm{NaCl}, 2.9 \mathrm{mM} \mathrm{KCl}, 12$ $\mathrm{mM} \mathrm{NaHCO}_{3}, 0.4 \mathrm{mM} \mathrm{MgCl}_{2}, 5.5 \mathrm{mM}$ Dextrose, $0.36 \mathrm{mM} \mathrm{NaH}_{2} \mathrm{PO}_{4}, 1.8 \mathrm{mM}$ $\mathrm{CaCl}_{2}, \mathrm{pH} 7.4$ ) at $2.5 \times 10^{8}$ platelets $/ \mathrm{ml} .100 \mu \mathrm{l}$ of platelets were incubated with 20 $\mu \mathrm{g} / \mathrm{ml} \mathrm{mFab7}$ or control Fab. Platelets were incubated with $20 \mu \mathrm{M}$ ADP or saline control for 30 minutes at $37^{\circ} \mathrm{C}$ to allow binding of plasma fibrinogen. Antifibrinogen FITC antibody was added and mixed and data were acquired using a 

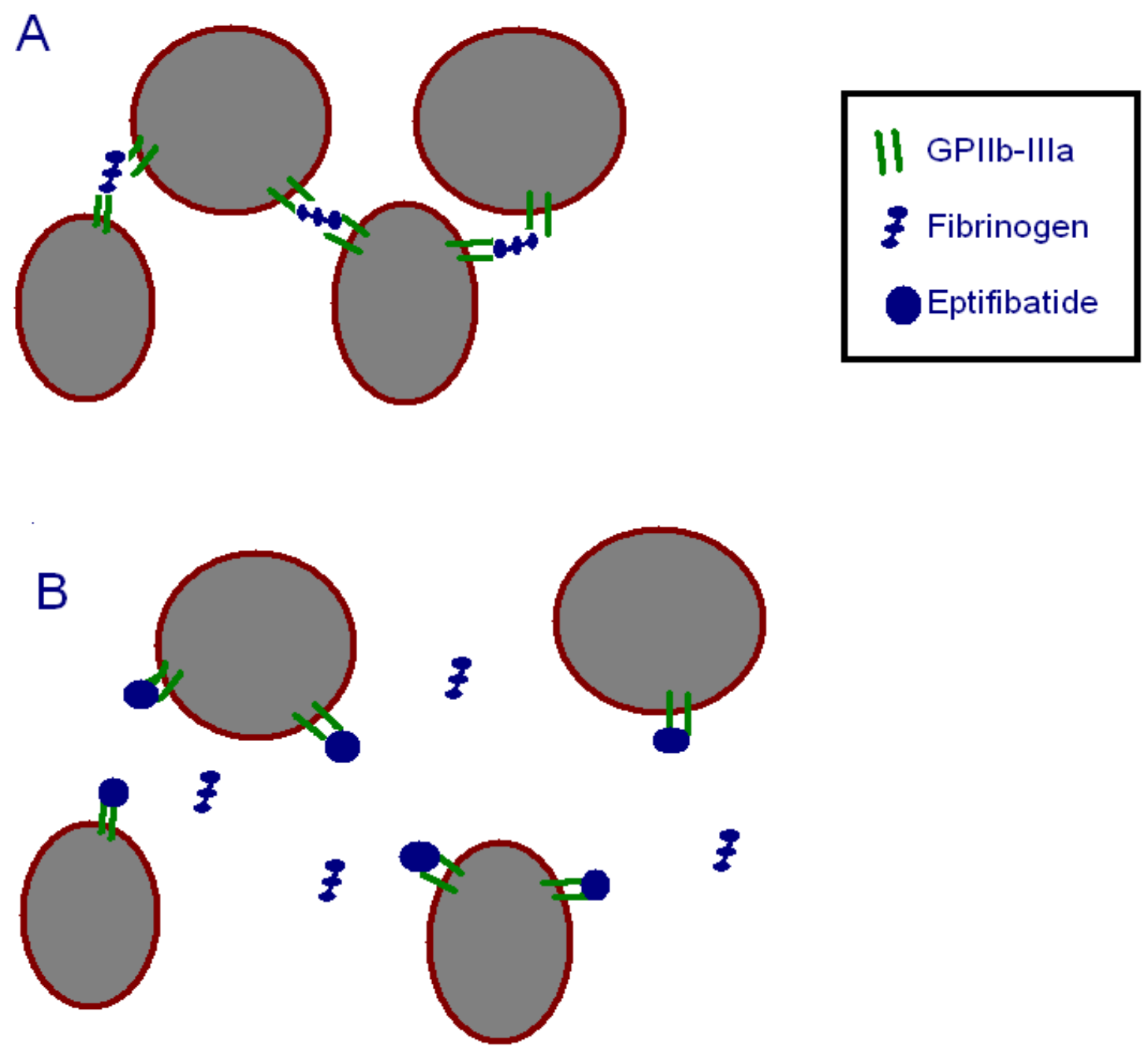

Figure 3.4 Eptifibatide-Induced Platelet Disaggregation

$A$, A platelet thrombus is maintained by fibrinogen binding and crosslinking GPIlb-IIla on adjacent platelets. $B$, Eptifibatide, a small peptide, interacts with GPIIb-IIla and competitively inhibits fibrinogen binding, resulting in platlelet disaggregation. The GPIIb-Illa antagonists abciximab and tirofiban work similarl.y. 
BD FASCalibur flow cytometer with Cell Quest Pro software (Becton Dickinson, Mountain View, CA).

\subsubsection{Cytoskeletal Incorporation}

Triton X-100-insoluble cytoskeletons of control and ADP-activated platelets in plasma, pretreated with $20 \mu \mathrm{g} / \mathrm{ml} \mathrm{mFab7} \mathrm{or} 20 \mu \mathrm{g} / \mathrm{ml}$ control Fab, were prepared according to the method of Kouns et al [Kouns WC, 1991]. Briefly, $\mathrm{PRP}$ in citrate were prepared at $3 \times 10^{8}$ platelets $/ \mathrm{mL}$. After pretreatment with Fab, $2 \mu \mathrm{M}$ ADP was added to stirring platelet suspension at $37^{\circ} \mathrm{C}$. After five minutes, samples were rapidly removed and lysed with ice-cold $2 \%$ Triton lysis buffer (100 $\mathrm{mM}$ Tris- $\mathrm{HCl}, 10 \mathrm{mM}$ EGTA, 2\% Triton X-100, 2 mM 2-mercaptoethanol, and protease inhibitor cocktail tablet; Table 3.13 ) and lysates were kept on ice.

Platelet lysates were centrifuged at $4^{\circ} \mathrm{C}$ at $15,600 \times g$ to isolate the platelet core cytoskeleton. The resulting samples were denatured and electrophoresed on a $5-20 \%$ SDS-polyacrylamide exponential gradient gel overnight. Proteins were visualized by staining with Coomassie Blue. Densitometry was performed by photocopying each gel, and carefully removing and weighing each band with a Sartorius Research quantitative electric balance (Sartorius Research, Goettingen, Germany).

\subsubsection{Akt Phosphorylation}

3.6.6.1 During Platelet Aggregation. PRP was prepared from whole blood and adjusted to $3 \times 10^{8}$ platelets $/ \mathrm{ml}$ with PPP. Samples were pretreated with saline, control Fab, or $\mathrm{mFab} 7$ for 15 minutes at room temperature, then monitored with a lumiaggregometer for five minutes upon addition of $2 \mu \mathrm{M}$ ADP or saline. Samples were then centrifuged, and pellets were collected, denatured, and subjected to electrophoresis on a $5-20 \%$ gradient SDS-PAGE. Proteins were transferred to a PVDF membrane, blocked with 5\% BSA in TBS-Tween, and incubated with an anti-phospho-Akt antibody overnight on a rocker at $4^{\circ} \mathrm{C}$. The primary antibody was labeled with a secondary donkey anti-rabbit-HRP antibody for 60 minutes in the presence of $5 \%$ BSA in TBS-Tween. Membranes were developed using the ECL-PLUS kit and stored in PBS at $4^{\circ} \mathrm{C}$ until continuing with stripping. To strip, membranes were completely submerged in Restore Western Blot Stripping Buffer and agitated for 15 minutes at $37^{\circ} \mathrm{C}$. After washing with TBS-Tween, western blotting was continued with an anti-Akt (total) antibody. Alternatively, the antibody 4G10 was used in place of anti-phospho-Akt antibody, to measure total protein tyrosine phosphorylation.

3.6.6.2 Without Stirring or Aggregation. PRP was prepared from whole blood and adjusted to $3 \times 10^{8}$ platelets $/ \mathrm{ml}$ with PPP. $500 \mu \mathrm{l}$ samples were treated with saline, control Fab, or mFab7 in eppendorf tubes for 15 minutes at 
Table 3.13 Cytoskeletal Extraction Buffers, pH 7.4

\begin{tabular}{lll}
\hline Reagent & $\begin{array}{l}\text { 2\% Triton X-100 } \\
\text { Extraction Buffer }\end{array}$ & Triton-free Wash Buffer \\
\hline Tris-HCl & $100 \mathrm{mM}$ & $100 \mathrm{mM}$ \\
EGTA & $10 \mathrm{mM}$ & $10 \mathrm{mM}$ \\
Triton X-100 & $2 \%$ & --- \\
2-mercaptoethanol & $2 \mathrm{mM}$ & $2 \mathrm{mM}$ \\
Protease Inhibitor Tablet & 1 per $10 \mathrm{ml}$ & 1 per $10 \mathrm{ml}$ \\
\hline
\end{tabular}


room temperature, then treated with saline or $2 \mu \mathrm{M}$ ADP. After addition of each treatment, the suspension was carefully and slowly brought up and down twice in a pipette to gently mix. After a five minute incubation, the samples were centrifuged in a pre-cooled microcentrifuge and pellets were washed twice with ice-cold saline.

Samples were denatured with reducing sample buffer and electrophoresed on a $5-20 \%$ gradient SDS-PAGE. Samples were transferred to a PVDF membrane, which was incubated overnight on a rocker at $4^{\circ} \mathrm{C}$ with antiphospho-Akt antibody. After generous washing with TBS-Tween, Akt was labeled with donkey anti-rabbit HRP, and 4G10 was labeled with goat anti-mouse HRP. Membranes were developed with ECL-PLUS kit and stored in PBS until continuing with stripping. To strip, membranes were completely submerged in Restore Western Blot Stripping Buffer and agitated for 15 minutes at $37^{\circ} \mathrm{C}$. After washing with TBS-Tween, western blotting was continued with an anti-Akt (total) antibody.

\subsubsection{Tetraspanin Web Organization}

Whole blood was obtained by venipuncture using ACD as an anticoagulant. Platelets were washed twice with CGS and resuspended at $250,000 / \mathrm{mm}^{3}$ in ACD. After pretreatment with $20 \mu \mathrm{g} / \mathrm{ml} \mathrm{mFab7} \mathrm{or} \mathrm{control} \mathrm{Fab} \mathrm{for}$ 15 minutes at room temperature, platelets were activated with $2 \mu \mathrm{M}$ ADP or allowed to remain in a resting state. Samples were removed for flow cytometric evaluation of CD63 and P-selectin on the platelet surface to verify platelet activation. Platelet samples were then resuspended in 1\% Brij-98 lysis buffer and lysed overnight on a rocker at $4^{\circ} \mathrm{C}$. Samples were clarified by centrifugation at $18,300 \times g$ for 10 minutes at $4^{\circ} \mathrm{C}$ and the pellet was discarded. Protein concentration was detected using the Biorad Detergent-Compatible Assay kit and protein concentration adjusted to $1.5 \mathrm{mg} / \mathrm{ml}$.

Samples were precleared with Protein A beads, centrifuged, and the supernatant transferred to a clean tube. Samples were then incubated for one hour at $4^{\circ} \mathrm{C}$ with $\mathrm{mlgG}$ as a control or with $10 \mathrm{E} 5$, an antibody that binds the GPIlb-IIla complex regardless of activation conformation. Samples were then incubated with Protein $\mathrm{A}$ beads overnight on a rocker at $4^{\circ} \mathrm{C}$.

Immunoprecipitation complexes were separated on a 5-20\% reducing SDS-PAGE and transferred to a PVDF membrane. After the transfer, the membrane was cropped from $15 \mathrm{kDa}$ to $35 \mathrm{kDa}$ to probe for CD9 (mAb7); from $35 \mathrm{kDa}$ to $75 \mathrm{kDa}$ to probe for CD63 (BD anti-CD63); and from $75 \mathrm{kDa}$ to above $160 \mathrm{kDa}$ to probe for GPIIb-IIla (C3). Probing occurred overnight at $4^{\circ} \mathrm{C}$. Primary antibodies were then labeled with HRP-conjugated Sheep anti-mouse antibody in TBS-Tween $+5 \%$ nonfat dry milk and images developed with ECL-PLUS kit. 


\subsubsection{Clot Retraction}

Whole blood was obtained by venipuncture using $0.1 \mathrm{M}$ buffered citrate as an anticoagulant. PRP was obtained and diluted with PPP to obtain platelets at either $250,000 / \mathrm{mm}^{3}$ or $100,000 / \mathrm{mm}^{3}$. After 15 minutes incubation in eppendorf

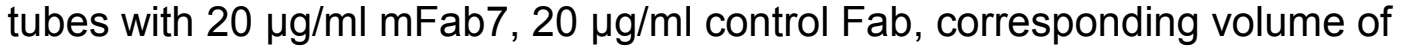
saline, or $20 \mu \mathrm{g} / \mathrm{ml} \mathrm{D3}$ (as a positive control) samples were transferred to $12 \times 75$ glass tubes. $\mathrm{CaCl}_{2}$ was added to each tube, samples were mixed by flicking, and each tube was capped and incubated in a $37^{\circ} \mathrm{C}$ waterbath. Tubes were observed every 15 minutes until retraction was complete.

\subsection{Statistical Significance}

Values are reported as mean \pm standard deviation as calculated by Microsoft Excel (Microsoft Corporation, Seattle, WA). T-tests were performed using Microsoft Excel. Results of cytoskeletal incorporation and aggregation with recombinant proteins were evaluated using ANOVA (Boneferroni test) with Sigma stat software.

Results are expressed as percentages \pm standard deviation. $p$ value of $\leq 0.05$ was accepted as statistically significant. 


\section{CHAPTER 4 RESULTS}

\subsection{Tetraspanin Expression on Resting and Activated Platelets}

The surface expression levels of CD9, the tetraspanins CD63 and CD151, and the tetraspanin-associated proteins GPIb and GPIlb-IIla (integrin allbß3) was evaluated in platelets that were either allowed to remain resting or were activated with $10 \mu \mathrm{M}$ ADP or $5 \mu \mathrm{M}$ TRAP (Fig 4.1A). Although TRAP is a more potent agonist than ADP, these concentrations should induce platelet activation, including granule release.

Although CD9 has been characterized as a member of alpha granules (Brisson 1997, Cramer 1994), the surface expression of CD9 in resting platelets (mean fluorescence intensity (MFI) $=183.2 \pm 28.7$ ) versus ADP- $(236.4 \pm 25.8$ ) or TRAP-activated $(229.0 \pm 30.3)$ platelets was not statistically significantly different. The lack of statistical significance may be due to the wide range of CD9 expression among individual donors, as each donor showed an increase in CD9 surface expression upon activation, particularly with ADP (ig 4.1B).

As expected, resting platelets did not express CD63 (MFI $=8.2 \pm 1.3$, compared to background control mlgG (MFI $=8.0 \pm 1.0$ ). CD63 expression was detected upon ADP activation (16.5 \pm 3.2$)$ and TRAP activation (27.7 \pm 5.9$)$. The increase in CD63 expression was statistically significant in activated vs. resting platelets $(p<0.05)$, but not between ADP and TRAP activation $(p>0.05)$.

CD151 was detected on the surface of resting platelets (MFI $=24.6 \pm 2.5)$, and was statistically significantly increased by ADP activation (MFI $=42.4 \pm 2.8$, $p \leq 0.01$ compared to resting) or by TRAP activation (MFI $=46.2 \pm 3.4, p \leq 0.01$ ).

GPIlb-Illa surface expression was detected by the antibody $10 \mathrm{E} 5$. This antibody binds to the GPIIb-IIla complex, and has an equal affinity for both the active and inactive conformation of GPIIb-IIla, so integrin activation following platelet activation will not alter detection of surface expression. GPIllb-IIla was detected on the surface of resting platelets (MFI = 129.6 \pm 11.0$)$, and was statistically significantly increased by activation by ADP (MFI $=218.5 \pm 15.8$, $\mathrm{p}<0.01)$ or TRAP $(\mathrm{MFI}=214.4 \pm 13.8, \mathrm{p}<0.01)$.

GPIb, part of the GPIb-IX-V complex, was also detected on the surface of resting platelets (MFI $=84.5 \pm 4.5$ ). Its level was increased to $117.2 \pm 7.7$ by ADP activation and to $103.9 \pm 7.3$ by TRAP activation. The difference between resting and ADP-activated platelets was statistically significant $(p<0.01)$, but the difference between resting and TRAP-activated platelets was not statistically significant ( $p>0.05)$. This slight decrease following TRAP activation, compared to ADP activation, may be due to this receptor shedding its alpha subunit following potent activation (Bergmeier 2004). 


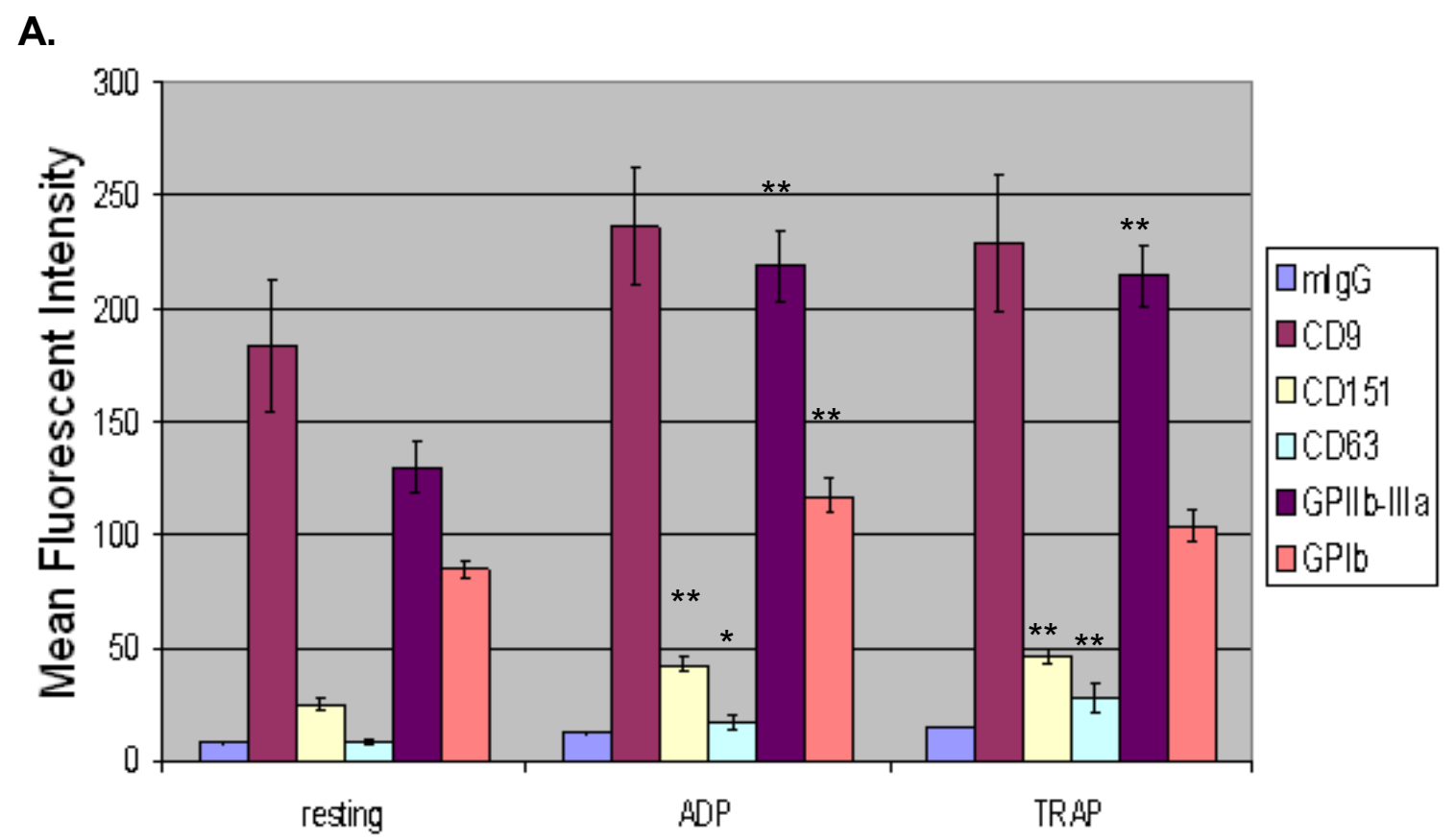

B.

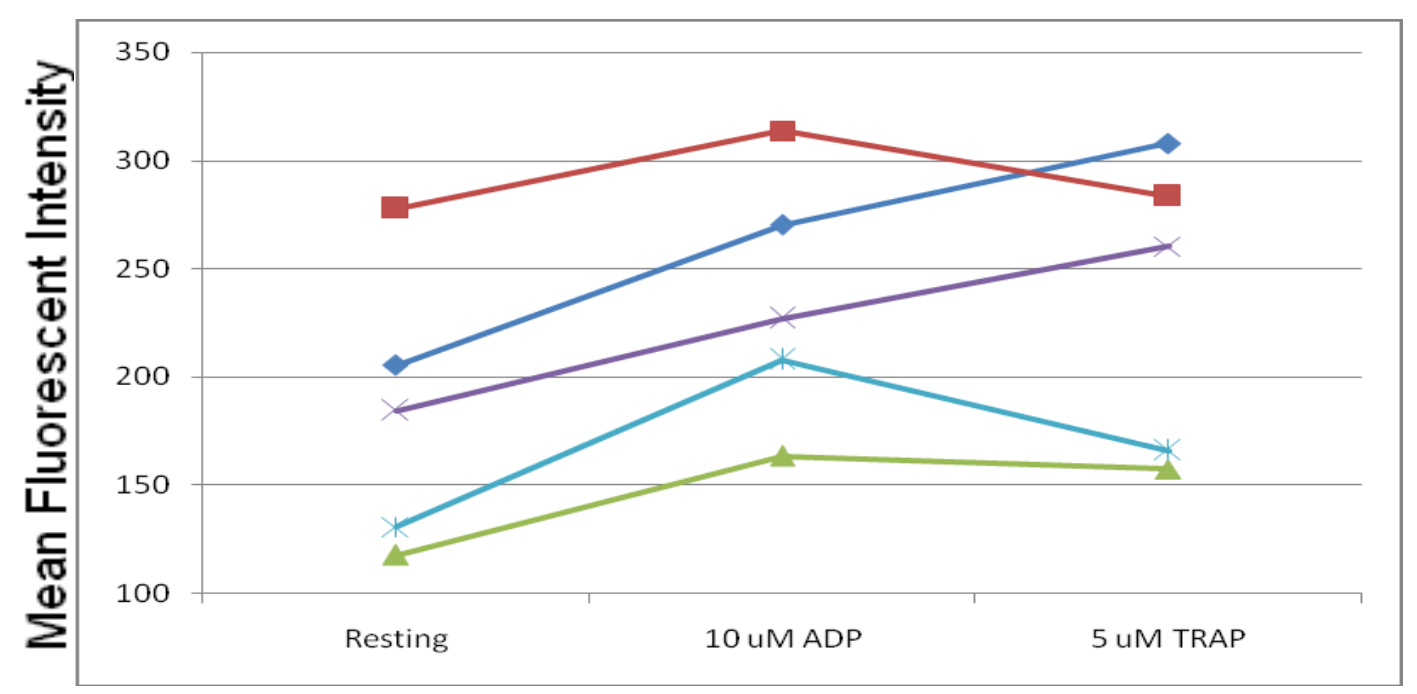

\section{Figure 4.1 Expression of Tetraspanins on the Platelet Surface}

$A$, Platelet surface expression of CD9, CD151, CD63, GPIIb-IIla, and GPIb under resting conditions or activated with ADP or TRAP, as measured by flow cytometry. mlgG provides a negative background control. CD9 does not show a statistically significant increase in expression upon platelet activation. CD151, CD63, and GPIlb-IIla display a statistically significant increase in expression upon platelet activation, whether by ADP or TRAP. GPIb displays an increase in surface expression upon mild activation by ADP, but not a statistically significant increase upon stronger activation by TRAP. $B$, mAb7 binding to resting or activated platelets of individual donors. ${ }^{*}, p<0.05 ;{ }^{* *}, p<0.001 ; n=5$. 


\subsection{Association of CD9 and GPIIb-Illa in Resting and Activated Platelets}

\subsubsection{Co-Immunoprecipitations}

Immunoprecipitations were performed using 1\% CHAPS, a mild detergent which does not disrupt the integrity of the tetraspanin web. The platelet lysate was either immunoprecipitated with $\mathrm{mlgG}$, a nonspecific antibody; mAb7, a CD9 EC2 antibody; or D3, a GPIIb-IIla antibody (Fig 4.2). D3 was used in the presence or absence of eptifibatide to evaluate the effect of receptor occupancy on CD9-GPIlb-IIla interactions.

After protein separation by SDS-PAGE, a denaturing polyacrylamide gel electrophoresis, immunoprecipitates were probed for CD9 or GPIlb (a component of GPIIb-IIla). D3 was found to immunoprecipitate GPIlb, with no difference upon inclusion of eptifibatide. D3 also co-immunoprecipitated a portion of CD9, with no difference upon inclusion of eptifibatide. Conversely, mAb7 was able to immunoprecipitate CD9 and co-immunoprecipitate a portion of GPIlb. The negative control, mlgG, was not able to immunoprecipitate either protein, confirming antibody specificity.

These results indicate that a portion of CD9 and GPIIb-IIla associate with each other in the membrane, and that this interaction is maintained with $1 \%$ CHAPS. Integrin binding to eptifibatide does not appear to alter the association between CD9 and GPIIb-IIla, suggesting that the association between CD9 and GPIIb-IIla may be controlled by another mechanism besides ligand binding to the integrin.

\subsubsection{Confocal Analysis}

Platelets were allowed to spread on four matrix substrates: FG, FN, Fb$\mathrm{FN}$, or $\mathrm{Fb}$ (Fig 4.3). All of these matrix proteins are ligands for GPIlb-Illa, and FN is additionally a ligand of CD9. After 60 minutes, most adherent platelets were fully spread, although there were some platelets just extending filopodia or lamellipodia. At this concentration, some platelets did not contact other platelets, while other platelets were in direct physical contact with adjacent platelets.

On all matrices, CD9 was most intense at platelet-platelet contacts. Additionally, CD9 was pronounced at the platelet periphery, within the extended filopodia and lamellipodia, and centralized at discrete points in the platelet body (potentially where granules were clustered).

The matrices displayed some modest differences in CD9 distribution. CD9 localization on fibrin or fibrin-FN was more diffuse, with increased signal across the entire surface of the platelet compared to FG or FN. 

A I.P.: lysate mlgG mAb7 D3+Eptif. D3

Blot: anti GPIIb--

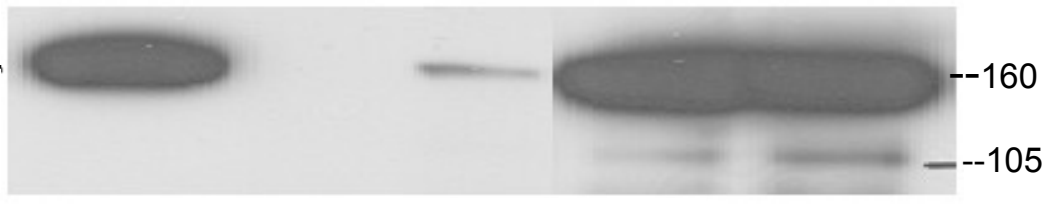

B I.P.: lysate mlgG mAb7 D3+Eptif. D3

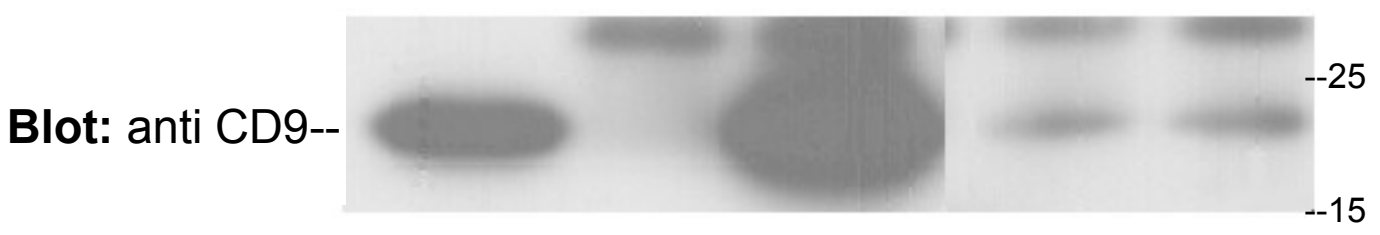

Figure 4.2 Co-Immunoprecipitation of CD9 and GPIlb-IIla

$A$, GPIlb is detected in samples immunoprecipitated with the CD9 antibody mAb7, as well as the GPIIb-IIla LIBS antibody D3 in the presence or absence of $4000 \mathrm{nM}$ eptifibatide. $B, \mathrm{CD} 9$ is deteted in samples immunoprecipitated with $\mathrm{mAb7}$, and a fraction of $\mathrm{C} 9$ is co-immunoprecipitated with D3. Coimmunoprecipitation is not altered by the presence of $4000 \mathrm{nM}$ eptifibatide. mlgG is not able to precipitate GPIIb or CD9. 


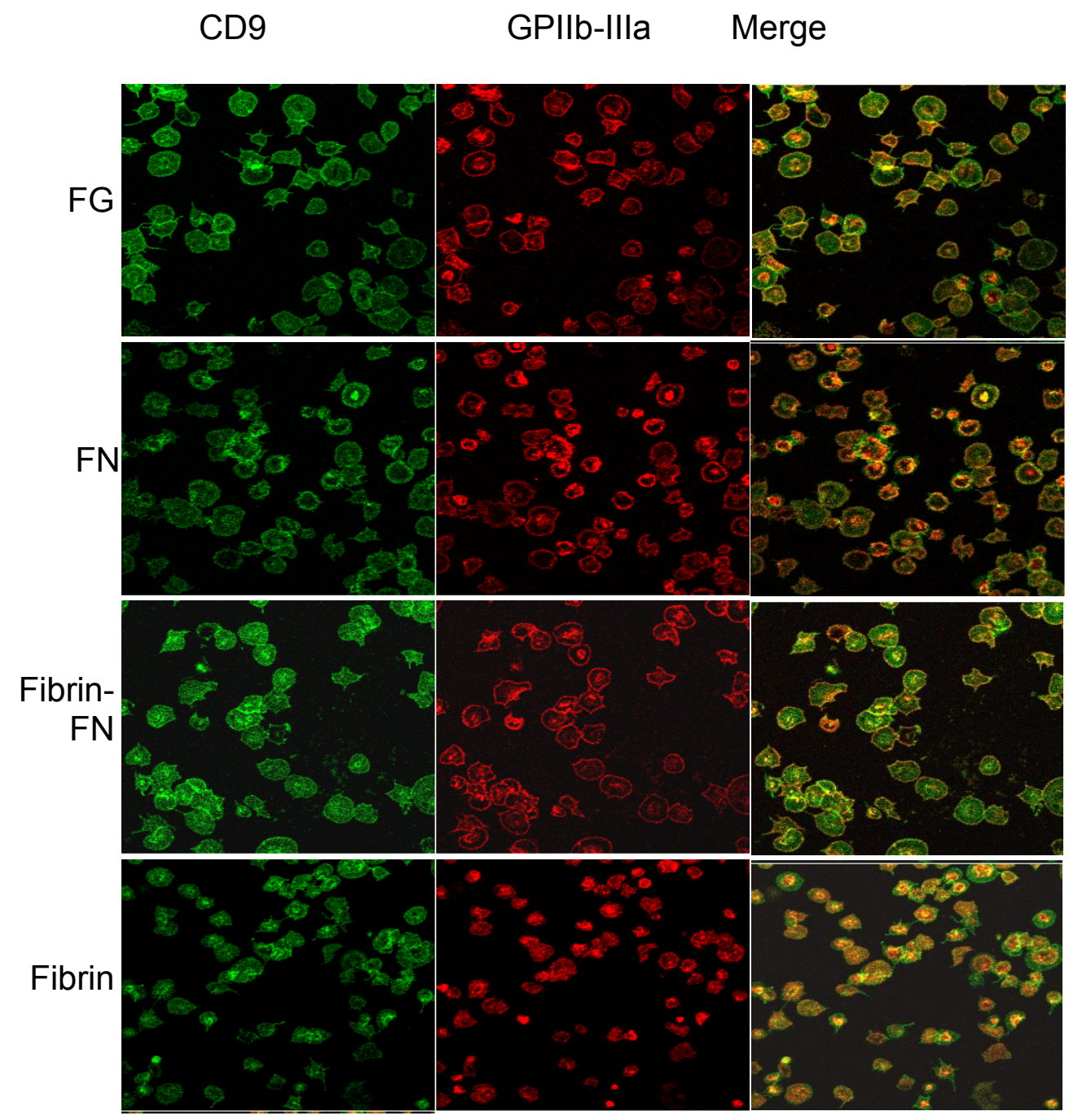

Figure 4.3 Localization of CD9 and GPIIb-IIla in Spread Platelets

CD9 staining by ML13-FITC is similar in platelets spread on either FG or FN. CD9 can be found across the entire platelet surface, but is most intense at the platelet periphery or in filopodia. There is also an increased level of CD9 at platelet-platelet contact sites. GPIIb-IIla staining by D3-TRITC on both matries is concentrated on the periphery of the spread platelets. Staining is also present in platelet centers. Colocalization between CD9 and GPIIb-IIla is found at the platelet periphery. Colocalization is also found at platelet-platelet contact sites in platelets spread on FG. In platelets spread on fibrin, CD9 localization is diffuse across the entire platelet surface. In platelets spread on fibrin, CD9 localization is diffuse across the entire platelet surface. In platelets spread on fibrin-FN, the CD9 localizaiton appears as an intermediate between platelets spread on fibrin. On both matrices, colocalization is found at the platelet-platelet contact sites. 
GPIIb-IIla also tended to be most intense at the platelet periphery and platelet centers. GPIlb-Illa was most diffuse in platelets spread on fibrin. There was extensive co-localization between CD9 and GPIIb-IIla in spread platelets on all matrices. Co-localization was most pronounced at the platelet periphery and at platelet-platelet contacts. This suggests that CD9 plays an important role in modulating GPIIb-IIla adhesive functions at platelet-platelet contacts and in platelet spreading. CD9 may alter the conformation of GPIIb-IIla at these areas, or may be modulating the presentation of ligand to integrin.

\subsubsection{Impact of Mutant GPIIb-IIla}

Platelets from patients with Glanzmann Thrombasthenia, expressing mutant GPIIb-IIla on the surface that is incapable of binding ligand, were able to bind and spread on fibronectin and fibrin-fibronectin (Fig 4.4). The platelet adhesion and spreading ability may be due to other platelet integrins, to CD9, or to a possible unaffected ligand binding site on GPIIb-IIla. Interestingly, a subset of the platelets expressing the mutant GPIlb-IIla exhibited abnormal platelet spreading on both matrices - they spread over a larger surface area on fibrin, and over a smaller surface area on fibrin-fibronectin, compared to normal controls.

Although co-localization analysis is difficult to perform due to the diminished GPIIb-Illa staining, it appears that the expressed GPIIb-IIla exhibits localization and CD9 colocalization similar to normal platelets.

In the platelets expressing mutant GPIIb-IIla, flow cytometric analysis demonstrated that CD9 expression was increased (data not shown). This could be due to attempted compensation, as CD9 is believed to be a receptor for fibronectin and could attenuate the impact of mutated GPIlb-Illa. However, it is also possible that the mutation of GPIIb-IIla alters the CD9-GPIIb-IIla association to such an extent that there is better access for antibody binding.

\subsection{Localization of CD9 during Platelet Spreading}

\subsubsection{Platelet-Matrix Contact}

Slices of spread platelets were viewed independently of other slices above or below the desired plane using the confocal microscope (Fig 4.5). Platelets were sliced into three sections: the basal section included the segment of the platelet in contact with the matrix; the apical section was the upper third of the platelet facing away from the matrix; and the central section comprised the portion of the platelet between these two sections. 


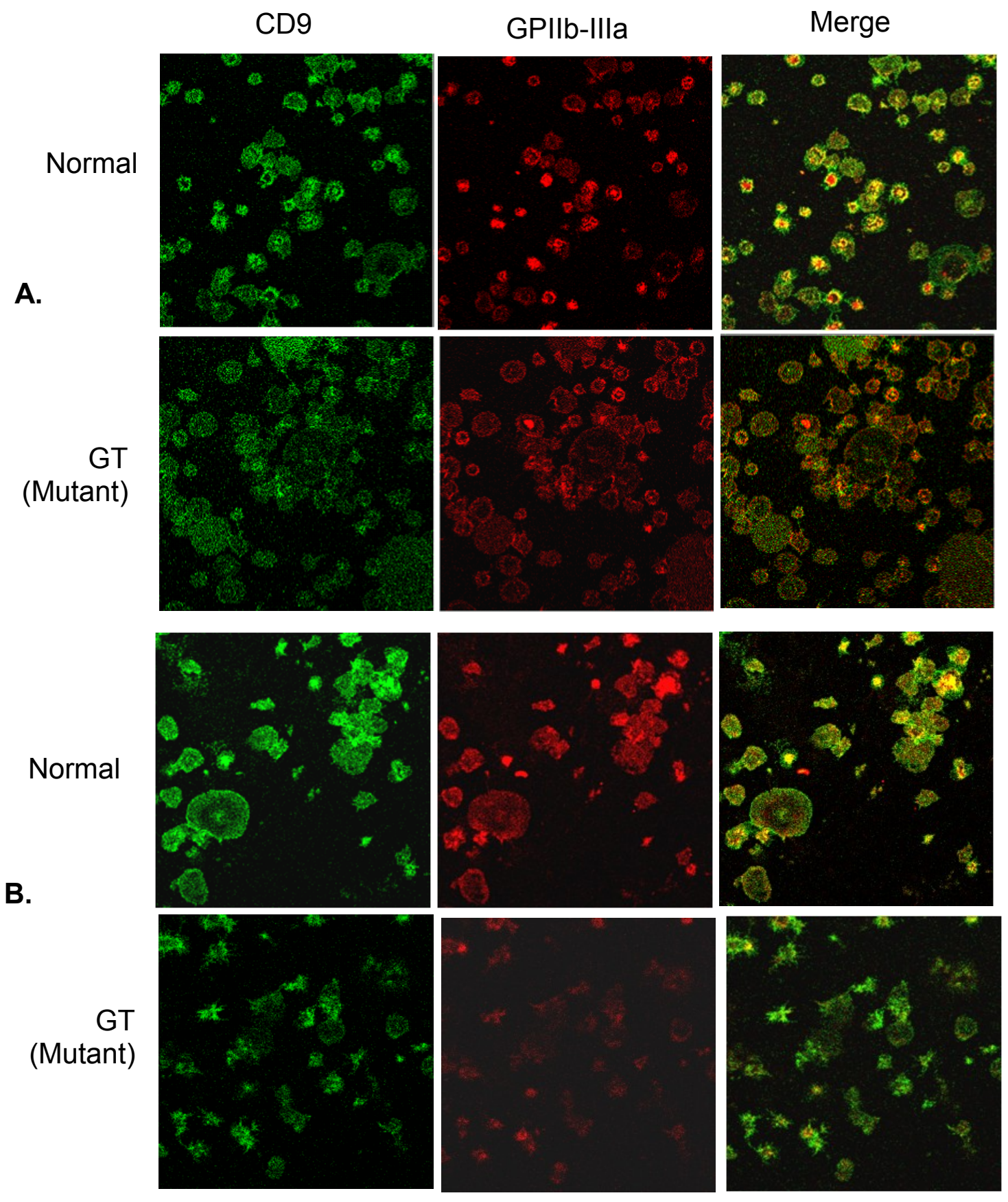

Figure 4.4 CD9 Localization in Glanzmann Thrombasthenia

$A$, Comparison of normal and GT platelets spread on FN. $B$, Comparison of normal and GT platelets spread on Fb-FN. Green, CD9 ; Red, GPIIb-IIla ; Yellow, merge. Note that GPIIb-IIla mutation does not alter platelet adhesion nor the colocalization etween CD9 and GPIIb-IIla ; however, extent of platelet spreading is altered, with platelets spreading more on $\mathrm{Fb}$ and less on $\mathrm{Fb}-\mathrm{FN}$ compared to normal controls. 


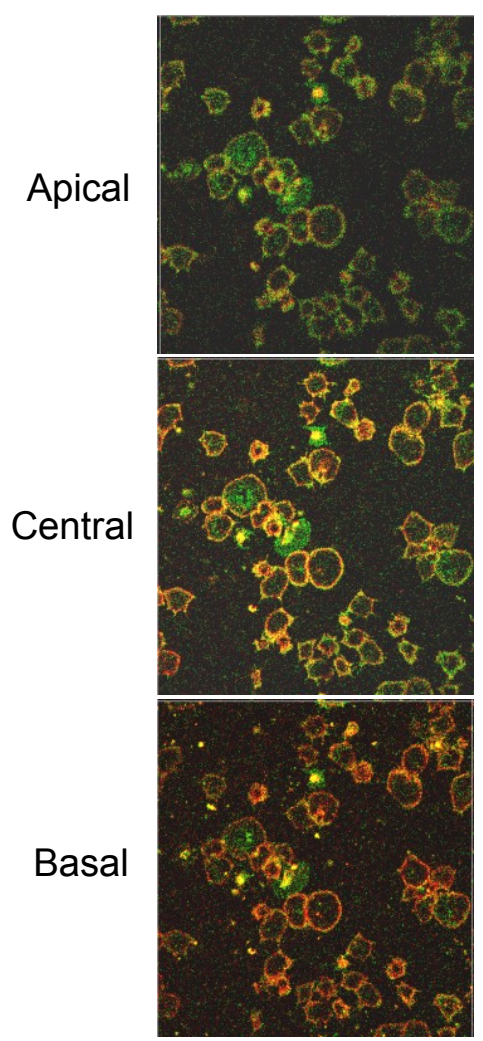

FG
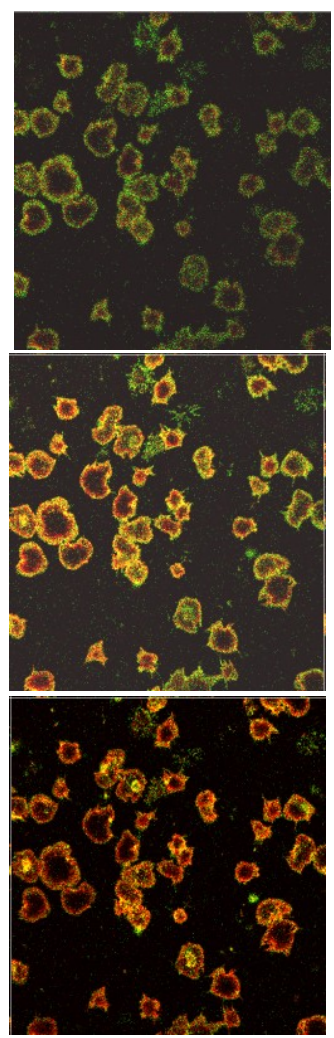

FN
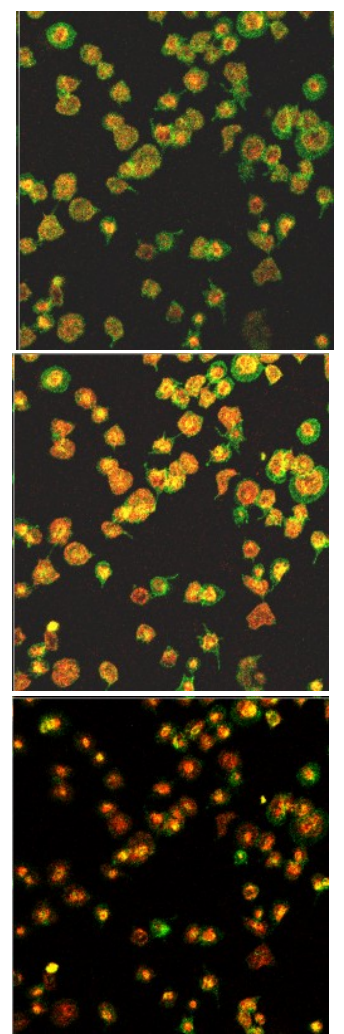

Fibrin
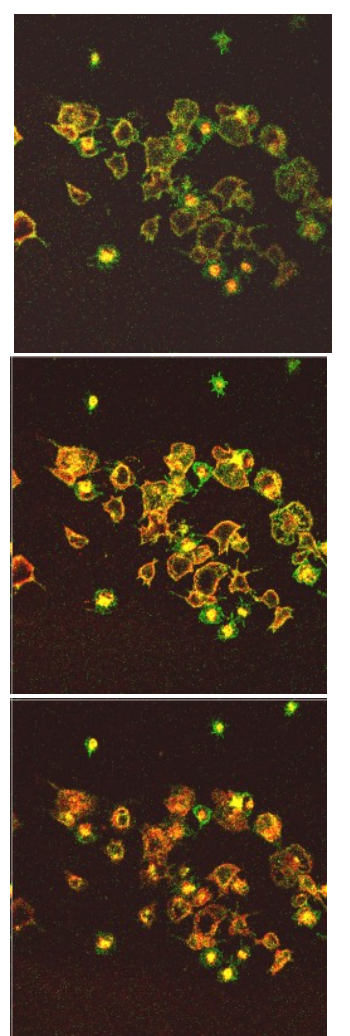

Fibrin-FN

\section{Figure 4.5 Analysis of CD9 Localization in Platelet Sections with or without Matrix Contact}

GPIIb-IIla (D3-TRITC, red) is localized in the basal portion of the platelet (in contact with the matrix). Much lower GPIlb-Illa levels are observed in the apical sections of the platelet. CD9 (ML13-FITC, green) is found in the apical and central sections of the platelet, but only a low level of expression is observed in contact with matrix. Co-localization (yellow) between CD9 and GPIIb-IIla is found mainly at the platelet-platelet contact sites. There is only a low level of CD9 and GPIIb-IIla colocalization at platelet-matrix contact sites on the basal portion of the platelet. Additionally, only a low level of colocalization is observed at the apical sections of the platelets. 
GPIIb-IIla expression was found to be intense in the basal section, where platelets were in contact with the matrix. GPIlb-Illa was also found at regions of platelet-platelet contact in the basal and central sections. Surprisingly, there was very little CD9 expression observed in the basal section of the platelets on any of the matrices. This indicates that CD9 does not likely have an important role in direct adhesion to the matrix - even to fibronectin, a known ligand —or to modulating GPIIb-IIla adhesion to the matrix. However, the expression of CD9 in spreading structures such as filopodia and lamellipodia suggests a role for CD9 in platelet spreading events. CD9 expression was intense in the central region of the platelet, where it was strongly colocalized with GPIIb-IIla, particularly at platelet-platelet contact sites. This further indicates a likely involvement of CD9 in modulating the role of GPIlb-IIla in platelet-platelet interaction and thrombus stability.

Only low levels of CD9 or GPIIb-IIla were observed in the apical sections of platelets. This is not unusual, as both proteins would be expected to be localized to sections of the platelet membrane involved in contact with platelets or matrix.

\subsubsection{Platelet-Platelet Contact}

When platelet spreading resulted in platelet-platelet contact, CD9 staining was greatly intensified at these contact points (pixel intensity $=141.5 \pm 8.9$ ) compared to the platelet periphery not involved in platelet-platelet contact (pixel intensity $=32.7 \pm 16.2$ ) (Fig 4.6). It is evident that CD9 is being actively localized into areas of platelet-platelet contact, and not merely an additive effect, as the intensity at platelet-platelet contact is more than double the intensity at noncontact periphery.

\subsubsection{Platelet Spreading Structures}

The localization of CD9 was initially characterized in platelets throughout the stages of adhesion and spreading on fibrinogen, as well as its colocalization with F-actin, using confocal microscopy (Fig 4.7). Immediately upon adhesion to fibrinogen, platelets developed a rounded shape, with CD9 distributed throughout the entire platelet surface. CD9 was colocalized with F-actin as evidenced by the yellow merge signal. As the platelet began extending filopodia and lamellipodia, CD9 was increasingly localized to these extensions. Co-localization with F-actin was still observed, although the degree of co-localization was decreased as platelet spreading proceeded. As the platelet progressed to a fully spread morphology, CD9 was distributed evenly across the platelet membrane; however, after 60 minutes, a large portion of CD9 localized in punctate clusters at the leading edge of the platelet. Co-localization of CD9 and F-actin was no longer evident. 
A

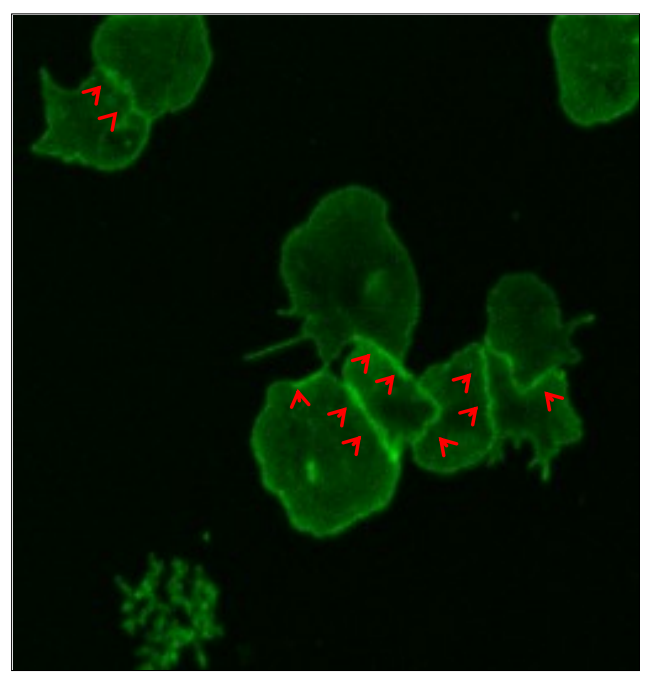

B

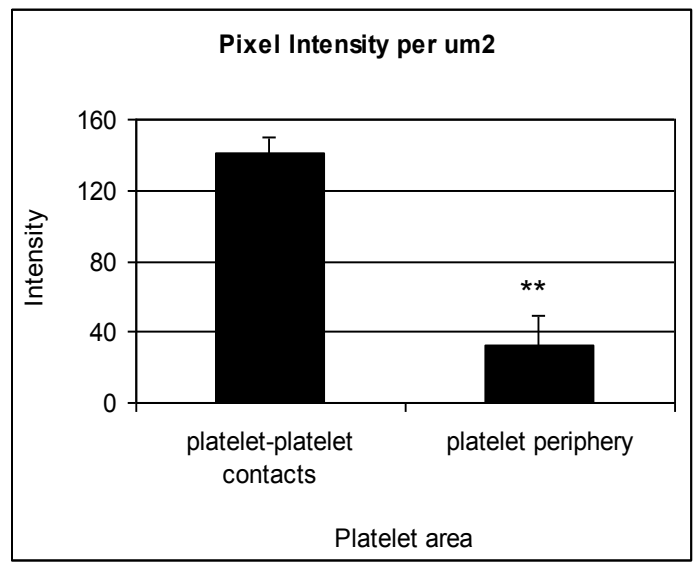

Figure 4.6 Localization of CD9 at Platelet-Platelet Contacts

$A$, CD9 staining is intensified at areas of contact between spread platelets (red arrowheads). B, Quantitation of pixel intensity at platelet-platelet contacts vs. the platelet periphery not involved in platelet-platelet contacts. These data indicate that CD9 is actively localized at platelet-platelet contacts, and that the observation is not due to the additive effect of multiple platelet membranes in contact. ${ }^{* *}, p<0.01 . n=4$. 


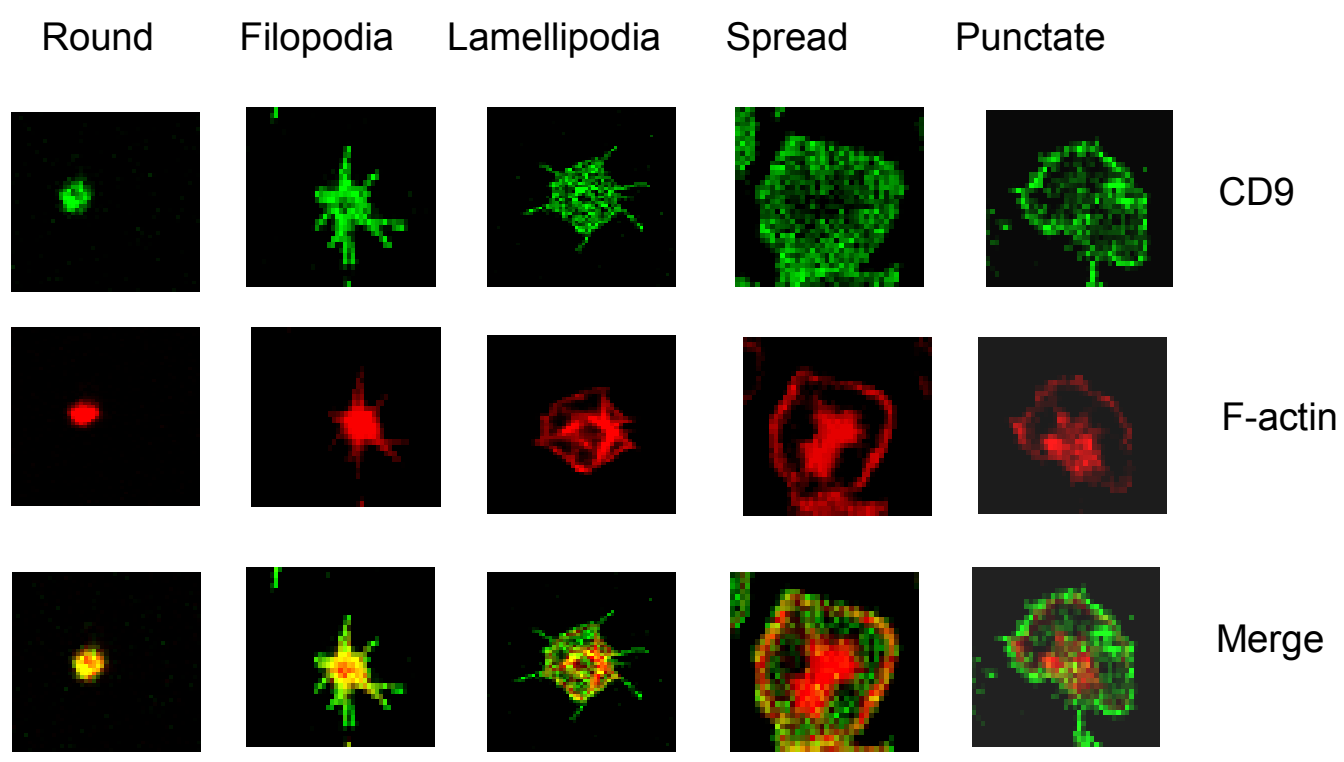

Figure 4.7 Localization of CD9 and Actin during Platelet Spreading Washed platelets in progressive stages of platelet spreading. In newly adherent, round platelets, CD9 (ML13-FITC) covers the platelet surface. There is a high level of colocalization with F-actin (Phalloidin-TRITC). As the platelet extends filopodia and lamellipodia, CD9 is highly expressed in these areas. The level of CD9 and actin co-localization appears to diminish as the platelet proceeds through the spreading process. In a nascent, spread platelet, the CD9 is found across the platelet membrane but is most strongly expressed at the platelet periphery. As platelets are allowed to spread for 60 minutes, CD9 localizes to discrete, punctuate areas on the platelet periphery, although there is still CD9 localized across the entire platelet surface. $n=4$. 


\subsection{Generation and Purification of mAb7 Fab (mFab7) Fragments}

To evaluate the role of CD9 independently from the platelet Fc $\gamma$ RII receptor, Fab fragments were created from the monoclonal antibody $\mathrm{mAb7}$, an antibody with a high affinity for CD9 EC2. This antibody was chosen due to its functional effects in smooth muscle cells (unpublished data) as well as its functional effects in CHO cells transfected with human GPIlb-IIla (Cook 1999).

Upon cleavage with papain and passage through a Protein A column, the isolated Fab fragments, henceforth designated $\mathrm{mFab7}$, along with intact $\mathrm{mAb} 7$ and control mlgG and control mlgG Fab fragments, were electrophoresed reduced and nonreduced through SDS $5-20 \%$ polyacrylamide gradient gels. Protein staining by Gelcode Blue showed a homogeneous preparation with no detectable intact $\mathrm{mAb} 7$ even with $\geq 50 \mu \mathrm{g}$ Fab protein loaded onto the gel (Fig $\underline{4.8 \mathrm{~A}}$ ). The contaminant band of approximately $60 \mathrm{kDa}$ in mAb7 and mFab7 lanes was excised and subjected to mass spectrometry. This protein was identified as murine albumin (data not shown).

As intact $\mathrm{mAb} 7$ can induce platelet aggregation, aggregation tracings were recorded with $\mathrm{mAb} 7$ and $\mathrm{mFab} 7$ to verify that $\mathrm{mFab} 7$ was purified, without any traces of intact antibody. Aggregations performed using up to $100 \mu \mathrm{g} / \mathrm{ml} \mathrm{mFab7}$ did not induce aggregation even after 15 minutes, while mAb7 concentrations $\geq$ $0.2 \mu \mathrm{g} / \mathrm{ml}$ induced an aggregation response (Fig 4.8B). Therefore, from a functional perspective, the mFab7 was virtually free of intact, functional mAb7.

A FITC-labeled, goat anti-mouse-Fab antibody was used to verify binding competency of mFab7 under flow cytometry. Mean fluorescence intensity (MFI), measuring binding of anti-Fab to mAb7 and mFab7, was 92.45 and 112.84, respectively, indicating Fab7 binding was similar to that of the intact $\mathrm{mAb7}$ antibody (Fig 4.8C). When a FITC-labeled goat anti-mouse-Fc antibody was used, the MFI for the mAb7 sample was 108.58 as expected, while the MFI of the $\mathrm{mFab7}$ sample was reduced to control mouse levels, further indicating that the $\mathrm{mFab7}$ sample was free of intact mAb7 (Fig 4.8D).

\subsection{CD9 Perturbation}

\subsubsection{Platelet Spreading}

Human platelets were pre-incubated with either control isotype-matched Fab (control) or $\mathrm{mFab} 7$ then allowed to spread on one of four matricesfibronectin $(F N)$, fibrin $(F b), F b-F N$ cross-linked matrix, or fibrinogen $(F G)$-all four of which are ligands for GPIIb-IIla, the major platelet integrin, and are 
Figure 4.8 Purification of $\mathrm{mFab7}$ from $\mathrm{mAb7}$

$A, \mathrm{mAb} 7$ digests on a non-reducing or reducing SDS-PAGE. Lane 1, undigested control mlgG; lane 2, control Fab; lane 3 undigested mAb7; lane 4, mFab7; $50 \mu \mathrm{g}$ protein per lane. $B, \mathrm{mAb} 7$ causes platelet aggregation when added to a stirring suspension of platelets, but mFab7 does not cause platelet aggregation. $C$, Flow cytometric analysis indicates $\mathrm{mFab7}$ binding ability on the platelet surface. $D$, Flow cytometric analysis reveals that an anti-Fc antibody does not bind to platelets with $\mathrm{mFab7}$, further indicating purity. 
A.

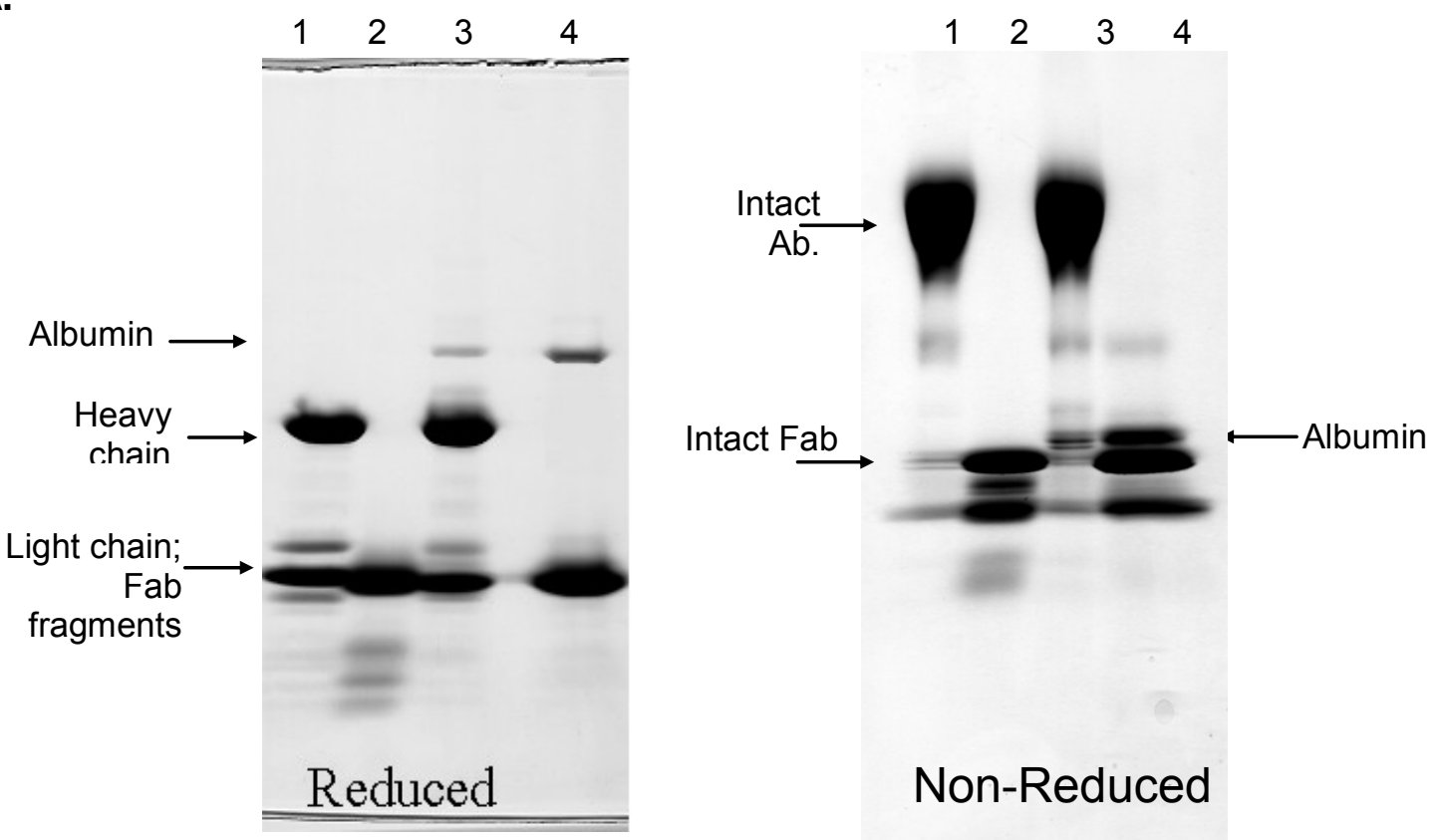

B.

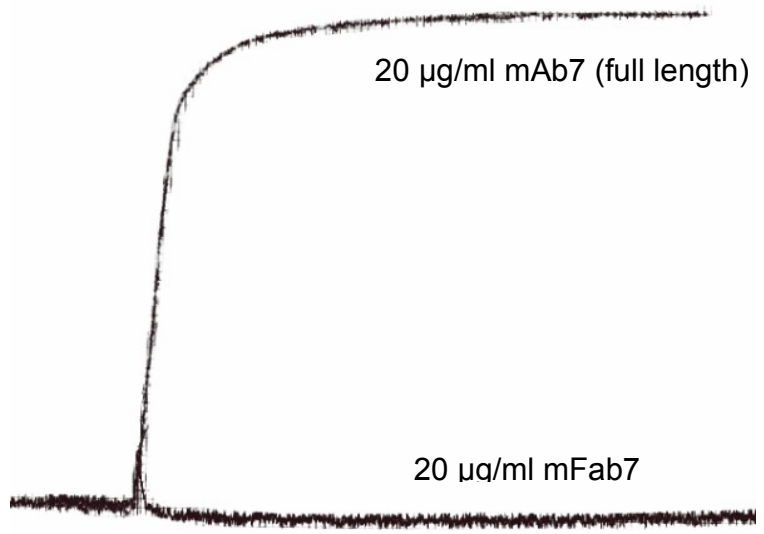


C.

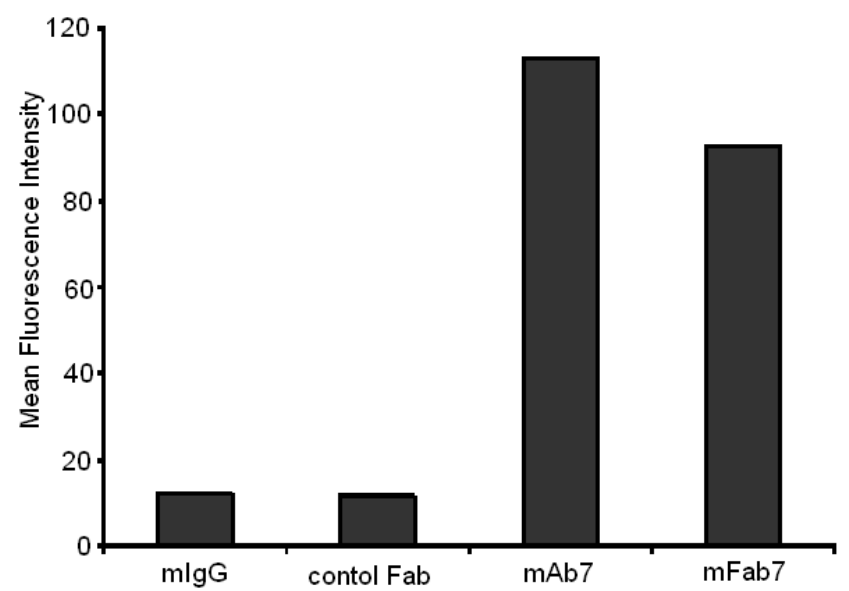

D.

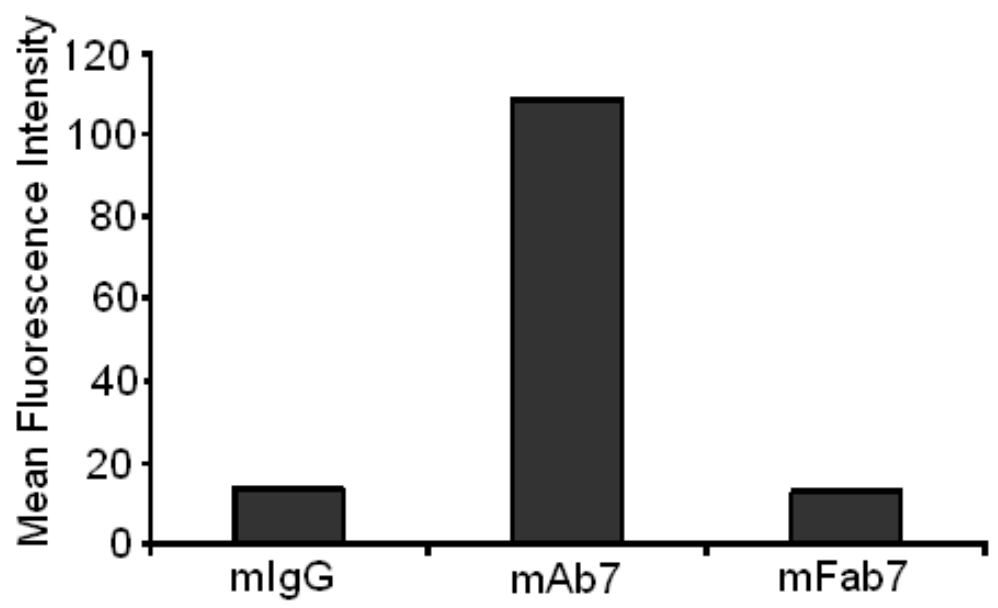

Figure 4.8 (continued) 
exposed to platelets as components of plasma, atherosclerotic plaques, or at sites of vascular injury.

Pre-incubation with mFab7 did not appear to alter the localization or staining pattern of CD9 or F-actin, but it increased the stage of spreading of platelets on all four matrices (Fig 4.9). When platelets on Fb were quantified based on stage of spreading, it was found that platelets were in the early stages of platelet spreading - either newly adherent or extending filopodia-when they were preincubated with control Fab $(p<0.05)$, whereas platelets treated with the $\mathrm{mFab7}$ were more likely to be fully spread. Similarly, platelets on FN, Fb-FN, or FG were adherent or extending filopodia when pretreated with control Fab $(p<0.05)$, but were extending lamellipodia or fully spread when pretreated with mFab7.

Interestingly, treatment with $\mathrm{mFab} 7$ increased the total number of adherent platelets on Fb-FN per frame $(p<0.05)$, but this treatment led to no difference in the total number of adherent platelets per frame on the other matrices.

Additionally, $\mathrm{mFab} 7$ decreased the relative amount of actin co-localizing with $\mathrm{CD} 9$ on $\mathrm{FbFN}(62 \pm 12 \%$ with control Fab vs $30 \pm 6 \%$ with mFab7) and on FG (45 $\pm 7 \%$ with control Fab vs $24 \pm 7 \%$ with mFab7) (Fig 4.10), but a change was not statistically significant on $\mathrm{FN}$ or $\mathrm{Fb}$. A decrease in colocalization is likely because $\mathrm{mFab} 7$ treatment enhances platelet spreading, and a normal decrease in CD9-actin colocalization is observed as platelets spread more fully.

\subsubsection{Platelet Aggregation and Disaggregation}

MFab7 also increased the aggregation of platelets in response to low concentrations of ADP $(2-3 \mu \mathrm{M})$ or collagen $(0.6-1.0 \mu \mathrm{g} / \mathrm{ml})$ (Fig 4.11 and Table 4.1). In response to threshold ADP, the control sample exhibited a mean maximal aggregation of $54.3 \pm 5.0 \%$, which then decreased to $43.7 \pm 4.7 \%, 26.7 \pm 4.0 \%$, and $20.0 \pm 2.0 \%$ after 5,10 , and 15 minutes, respectively. When mFab7 was used, the maximal aggregation is $73.7 \pm 7.5 \%$, and the aggregate is more stable, with $70.7 \pm 12.7 \%, 64.7 \pm 16.3 \%$, and $59.3 \pm 15.5 \%$ aggregation for 5,10 , or 15 minutes after addition of agonist. When threshold levels of collagen were used, the results were similar: for control-treated platelets, the percent aggregation is $62.0 \pm 10.4 \%, 60.3 \pm 13.3 \%, 52.0 \pm 14.9 \%$, and $44.7 \pm 14.1 \%$, respectively, for maximal aggregation, and 5,10 , or 15 minutes after addition of agonist. For $\mathrm{mFab7-treated} \mathrm{platelets,} \mathrm{this} \mathrm{increased} \mathrm{to} 72.3 \pm 3.1 \%, 72.3 \pm 3.1 \%, 68.0 \pm$ $2.6 \%$, and $62.3 \pm 2.1 \%$, respectively. When platelets were activated by threshold levels of Thrombin Receptor Agonist Peptide (TRAP, 5-10 $\mu \mathrm{M}$ ), mFab7 did not increase the aggregation: $72.3 \pm 7.6 \%, 71.3 \pm 8.7 \%, 65.3 \pm 13.6 \%$, and $58.7 \pm$ $15.3 \%$ for control vs. $72.7 \pm 9.7 \%, 71.7 \pm 11.7 \%, 66.7 \pm 14.0 \%$, and $61.0 \pm 14.9 \%$ for mFab7 (Fig 4.11C and Table 4.1). 
Figure 4.9 CD9 Affects Platelet Spreading on Fibronectin (FN), Fibrin (Fb), Fibrin-Fibronectin Matrix (Fb-FN), or Fibrinogen (FG)

$A$, Quantification of platelets throughout stages of platelet spreading. $B$, Confocal microscopy images show platelets that are incubated with $20 \mu \mathrm{g} / \mathrm{ml} \mathrm{mFab7} \mathrm{(right)}$ exhibit greater spreading on all matrices than platelets that are incubated with 20 $\mu \mathrm{g} / \mathrm{ml}$ of a nonspecific control Fab. Localization of CD9 does not appear to be altered by mFab7 binding. $C$, Zoom of Merge view from B. ${ }^{*}, p<0.05 .{ }^{* *}, p<0.01$. $n=5$. 
A.

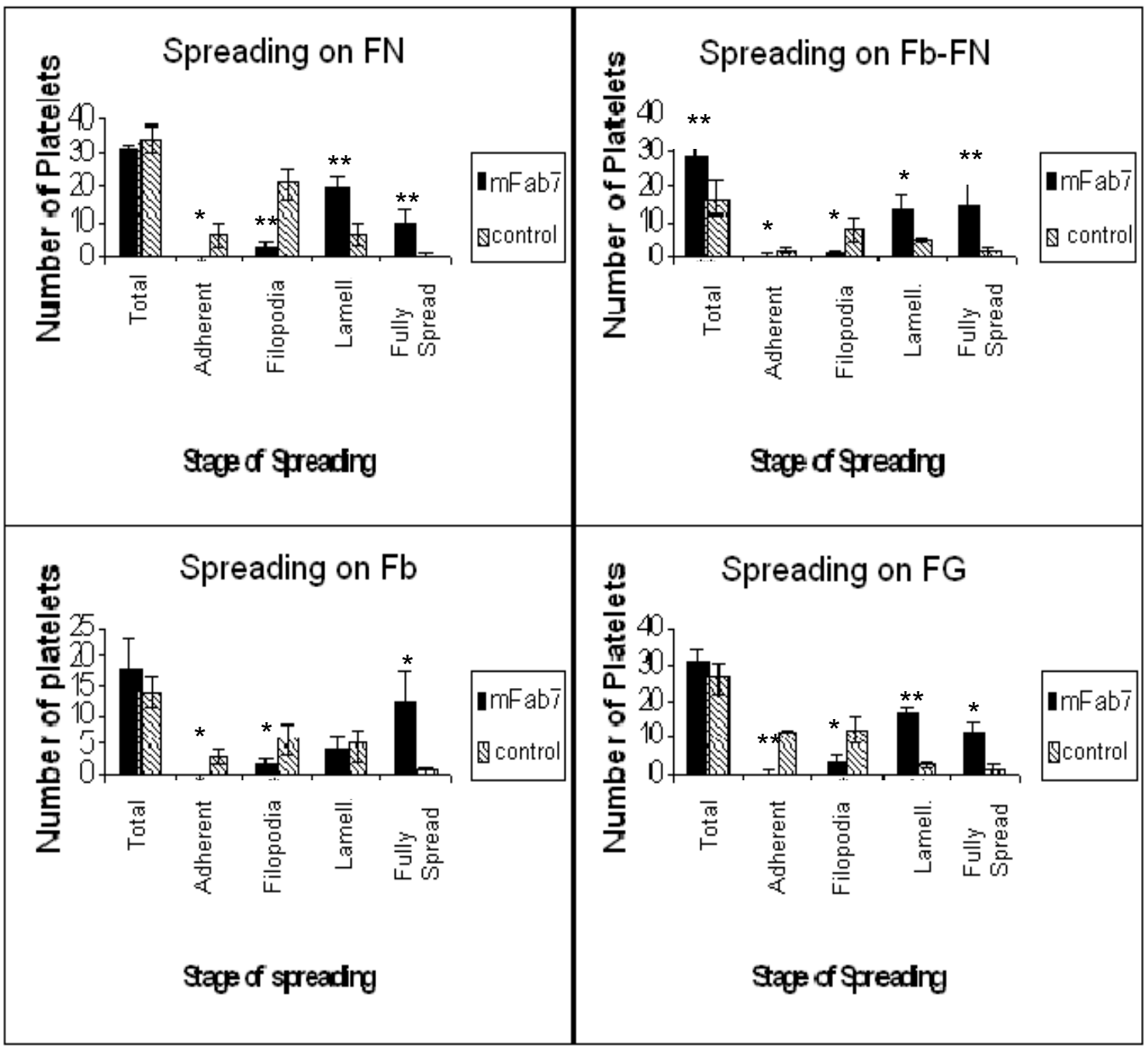


B.

Control

Fab

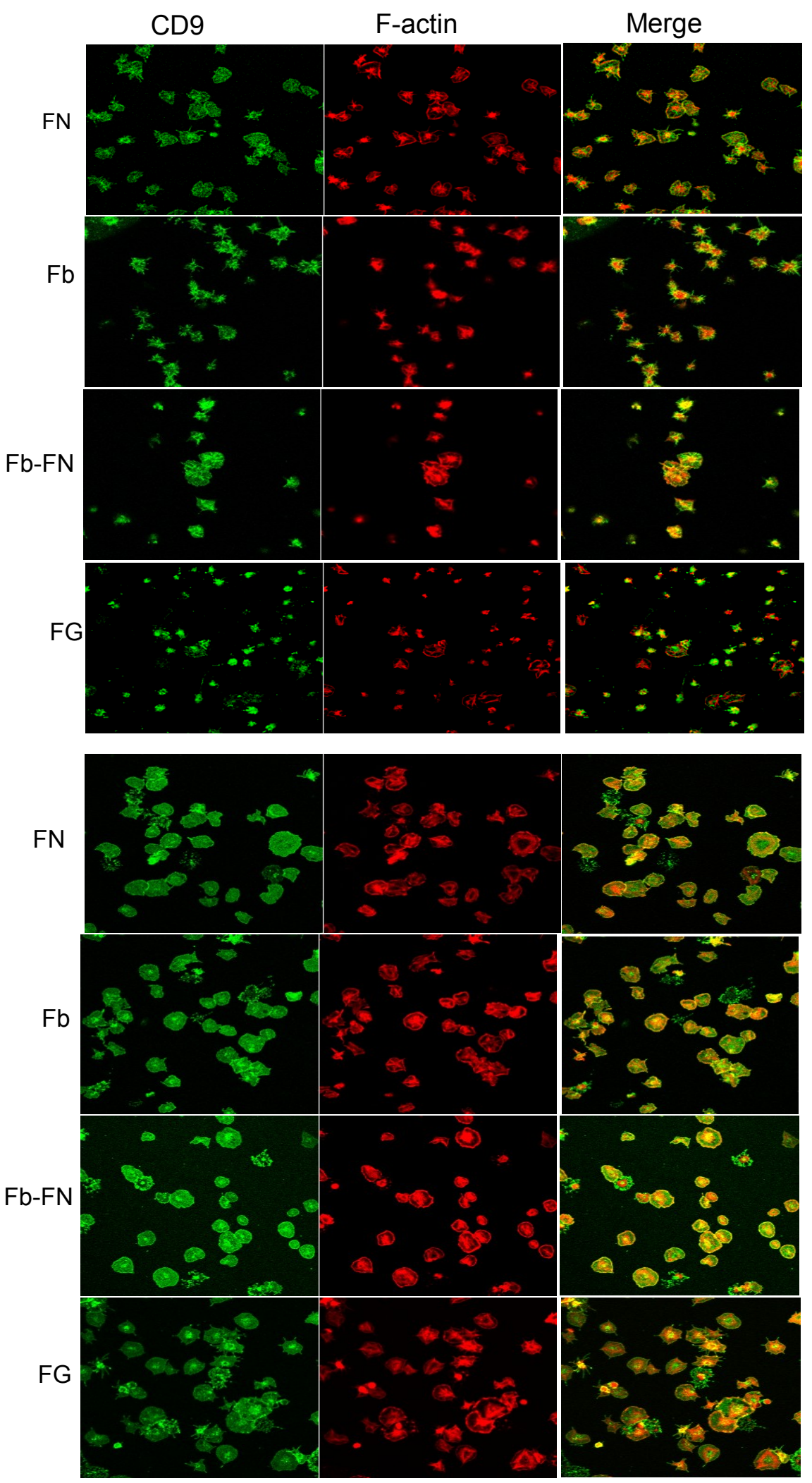

Figure 4.9 (continued) 
C.

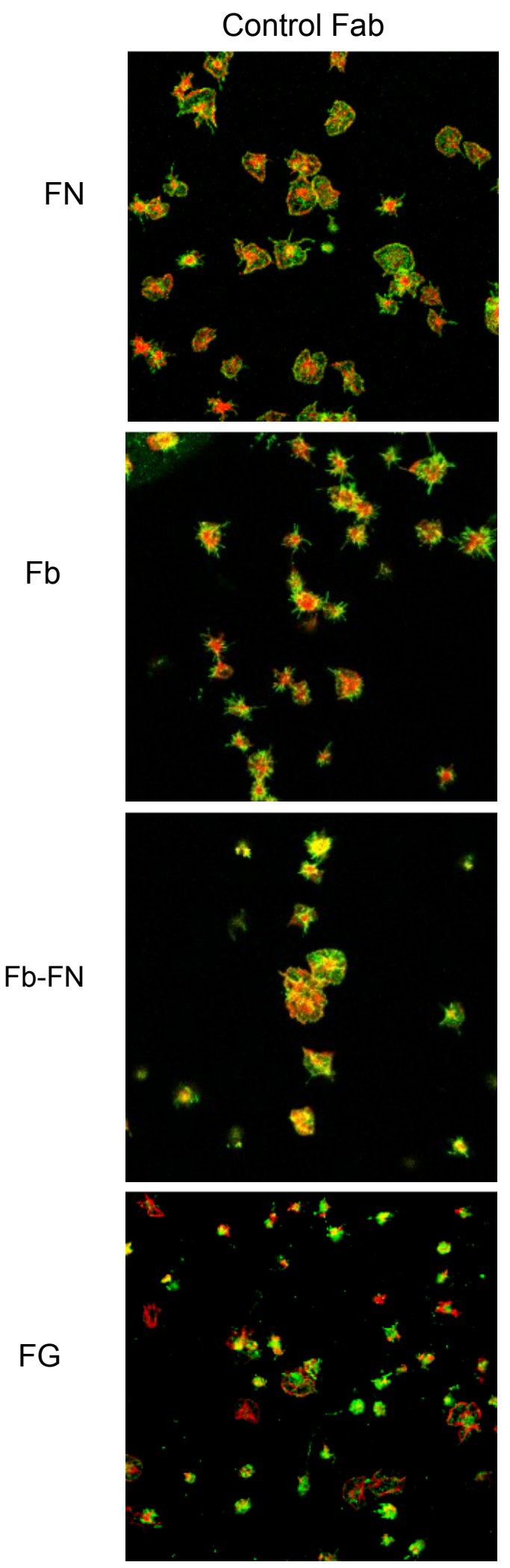

mFab7
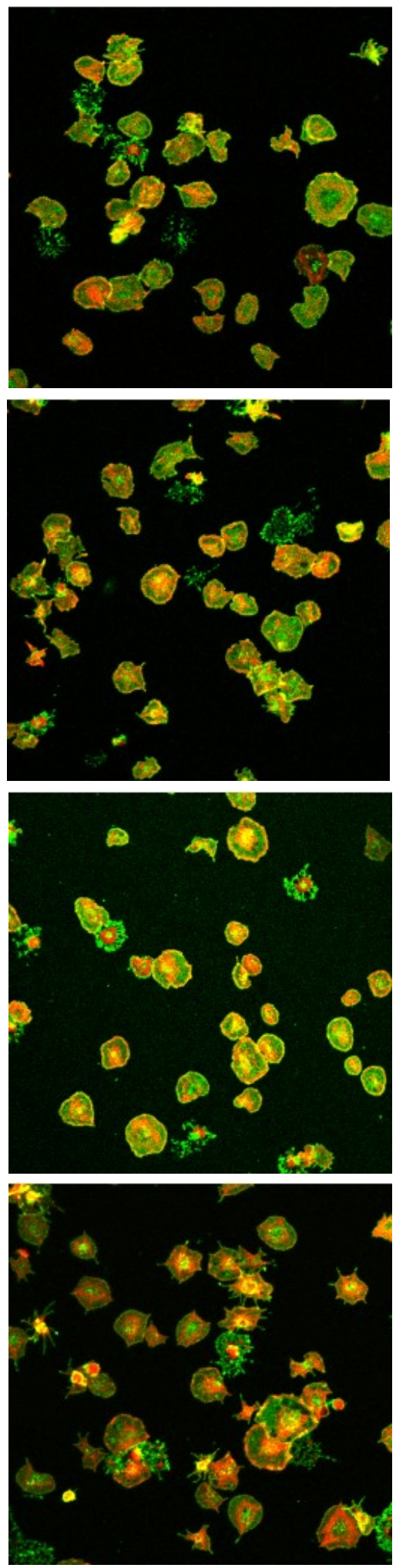

Figure 4.9 (continued) 


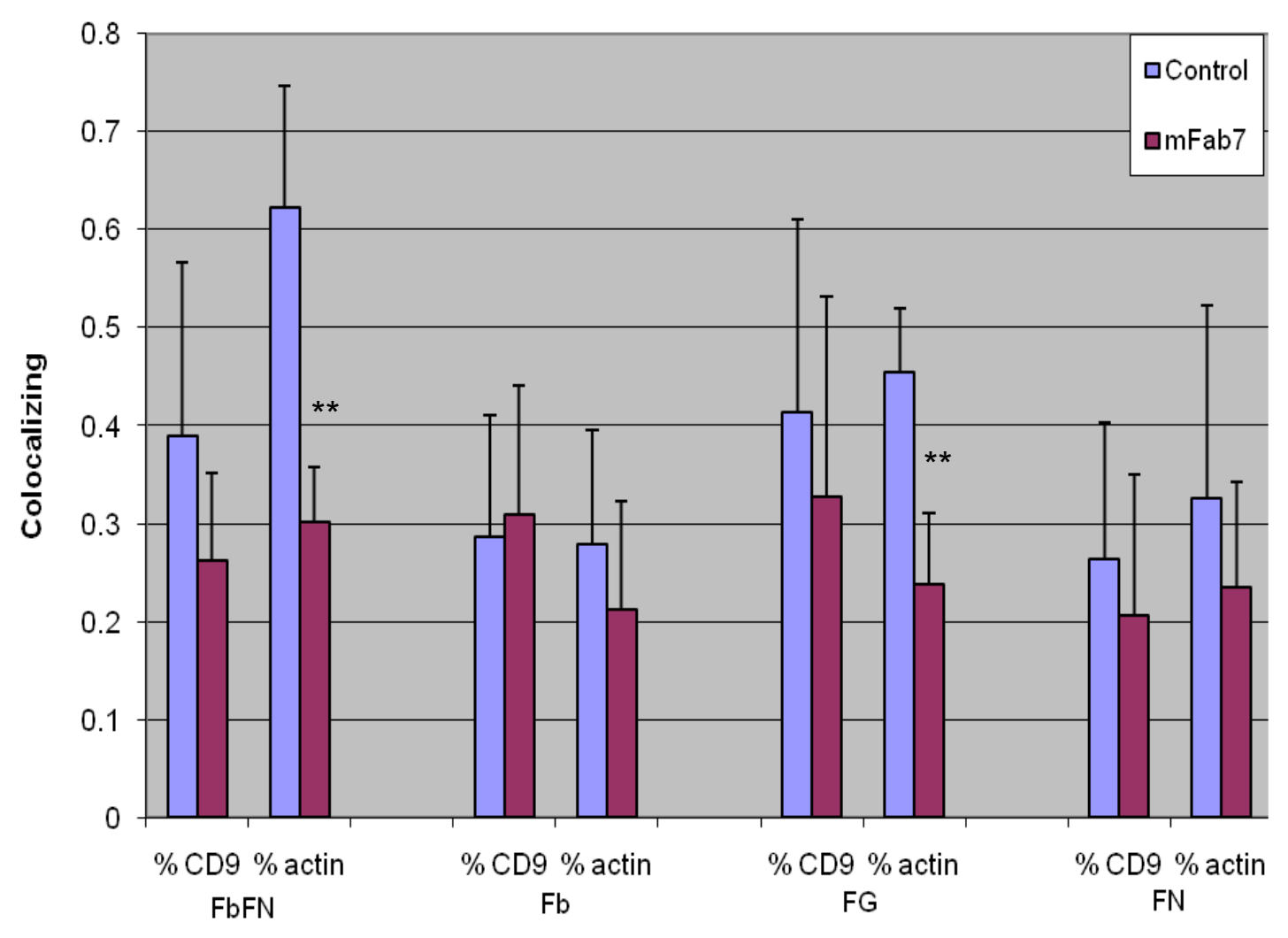

Figure 4.10 Impact of CD9 Perturbation on Colocalization with F-actin CD9 perturbation with mFab7 results in decreased levels of $F$-actin (as measured by TRITC-phalloidin) co-localizing with CD9 (as measured by ML13-FITC) in platelet spreading on FbFN and on FG. Perturbation does not lead to statistically significant changes in colocalization in platelets spread on $\mathrm{Fb}$ or on $\mathrm{FN} . \mathrm{n}=5 .{ }^{* *}, \mathrm{p}<0.01$. 
Figure 4.11 CD9 Affects Platelet Aggregation

$A$, Platelets activated by ADP. Preincubation with $\mathrm{mFab} 7$ results in a significant increase in percent aggregation at all time points compared to preincubation with control Fab. B, Platelets activated by collagen. Preincubation with $\mathrm{mFab7}$ results in a significant increase in percent aggregation at maximum aggregation and at 10 and 15 minutes after addition of collagen. $C$, Platelets activated by thrombin receptor agonist peptide (TRAP). Preincubation with $\mathrm{mFab7}$ does not alter platelet aggregation. max, maximum aggregation after addition of agonist. ${ }^{*}, p<0.05 .{ }^{* *}, p<0.01 . n=4$. 
A.

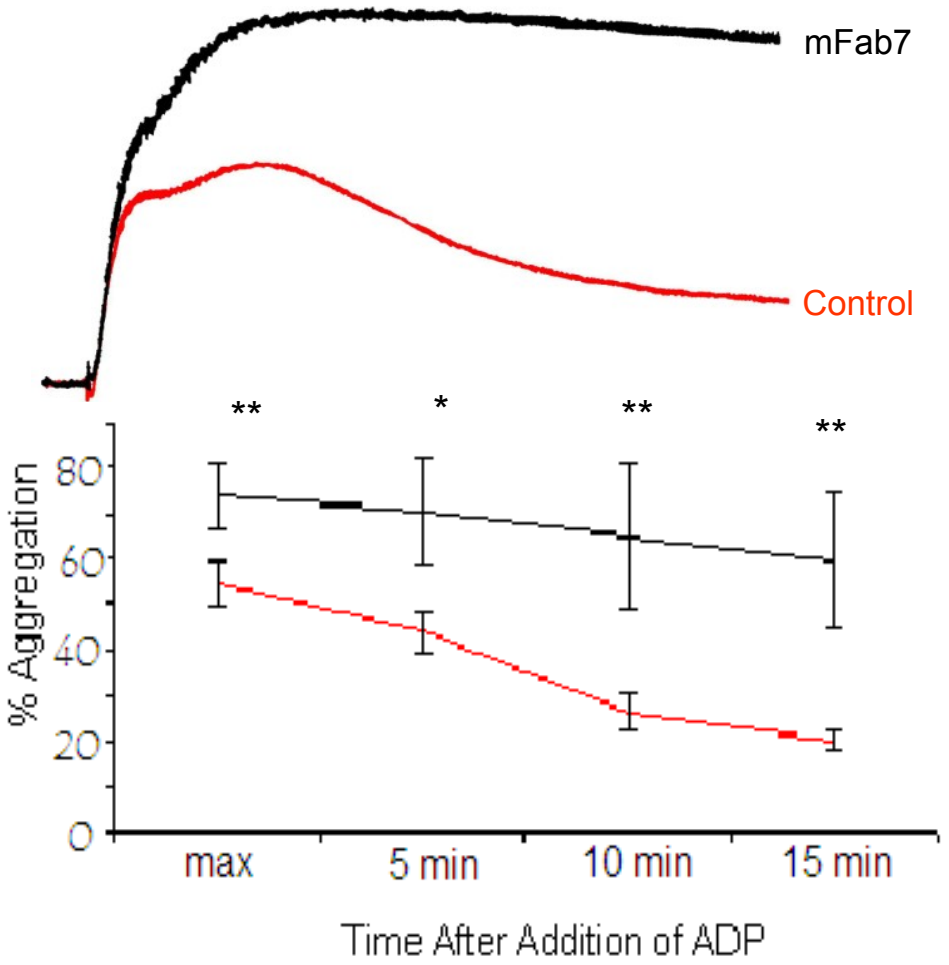

B.
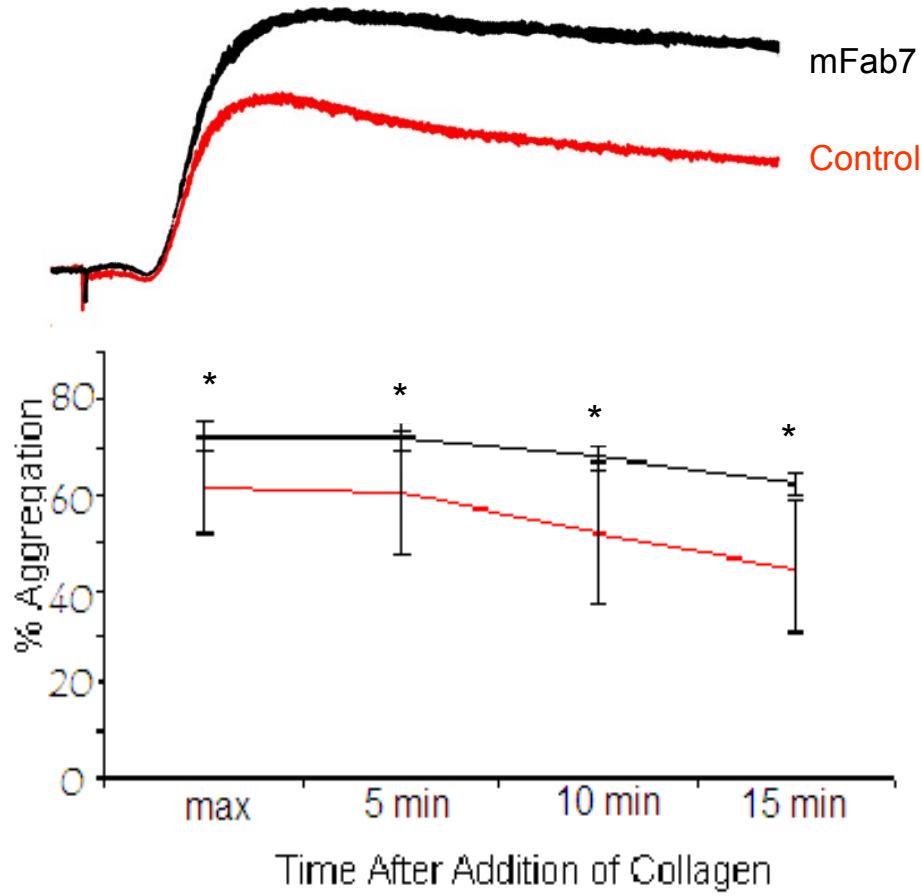
C.

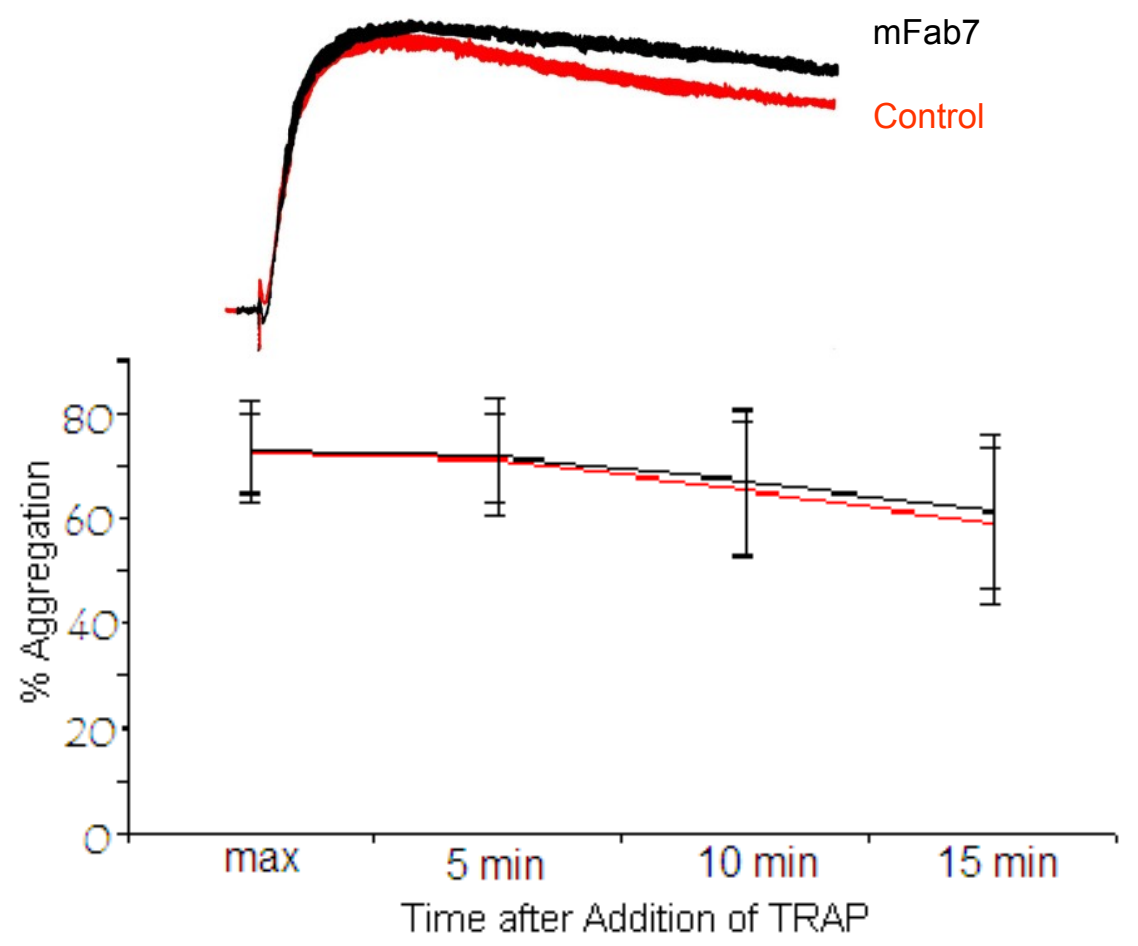

Figure 4.11 (continued) 
Table 4.1. Perturbation of CD9 Affects Percent Platelet Aggregation ${ }^{1}$

\begin{tabular}{|c|c|c|c|c|c|}
\hline Agonist & Fab & $\begin{array}{l}\text { Max } \\
\text { aggregation }\end{array}$ & $5 \mathrm{~min}$ & $10 \mathrm{~min}$ & $15 \mathrm{~min}$ \\
\hline ADP & $\begin{array}{l}\text { mFab7 } \\
\text { control Fab }\end{array}$ & $\begin{array}{l}73.7 \pm 7.5 \\
54.3 \pm 5.0\end{array}$ & $\begin{array}{l}70.7 \pm 12.7 \\
43.7 \pm 4.7\end{array}$ & $\begin{array}{l}64.7 \pm 16.3 \\
26.7 \pm 4.0\end{array}$ & $\begin{array}{l}59.3 \pm 15.5 \\
20.0 \pm 2.0\end{array}$ \\
\hline Collagen & $\begin{array}{l}\text { mFab7 } \\
\text { control Fab }\end{array}$ & $\begin{array}{l}72.3 \pm 3.1 \\
62.0 \pm 10.4\end{array}$ & $\begin{array}{l}72.3 \pm 3.1 \\
60.3 \pm 13.3\end{array}$ & $\begin{array}{l}68.0 \pm 2.6 \\
52.0 \pm 14.9\end{array}$ & $\begin{array}{l}62.3 \pm 2.1 \\
44.7 \pm 14.1\end{array}$ \\
\hline TRAP & $\begin{array}{l}\text { mFab7 } \\
\text { control Fab }\end{array}$ & $\begin{array}{l}72.7 \pm 9.7 \\
72.3 \pm 7.6\end{array}$ & $\begin{array}{l}71.7 \pm 11.7 \\
71.3 \pm 8.7\end{array}$ & $\begin{array}{l}66.7 \pm 14.0 \\
65.3 \pm 13.6\end{array}$ & $\begin{array}{l}61.0 \pm 14.9 \\
58.7 \pm 15.3\end{array}$ \\
\hline
\end{tabular}

${ }^{1}$ Percent platelet aggregation, showing the maximum aggregation achieved, and percent aggregation at 5, 10, and 15 minutes after addition of agonist, \pm standard deviation. 
Eptifibatide, a GPIlb-IIla antagonist, is also used in conjunction with these agonists to evaluate platelet disaggregation. The addition of eptifibatide to platelet aggregates enhances the rate and extent of disaggregation of platelet aggregates by displacing bound fibrinogen to the activated GPIIb-IIla receptor. The ability of eptifibatide to increase the rate and extent of platelet disaggregation was decreased by treatment with $\mathrm{mFab7}$ with all three agonists studied (Fig 4.12 and Table 4.2); however, the effect of eptifibatide was not totally blocked. When threshold ADP was the agonist, percent aggregation at 5 , 10 , and 15 minutes after addition of eptifibatide was $38.3 \pm 2.1 \%, 23.7 \pm 2.5 \%$, and $19.3 \pm 2.3 \%$, respectively, for control-treated platelets, and $57.3 \pm 5.1 \%, 44.7$ $\pm 6.1 \%$, and $38.7 \pm 6.7 \%$, respectively, for mFab7-treated platelets. When threshold collagen was the agonist, the percent aggregation for control-treated platelets was $31.0 \pm 19.1 \%, 27.0 \pm 17.4 \%$, and $24.6 \pm 16.7 \%$, respectively, while for mFab7-treated platelets it was $62.3 \pm 8.1 \%, 57.0 \pm 9.8 \%$, and $53.3 \pm 11.2 \%$, respectively. mFab7 even exerted an effect on disaggregation when TRAP was used as the agonist: percent aggregation was $45 \pm 18.1 \%, 33.7 \pm 15.3 \%$, and $29.0 \pm 13.0 \%$ with control-treated platelets, and $63.3 \pm 1.5 \%, 51.3 \pm 3.1 \%$, and $46.3 \pm 2.1 \%$ for $\mathrm{mFab} 7$-treated platelets.

Additionally, mFab7 and control Fab were pre-incubated with a goat $\mathrm{F}(\mathrm{ab}){ }_{2}$ anti-mouse-Fc before adding to platelets, at a rate of $10 \mathrm{~F}(\mathrm{ab})_{2}{ }_{2}$ per possible intact $\mathrm{mAb7}$, as calculated above. Although the $F(a b)_{2}{ }_{2}$ slightly decreased aggregation, the $\mathrm{mFab} 7$ still exhibited increased aggregation and thrombus stability compared to the control Fab.

The results from these experiments led to the hypothesis that CD9 may indeed serve as a link to integrin activation and its function may serve as a tipping point for platelet reactivity. Further examination of GPIIb-IIla function, such as fibrinogen binding, was measured with or without Fab treatments.

\subsubsection{Platelet Activation}

Platelet activation was assessed by detection of CD63 and P-selectin (CD62) via flow cytometric analyses (Fig 4.13). Resting platelets, in the absence of agonist, did not have a statistically significant difference in the measurement of either CD63 or P-selectin between control- and mFab7-treated platelets. However, when platelets were activated by threshold levels of ADP $(2 \mu \mathrm{M})$, $\mathrm{mFab} 7$ treatment increased the expression of both CD63 and P-selectin: the MFI for control-treated platelets was $33.3 \pm 0.2$ for P-selectin and $14.1 \pm 3.0$ for CD63, while for mFab7-treated platelets the MFI was increased to $91.1 \pm 14.8$ for $\mathrm{P}$-selectin and $25.6 \pm 3.3$ for CD63. Interestingly, mFab7 did not increase the expression of either protein when platelets were activated with threshold TRAP $(10 \mu \mathrm{M})$. Future studies can be performed to determine the optimal concentration of TRAP for mFab7 to amplify the signal. 
Figure 4.12 CD9 Affects Eptifibatide-Induced Platelet Disaggregation $4000 \mathrm{nM}$ eptifibatide is added to agonist-activated platelets at the point of maximum aggregation (2.5 min after addition of agonist). Incubation with $\mathrm{mFab7}$ results in more stable aggregates with all agonists tested. A, ADP; $B$, Collagen; C, TRAP. ${ }^{*}, p<0.05 ;{ }^{* *}, p<0.01 . n=4$. 
A.
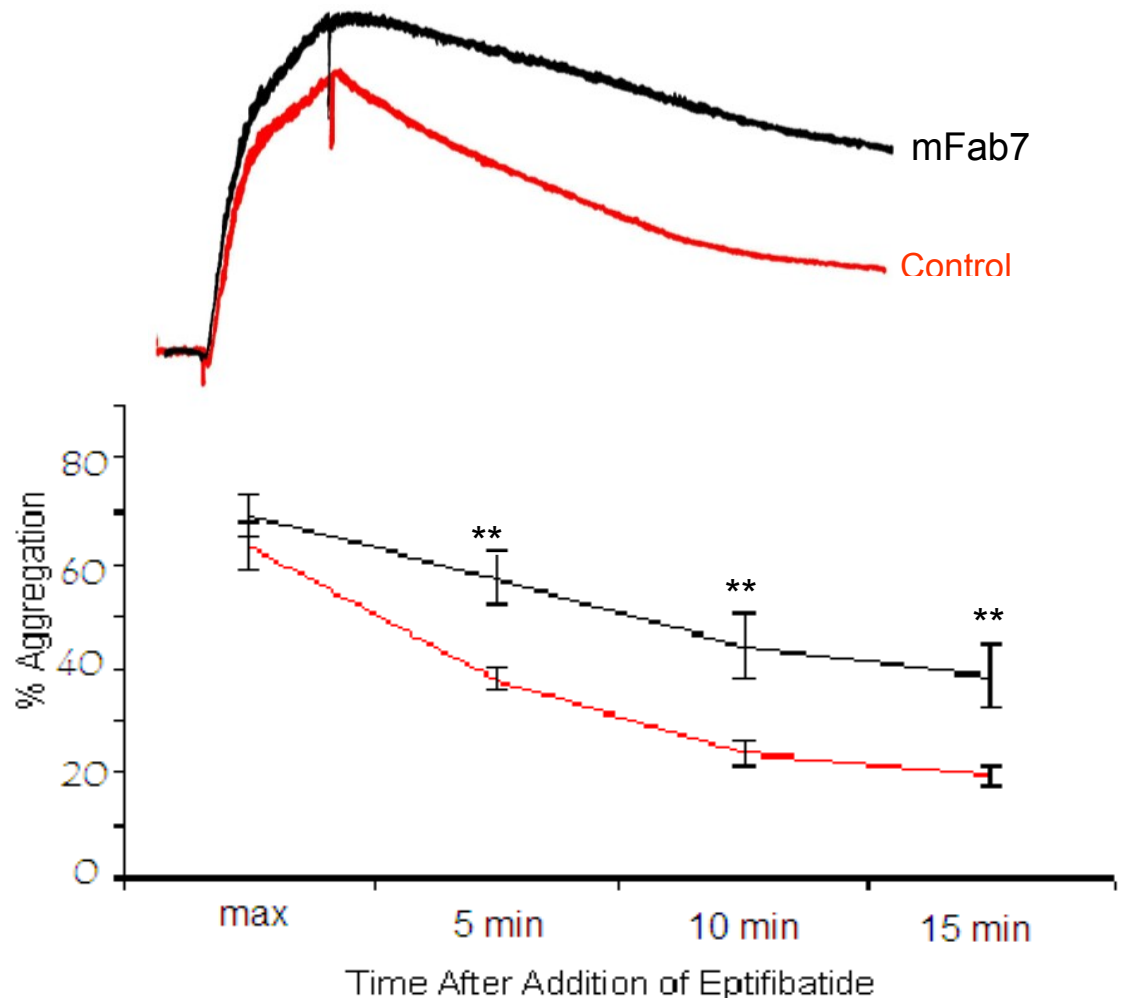

B.

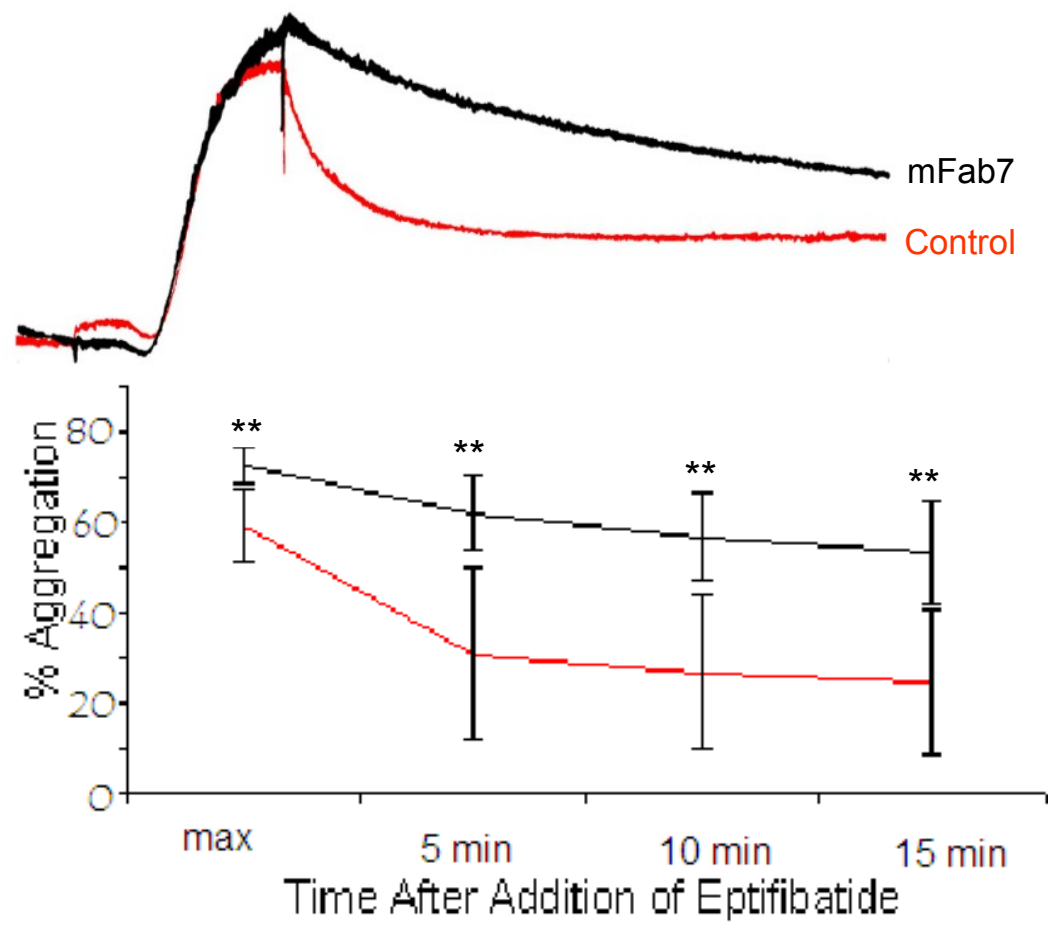


C.
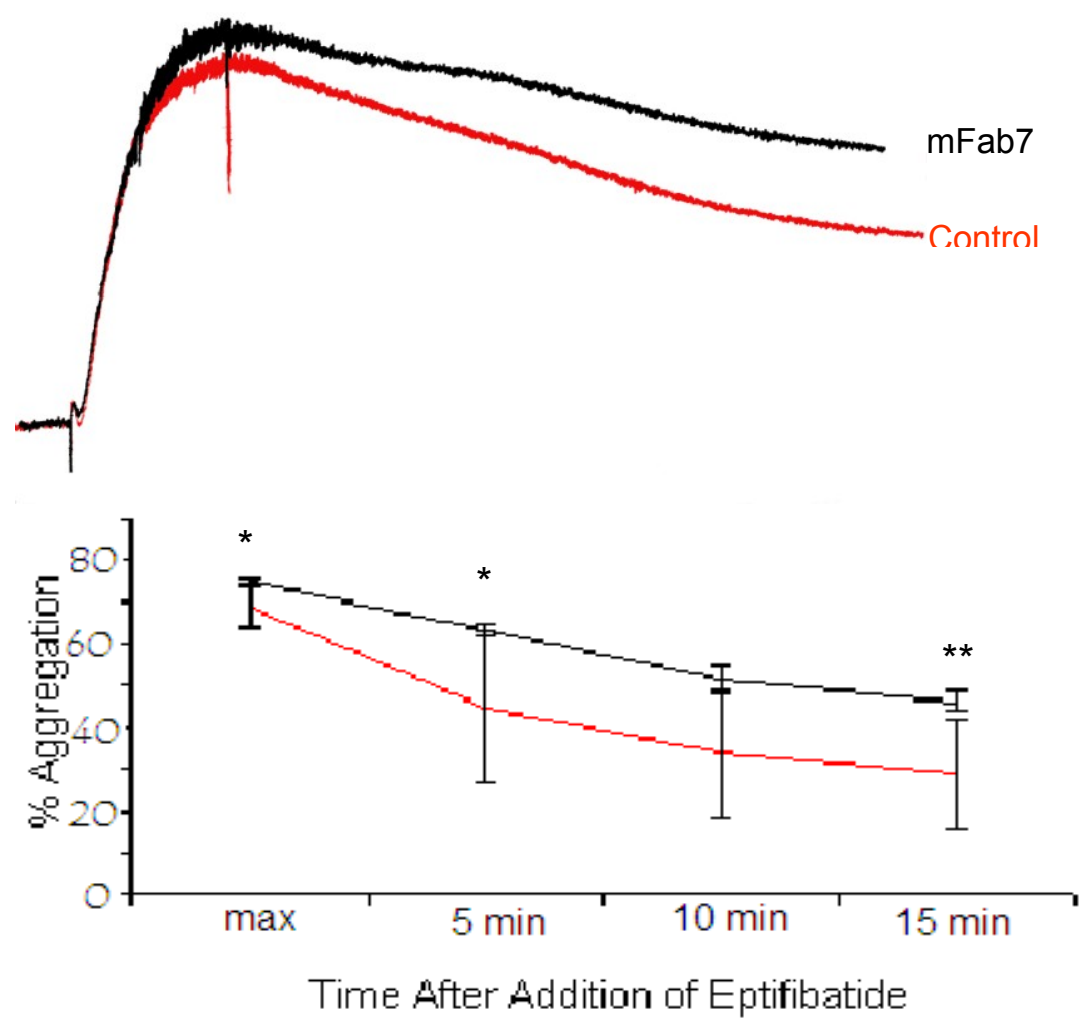

Figure 4.12 (continued) 
Table 4.2. Perturbation of CD9 Affects Eptifibatide-Induced Platelet Disaggregation ${ }^{2}$

\begin{tabular}{llllll}
\hline Agonist & Fab & $\begin{array}{l}\text { Max } \\
\text { aggregation }\end{array}$ & $\mathbf{5} \mathbf{~ m i n}$ & $\mathbf{1 0} \mathbf{~ m i n}$ & $\mathbf{1 5} \mathbf{~ m i n}$ \\
& & & & \\
\hline ADP & mFab7 & $69.4 \pm 4.0$ & $57.3 \pm 5.1$ & $44.7 \pm 6.1$ & $38.7 \pm 6.7$ \\
& control Fab & $63.3 \pm 4.5$ & $38.3 \pm 2.1$ & $23.7 \pm 2.5$ & $19.3 \pm 2.3$ \\
Collagen & mFab7 & $72.7 \pm 3.7$ & $62.3 \pm 8.1$ & $57.0 \pm 9.8$ & $53.3 \pm 11.2$ \\
& control Fab & $59.3 \pm 8.0$ & $31.0 \pm 19.1$ & $27.0 \pm 17.4$ & $24.6 \pm 16.7$ \\
TRAP & mFab7 & $74.7 \pm 0.6$ & $63.3 \pm 1.5$ & $51.3 \pm 3.1$ & $46.3 \pm 2.1$ \\
& control Fab & $68.7 \pm 4.5$ & $45 \pm 18.1$ & $33.7 \pm 15.3$ & $29.0 \pm 13.0$ \\
\hline
\end{tabular}

${ }^{2}$ Percent platelet aggregation, showing the maximum aggregation achieved, and percent aggregation at 5,10 , and 15 minutes after addition of eptifibatide, \pm standard deviation. 


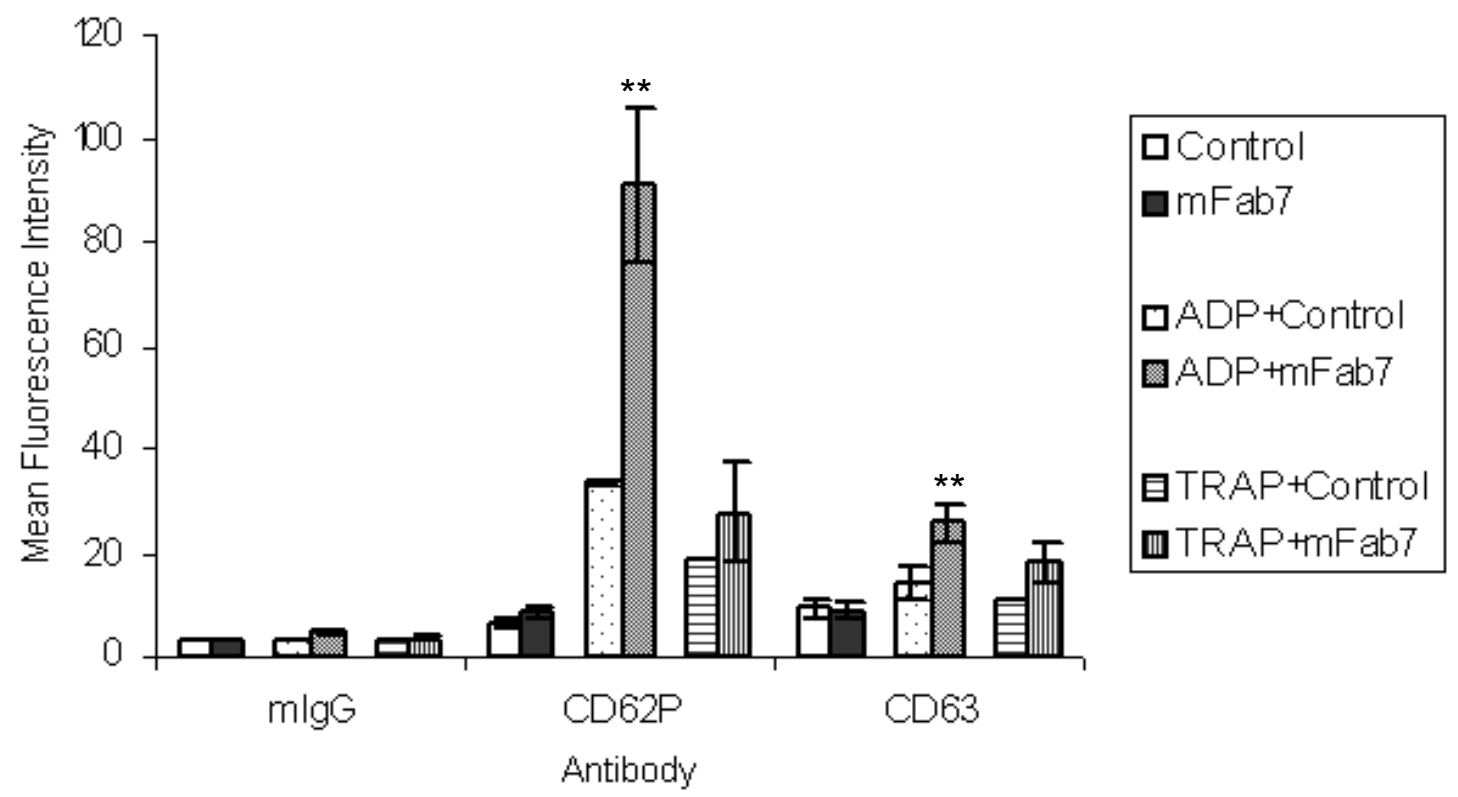

Figure 4.13 CD9 Affects Platelet Activation

Pre-incubation with $20 \mu \mathrm{g} / \mathrm{ml} \mathrm{mFab7} \mathrm{increases} \mathrm{P-selectin} \mathrm{(CD62P)} \mathrm{and} \mathrm{CD63}$ expression on platelets activated with $2 \mu \mathrm{M} A D P$, compared to platelets preincubated with $20 \mu \mathrm{g} / \mathrm{ml}$ nonspecific control Fab. mFab7 did not affect P-selectin or CD63 expression on platelets that were activated with $10 \mu \mathrm{M}$ TRAP or on platelets that were not activated by agonist. ${ }^{* *}, p<0.01 . n=5$. 


\subsubsection{Fibrinogen Binding}

In the absence of agonist stimulation, platelets bound a low level of fibrinogen, with no difference between control Fab-treated platelets and mFab7treated platelets (mean MFI $=48.06 \pm 22.3$ and $48.13 \pm 22.5$, respectively) (Fig 4.14). When platelets were activated without stirring by $2 \mu \mathrm{M} \mathrm{ADP}$, the binding of fibrinogen increased slightly (MFI $=70.13 \pm 5.4$ ). The most notable increase in fibrinogen binding occurred when platelets treated with $\mathrm{mFab7}$ and activated by ADP (MFI $=122.1 \pm 15.9)$. The increase in fibrinogen binding of ADP-activated platelets that are treated by mFab7 versus treated by control Fab is significant as determined by ANOVA.

\subsubsection{Cytoskeletal Incorporation}

In order to explore CD9 effects on the integrin-cytoskeleton linkage, core cytoskeletons were prepared from $\mathrm{mFab} 7$ treated platelets. Platelet samples were lysed at five min after addition of agonist. mFab7 increased the incorporation of the cytoskeletal proteins actin binding protein (ABP), $\alpha$-actinin, and actin into the core cytoskeleton compared to control-treated platelets (Fig 4.15A). Platelets activated by $2 \mu \mathrm{M}$ ADP, pre-incubated with control Fab or without Fab, did not form stable aggregates, and thus the incorporation of these proteins was similar to the level of incorporation in resting platelets. Similarly, incubation with mFab7 or control Fab in the absence of ADP did not increase cytoskeletal protein incorporation. However, when platelets were incubated with mFab7 and activated with $2 \mu \mathrm{M}$ ADP, the incorporation of ABP, $\alpha$-actinin, and actin into the core cytoskeleton increased to levels higher than seen with $\mathrm{mFab7}$ or ADP alone. The level of incorporation was similar to levels observed when platelets were activated with $5 \mu \mathrm{M}$ ADP, a concentration which allows formation of more stable aggregates. The relative density of actin incorporated into the platelet cytoskeletons is shown (Fig 4.15B). Statistical significance is designated by asterisks.

\subsubsection{Akt Phosphorylation}

In order to examine possible signaling molecules involved in CD9mediated platelet functions, platelets were pretreated with $\mathrm{mFab7}$, control Fab, or saline control and stirred in the aggregometer, with or without threshold ADP, for 5 minutes. Total platelet lysates were separated and transferred to a PVDF membrane, which was blotted with the antibody $4 \mathrm{G} 10$. This antibody is capable of binding to phosphorylated tyrosine residues without preference for a particular protein. This resulted in the appearance of several bands, most prominently Akt. However, CD9 ligation by mFab7 did not appear to alter the intensity of any of the bands (4G10 data not shown). 


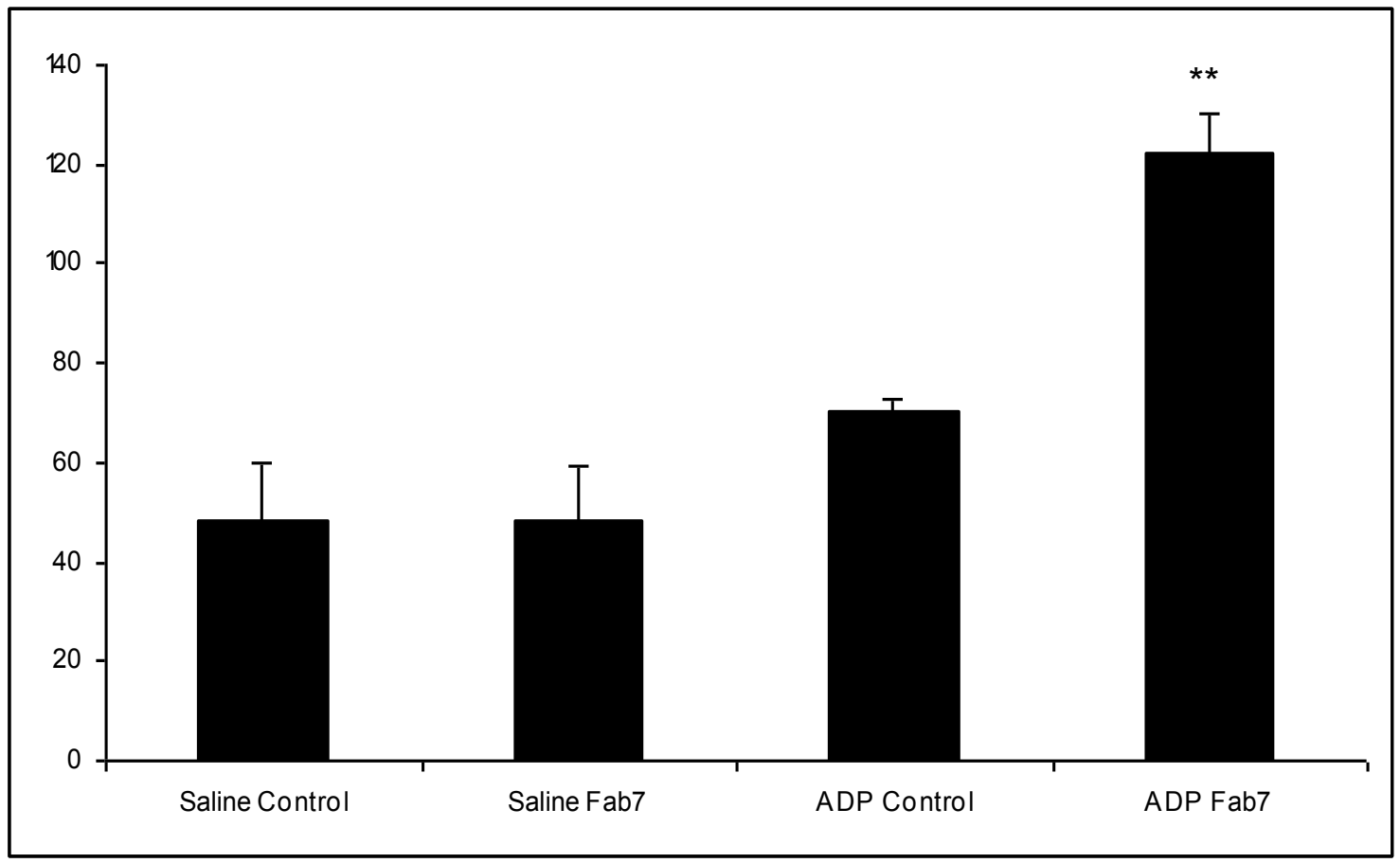

Figure 4.14 CD9 Affects Ligand Binding

Platelet incubation with $\mathrm{mFab7}$ results in increased fibrinogen binding in the presence of ADP as indicated by increased PAC-1 binding. mFab7 does not affect fibrinogen binding in resting platelets. ${ }^{* *}, p<0.01 . n=4$. 
A.

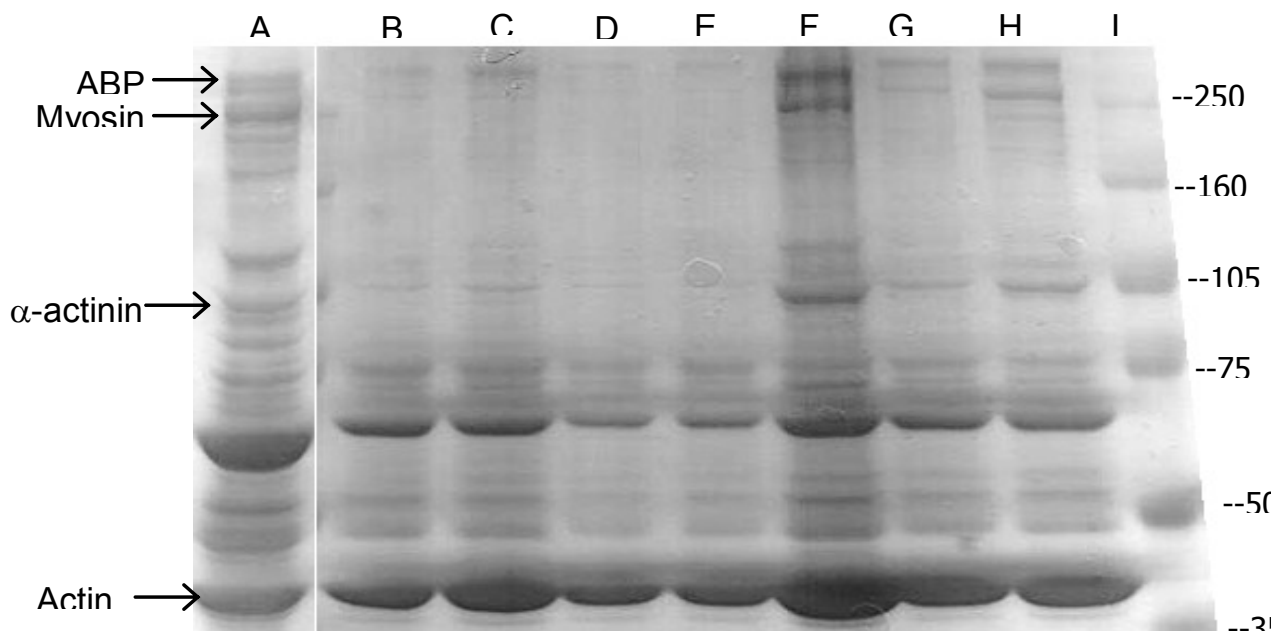

B.

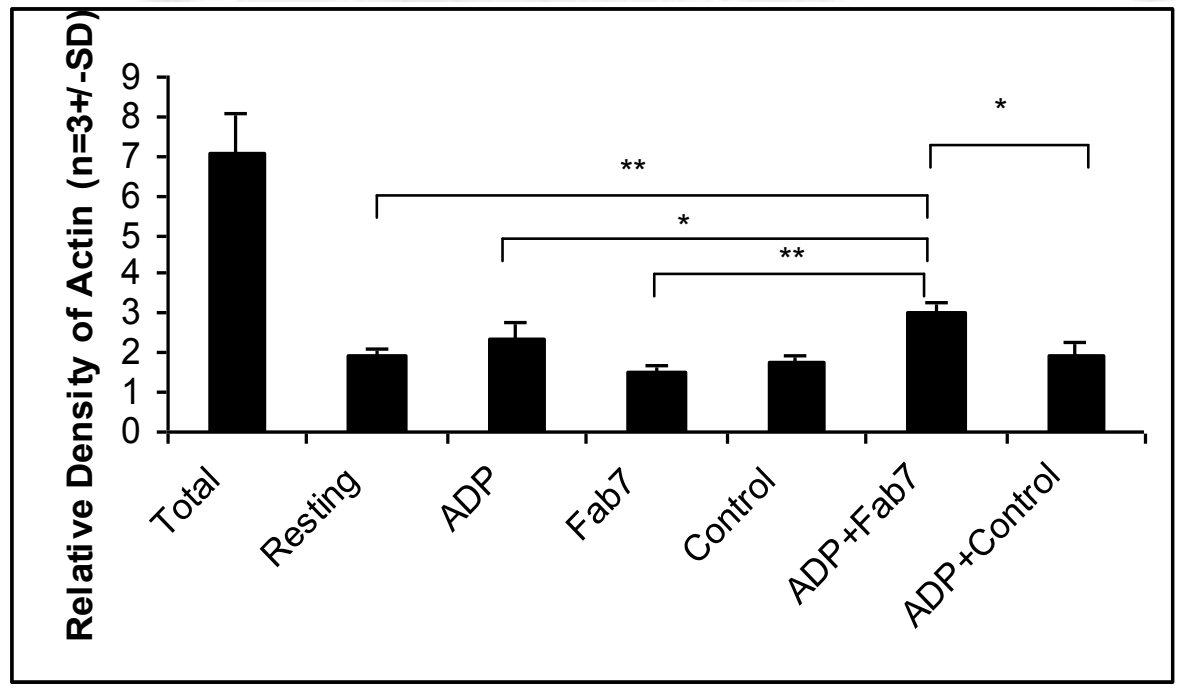

Figure 4.15 CD9 Alters the Platelet Core Cytoskeleton

$A$, Coomassie-blue-stained reduced gel showing increase in ABP, myosin, $\alpha-$ actinin, and actin in the presence of ADP and mFab7. Lanes: A, total platelet lysates, at $50 \%$ platelet count compared to other lanes; B, resting platelets; $C$, treated with $2 \mu \mathrm{M}$ ADP; D, treated with mFab7; E, treated with control Fab; F, treated with $2 \mu \mathrm{M}$ ADP+mFab7; G, treated with $2 \mathrm{uM} \mathrm{ADP+control} \mathrm{Fab;} \mathrm{H}$, treated with $5 \mu \mathrm{M}$ ADP; I, molecular weight standards. $B$, Quantification of actin incorporated into core cytoskeleton. ${ }^{*}, p<0.05 ;{ }^{* *}, p<0.01 . n=3$. 
Akt has been shown to be involved in CD9-related signaling cascades (Kotha 2008, Saito 2006), and its phosphorylation has been shown to be reduced by the tetraspanin CD151 in rat fibroblasts (Sawada 2003). For these reasons, Akt phosphorylation was specifically studied. However, it did not appear that $\mathrm{mFab} 7$ ligation to CD9 altered the level of phosphorylated Akt compared to control Fab or saline treatments (Fig 4.16). Although it appears that Akt phosphorylation is not involved in mediating the platelet activation through CD9 perturbation, it must be noted that the levels of Akt phosphosphorylation were very weak even in the positive controls.

Examination of Akt phosphorylation in the absence of stirring or incubation also showed that there was no effect induced by mFab7 ligation to CD9 (data not shown).

Future work may determine specific conditions under which CD9 modulates the Akt pathway, or another signaling pathway in platelets may be identified as crucial to the impact of CD9 on platelet phenotypes.

\subsubsection{Tetraspanin Web Organization}

Immunoprecipitations were carried out to observe the interactions between GPIIb-IIla, CD9, and CD63, key members of the tetraspanin web. This web may be a critical scaffolding feature in the cell membrane, as well as having key roles in regulating GPIIb-IIla regulation.

GPIlb-IIla was immunoprecipitated with the antibody $10 \mathrm{E} 5$, which is capable of binding both active and inactive GPIIb-Illa with equal affinity. It was capable of immunoprecipitating equivalent levels of GPIlb-Illa when platelets were treated with mFab7 or control Fab, in the presence or absence of $2 \mu \mathrm{M}$ ADP. An equal level of CD9 was immunoprecipitated in all samples (Fig 4.17). This indicates that although CD9 ligation via $\mathrm{mFab7}$ may have a subtle impact on CD9-GPIIb-Illa interactions, it is not capable of abolishing this interaction. As previous reports indicate that the CD9-GPIIb-IIla interaction is not dependent on platelet activation or integrin activation state, it is expected that mFab7 treatment would be capable of encouraging activation without altering the tetraspaninintegrin association.

When platelets were treated with control Fab, CD63 was not coprecipitated with GPIIb-IIla, even in the presence of $2 \mu \mathrm{M}$ ADP. This concentration of ADP is at the threshold of platelet activation and capable of inducing a low level of CD63 surface expression among a portion of the platelets.

Interestingly, mFab7 treatment increased the amount of CD63 coprecipitated with GPIIb-IIla. While this effect is most pronounced-as expectedin conjunction with low-level ADP, CD63 is also co-precipitated in the absence of 


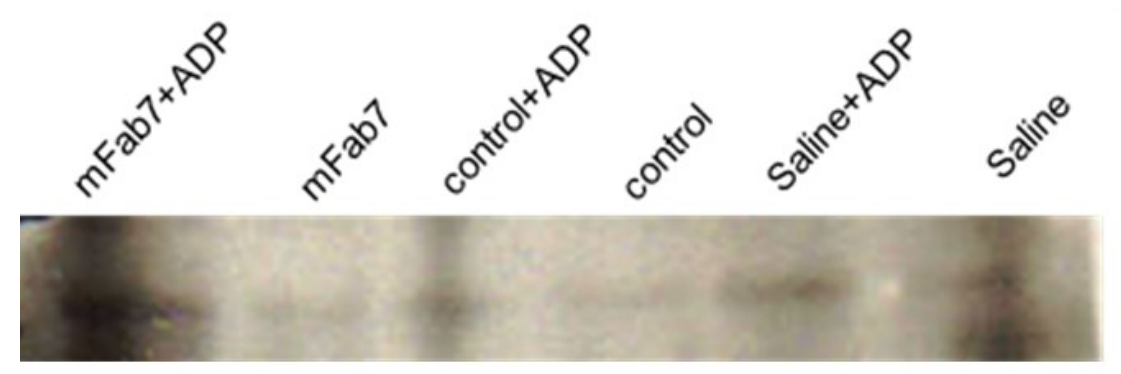

\section{Figure 4.16 CD9 Perturbation Does Not Appear to Alter the Phosphorylation of Akt}

Western blot showing level of phosphorylated Akt from platelet lysates.

Treatments: mFab7+ADP; mFab7 without agonist; control Fab+ADP; control Fab without agonist; Saline control+ADP; saline control without agonist. While it appears that platelet activation via ADP increases Akt phosphorylation compared to resting samples, there is not an appreciable difference in Akt phosphorylation in samples treated with mFab7 versus controls. Similar results were seen in nonstirred platelets. $\mathrm{n}=2$ 


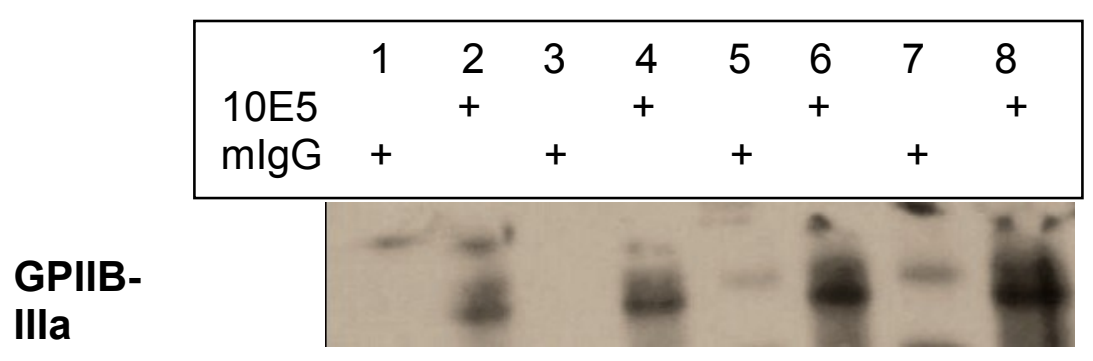

CD63

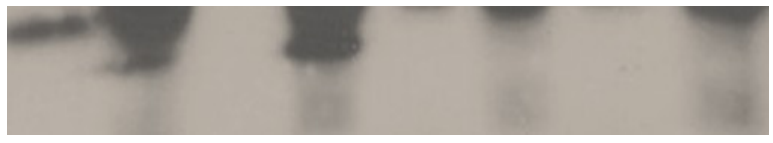

CD9

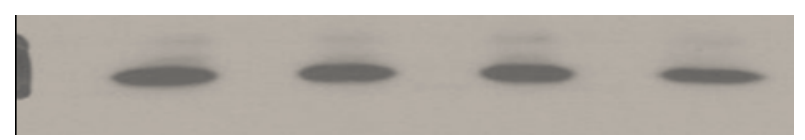

Figure 4.17 CD9 Perturbation Alters Tetraspanin Web Associations

A, GPIlb-Illa immunoprecipitated by 10E5. B, CD63 co-immunoprecipitates with GPIlb-Illa in the presence of $\mathrm{mFab7}$, even in the absence of agonist stimulation, but does not co-immunoprecipitate with GPIlb-IIla in the absence of mFab7, even in when activated by weak agonist $(2 \mu \mathrm{M}$ ADP). C, CD9 co-immunoprecipitates with GPIIb-IIla equally, regardless of presence of mFab7 or ADP.

Lanes: 1,2: mFab7; 3,4: mFab7 + $2 \mu$ M ADP; 5,6: control Fab; 7,8: control Fab + $2 \mu \mathrm{M}$ ADP. 
agonist. It is possible that a subset of platelets are mildly activated and thus expressing CD63 on the surface. It is also possible that, post-lysis, Fab7 enables association between CD63 from lysosomal membranes and GPIIb-IIla/CD9 from the cell surface or alpha granules. Future research on the importance of CD9 in organization of the platelet tetraspanin web will likely yield exciting results.

\subsubsection{Clot Retraction}

Surprisingly, although CD9 perturbation was shown to modulate a wide variety of platelet functions, treatment with $\mathrm{mFab7}$ did not alter clot retraction of platelets in PRP (Fig 4.18). Samples treated with $\mathrm{mFab7}$, control Fab, saline, and D3 had formed a clot by 5 minutes. Between 15 minutes and extending through to overnight incubation when retraction was complete, the samples treated with mFab7, control Fab, and saline exhibited a similar extent of platelet-mediated clot retraction and at a similar rate. This was true whether platelets were at $250,000 / \mathrm{mm}^{3}$ or at $100,000 / \mathrm{mm}^{3}$. However, D3 samples were consistently resistant to clot retraction. 
A.

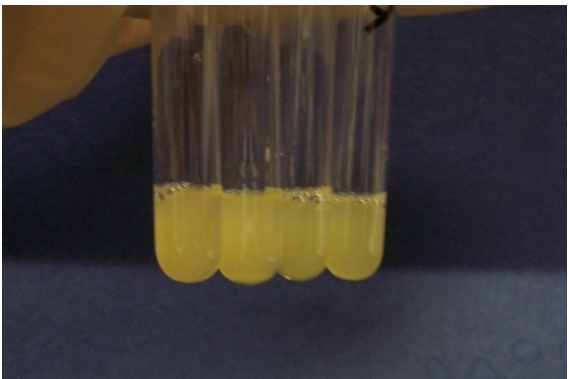

C.

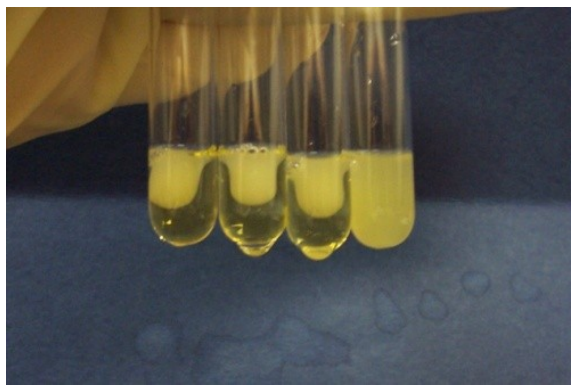

E.

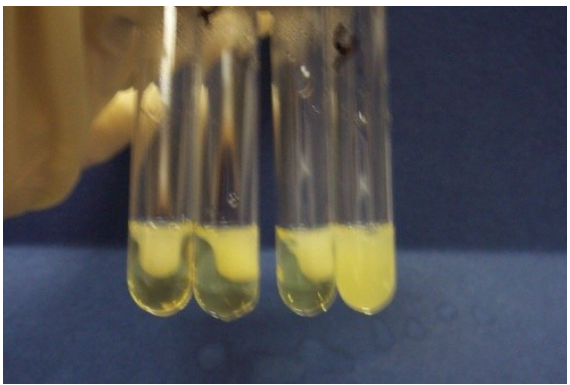

B.

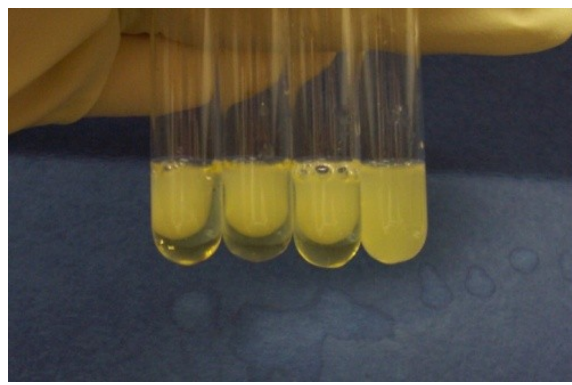

D.

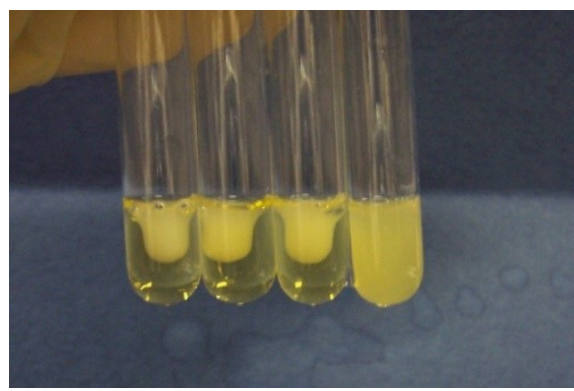

F.

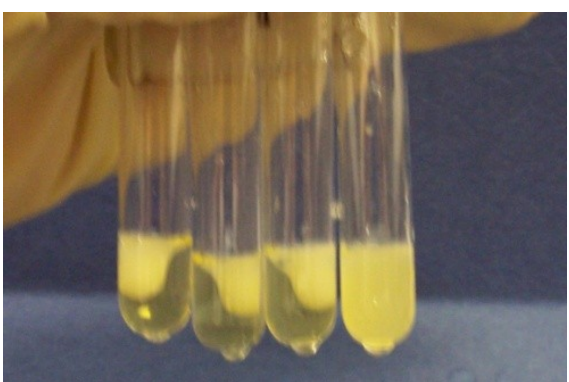

Figure 4.18 mFab7 Interaction with CD9 Does Not Alter Clot Retraction Left to right, samples are: saline; $40 \mu \mathrm{g} / \mathrm{ml}$ control Fab; $40 \mu \mathrm{g} / \mathrm{ml} \mathrm{mFab} 7 ; 80$ $\mu \mathrm{g} / \mathrm{ml} \mathrm{D3}$. A, 5 minutes after addition of $\mathrm{CaCl}_{2}$, clots are formed in all samples. $B-F$ : Samples at $15 \mathrm{~min}, 30 \mathrm{~min}, 60 \mathrm{~min}, 120 \mathrm{~min}$, and overnight. Samples treated with D3 resist clot retraction. There is no observable difference in clot retraction between samples treated with saline, control Fab, or mFab7. $n=4$. 


\section{CHAPTER 5 CONCLUSIONS AND RECOMMENDATIONS}

\subsection{Conclusions}

Tetraspanins have been implicated in a wide range of cell functions. These include cell motility (Huang 2006), tumor cell metastasis (Takeda 2007), cell proliferation (Ko 2006), differentiation (Unternaehrer 2007, Saito 2006), sperm-egg fusion (Ziyyat 2006), and virus-induced syncytia formation (GordonElonso 2006).

\subsubsection{Localization and Protein Partners of CD9}

The content of the tetraspanin web was studied under conditions of resting and activated platelets. As shown in Fig 4.1, the surface expression of CD9 was found to be quite high on platelets, and was not found to be altered when platelets were resting or activated with ADP or TRAP. However, there was a wide variability in CD9 surface expression, which could contribute to the lack of statistical significance. These observations suggest a role for CD9 in maintaining the scaffolding of the tetraspanin web or modulating the function of proteins, such as GPIIb-IIla, in the tetraspanin web, and thus modulating the activation state of platelets, rather than having a role directly involving or requiring platelet activation. GPIIb-IIla and CD151 were also found on the surface of resting platelets, although the surface expression of these proteins was increased upon platelet activation. The increase in expression is likely due to the fusion of granules with the surface membrane upon activation. CD63 is not expressed on the surface of resting platelets. It is mildly expressed under weak activation by $A D P$, and surface expression is further increased under stronger activation by TRAP, when platelet lysosomal membranes fuse with the platelet surface membrane. GPlb is found on the surface of platelets, and surface expression increases under ADP activation, but the surface expression is not increased following activation by TRAP. This may be due to the receptor becoming shed or endocytosed following potent activation (Bergmeier 2004).

Immunoprecipitations confirmed that CD9 and GPIIb-IIla associate with each other, as each was able to co-precipitate a portion of the other (Fig 4.2). Eptifibatide, a small molecule which which mimics RGD-containing proteins and binds to GPIIb-IIla, did not alter the level of co-precipitation, indicating that ligand binding does not alter the association between the integrin GPIIb-IIla and the tetraspanin CD9. This further suggests a role for CD9 in regulating GPIIb-IIla in both a resting and activated state.

The co-localization of CD9 and GPIIb-IIla was also studied in spread platelets. A portion of the two proteins were found to be co-localized (Fig 4.3), consistent with immunoprecipitation data. Co-localization was observed at the 
platelet periphery and platelet-platelet contacts, suggesting that modulation of GPIlb-Illa by CD9 is most critical in forming or maintaining platelet-platelet interactions and in platelet spreading (Fig 4.6). Both molecules were frequently localized to platelet centers, as expected, since both have been reported as members of alpha granules (Brisson 1997).

Platelets from patients with Glanzmann Thrombasthenia, who express a disfunctional GPIIb-IIla, were studied to analyze if integrin function is crucial to association with CD9. These platelets were still able to adhere and spread on fibrin and on fibrin-fibronectin, possibly through a contribution of CD9 or on other platelet integrins. These platelets exhibited greater spreading on fibrin, and decreased spreading on fibrin-fibronectin compared to normal controls (Fig 4.4). It is possible that these platelets exhibit an altered spreading ability, or that the alteration in spreading is due to an alteration in cytoskeletal linkages due to a mutant GPIlb-IIla. The spreading alterations could also be due to the activation of different signaling cascades than normal due to activation of alternative integrins. Co-localization of CD9 and GPIIb-IIla did not appear to be impacted by mutation of the integrin. It is interesting to note that flow cytometry confirmed a $10 \%$ increase in CD9 expression (data not shown), suggesting that CD9 may be partly compensating for the defective GPIlb-Illa. However, it is possible that the increased signal could be due to better access for antibody binding to CD9.

CD9 was found to localize to filopodia, lamellipodia, and platelet-platelet contacts in spread platelets, leading to the hypothesis that CD9 was involved in platelet spreading and platelet interactions, including thrombus stability (Fig 4.6 and Fig 4.7). Interestingly, multiple studies indicate CD9 clusters at cell-cell contacts in a variety of cell types (Gordon-Elonso 2006, Nakamura 1995, Yang 2006).

It is interesting that CD9 was not found to localize to platelet-matrix contact sites on any of the matrices studied (Fig 4.5). This indicates that CD9 may not have a direct involvement in platelet adhesion or in modulating GPIlbIIla during matrix adhesion, but rather modulates GPIIb-IIla activation during platelet-platelet interactions. These findings are consistent with other published reports, showing that tetraspanins do not localize to focal adhesions (Berditchevski 1999) and that modulation of integrins by tetraspanins can regulate adhesion strengthening but does not lead to cell adhesion to the extracellular matrix itself (Hemler 2001, Berditchevski 2001, Lammerding 2003).

\subsubsection{Platelet Functions Affected by CD9 Perturbation}

Platelet spreading has been shown to be affected by tetraspanins. CD151 knock-out platelets exhibit impaired cell spreading on fibrinogen (Lau 2004), as do platelets treated with CD63-blocking antibodies (Israels 2005). Additionally, transfection of CD9 into Chinese Hamster Ovary ( $\mathrm{CHO}$ cells) has been 
previously reported to increase $\mathrm{CHO}$ cell spreading on collagen and fibronectin (Cook, 1999). We here show that CD9 is involved in platelet spreading on four matrices: fibrin, cross-linked fibrin-fibronectin matrix, fibronectin, and fibrinogen (Fig 4.9). These four matrices are all ligands for GPIlb-Illa and are involved in platelet functions. Fibronectin, an extracellular matrix protein, is exposed upon vascular damage; fibrinogen is critical to platelet aggregation; fibrin is involved in clot retraction; and fibrin-fibronectin is important to wound healing. On all these matrices, spreading is enhanced by the presence of mFab7, an anti-CD9 Fab fragment, although CD9 localization is not affected. Moreover, on fibrinfibronectin matrix, the presence of $\mathrm{mFab} 7$ increases the number of platelets adherent to the coverslip.

Platelet aggregation has been shown to be impaired in studies using CD151 knockout (Lau 2004) or TSSC-6 knockouts (Goschnick 2006). This, combined with the results that CD9 localizes to platelet-platelet contacts, led to the hypothesis that CD9 would be involved in thrombus stability. As shown in Fig 4.11, when platelets were activated by threshold levels of ADP or collagen, preincubation with $\mathrm{mFab7}$ increased thrombus formation and inhibited spontaneous disaggregation. This effect was not seen with the potent agonist TRAP, even at low levels. This could be due to the fact that TRAP seems to act as an "all-or-nothing" signal; i.e., at increasingly lower concentrations it still induces a $>70 \%$ aggregation, until the concentration is insufficient to elicit any aggregatory response. However, in the absence of agonist, mFab7 cannot evoke an aggregation response, even at concentrations as high as $100 \mu \mathrm{g} / \mathrm{ml}$. Interestingly, platelet aggregations employing recombinant CD9 EC2, tagged with GST, show a decreased level of aggregation in response to low-dose ADP compared with GST-VAMP (Kotha, unpublished data). Reports also indicate that reduced CD9 surface expression correlate with increased platelet aggregation, although no causal relationship has been established yet (Vrelust 2007). It is possible that mFab7 treatment is inhibiting the ability of CD9 to restrain GPIIb-IIla to its inactive conformation.

Eptifibatide, a cyclic RGD heptapeptide which acts as a GPIlb-IIla antagonist, was used to examine platelet disaggregation responses. At threshold levels of ADP, collagen, and TRAP, platelet aggregates were more stable over fifteen minutes when they were pretreated with mFab7 compared to a nonspecific fab control (Fig 4.12). This leads us to believe that CD9 activation or blockade, via mFab7 treatment, can help stabilize the active conformation of GPIlb-IIla, in the presence of agonist. This effect is seen at low levels of agonist, whereas at higher levels, the activation of GPIlb-Illa is so sturdy as to overshadow the effect of CD9.

To examine the methods by which CD9 is activating GPIIb-IIla, ligand binding assays were performed (Fig 4.14). $\mathrm{mFab7}$, in the absence of agonist, did not have any effect, while in the presence of $2 \mu \mathrm{M}$ ADP, there is a significant increase in fibrinogen binding. This shows that CD9 does encourage GPIlb-IIla to 
adopt a ligand-binding-competent conformation in the presence of agonist. In Fig $\underline{4.13}$, flow cytometric analysis revealed that P-selectin and CD63, markers of platelet activation, were increased by $\mathrm{mFab} 7$ pretreatment combined with ADP activation but not in the absence of platelet activation, revealing that in addition to modulating GPIIb-IIla, CD9 perturbation also encourages platelet activation and release of platelet granules.

It is interesting that despite being strongly involved in other platelet functions, CD9 perturbation did not alter clot retraction of platelets in PRP (Fig 4.18). It is possible that the fibrin binding to GPIlb-Illa initiating clot retraction leads to such a potent signal cascade, that any involvement of CD9 in clot retraction is overshadowed. This is particularly pertinent, as the effects of CD9 modulation are particularly evident when platelets are mildly activated.

\subsubsection{Mechanisms Involved in Contribution of CD9 to Platelet Function}

As the platelet cytoskeleton plays a key role in platelet shape change, including filopodial and lammellipodial formation and granule release, a critical step in platelet spreading and aggregatory responses, any changes in cytoskeletal proteins induced by mFab7 were assayed. It was found, in Fig 4.15, that mFab7 treatment in the absence of aggregation did not impact incorporation of key cytoskeletal proteins compared to nonspecific control Fab. While low-dose $(2 \mu \mathrm{M}) \mathrm{ADP}$ induced aggregation, this aggregatory response was transient and insufficient to cause increased incorporation of cytoskeletal proteins in the absence of agonist stimulation. However, low-dose ADP combined with mFab7 treatment resulted in increased incorporation of cytoskeletal proteins, particularly actin binding protein (ABP), $\alpha$-actinin, and actin. This increased incorporation was statistically greater than either ADP treatment or mFab7 treatment alone, and was similar to the more potent changes resulting from activation by $5 \mu \mathrm{M}$ ADP.

Phosphorylation of signaling molecules were analyzed in an attempt to clarify the signaling cascade in platelets pertinent to CD9. Total tyrosine phosphorylation by the antibody 4G10 (not shown) indicated several proteins altered by platelet activation, but did not elucidate any alterations induced by CD9 ligation.

Akt phosphorylation in particular was examined (Fig 4.16), as Akt is involved in CD9-related signaling cascades (Kotha 2008, Saito 2006), and 4G10 results indicated that Akt was particularly important in platelet activation. However, CD9 binding did not alter the level of Akt phosphorylation in stirred or non-stirred platelets. Furture work may elucidate specific conditions under which CD9 modulates the Akt pathway. It is also possible that another signaling pathway in platelets may be identified as crucial to the impact of CD9 on platelet phenotypes. There are no known cytosolic binding partners for CD9 in human 
platelets, but as platelets have a putative PDZ binding domain on their cytosolic tail, the possibility exists that an interaction will yet be defined.

The importance of CD9 to the interaction of the membrane proteins GPIIbIIla, CD9, and CD63 in the tetraspanin web was also studied (Fig 4.17). CD9 and GPIIb-IIla association was consistent whether platelets were resting or activated, and was not impacted by mFab7 binding to CD9. This does not rule out the possibility that Fab treatment could be gently altering the association between CD9 and GPIlb-IIla, but it certainly shows that it neither prohibits nor encourages the association. It is interesting that $\mathrm{mFab7}$ treatment increased the association of CD63 into the tetraspanin web. This could be an indirect effect, as mFab7 treatment increases platelet activation, and thus there is more CD63 on the membrane to associate in the tetraspanin web. It is possible that events resulting from mFab7 ligation to CD9 preferentially causes an increase in CD63 inclusion into the tetraspanin web, and that CD9 modulates GPIIb-IIla via CD63. It is worth noting that CD9 perturbation increased CD63 association with GPIIb-IIla even in the absence of agonist, and thus it is possible that mFab7 treatment causes an increased association in trans post-lysis. The importance of CD9 in organization of the platelet tetraspanin web is worthy of further research.

\subsection{Proposed Model}

In the absence of CD9 perturbation via $\mathrm{mFab7}$ or platelet agonist, CD9 exists in the tetraspanin web in association with GPIlb-IIla, which assumes a bent, inactivated conformation (Fig 5.1A).

The addition of $\mathrm{mFab7}$, which binds to CD9 EC2, may modulate the association between CD9 and GPIIb-IIla, but this impact on CD9-GPIIb-IIla association is not sufficient to cause integrin activation (Fig 5.1B). mFab7 does not interact with the receptor FcyRII, nor does it induce signaling through this receptor.

In the presence of agonist, the alteration in CD9-GPIIb-IIla interaction is sufficient to stabilize the extended, active conformation of GPIIb-IIla (Fig 5.1C). This applies even to low, threshold levels of agonist, which would cause only a weak, transient activation of GPIllb-IIla in the absence of CD9 perturbation via $\mathrm{mFab7}$. Although mFab7 treatment does not completely abolish CD9-GPIIb-IIla interactions, it is possible that the $\mathrm{mFab} 7$ reduces the association of CD9 EC2 with the extracellular domains of GPIIb-IIla, causing a phenotype associated with reduced CD9 expression (Vrelust 2007). It is anticipated that the impact of CD9 perturbation would be diminished with increasing levels of agonist, as GPIIb-IIla would become more strongly activated. 
Figure 5.1 Proposed Model of CD9 Function in Platelets

A, Resting platelet membrane. B, Binding of mFab7 does not activate GPIIb-IIla. $\mathrm{C}, \mathrm{ADP}$ in conjunction of mFab7 strongly activates GPIlb-IIla. Black arrow, inside-out signaling from the ADP receptors $\mathrm{P} 2 \mathrm{Y} 1$ or $\mathrm{P} 2 \mathrm{Y} 12$ leading to activation and ligand binding of GPIIb-IIla. Black circle, ligand bound to active GPIllb-IIla.

$\mathrm{D}$, activation leads to increased linkage to the cytoskeleton and increased thrombus stability. 
A.

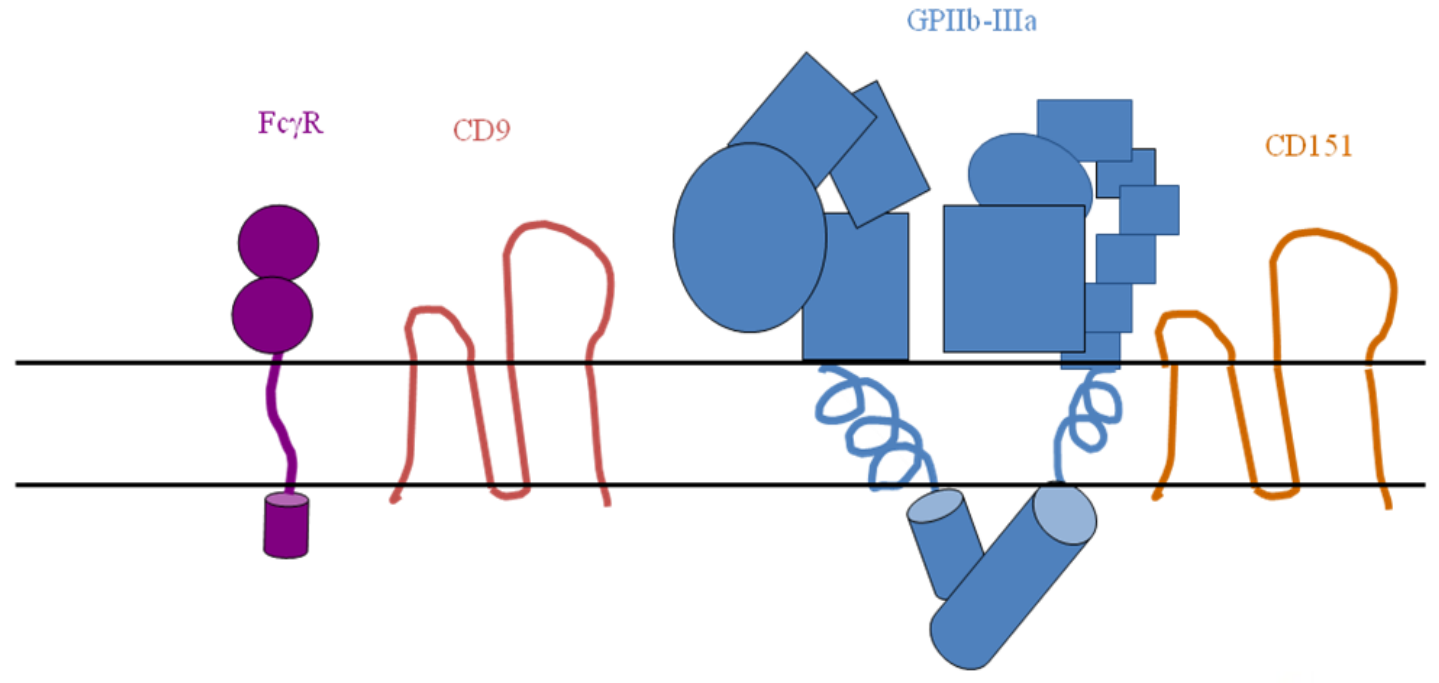

B.

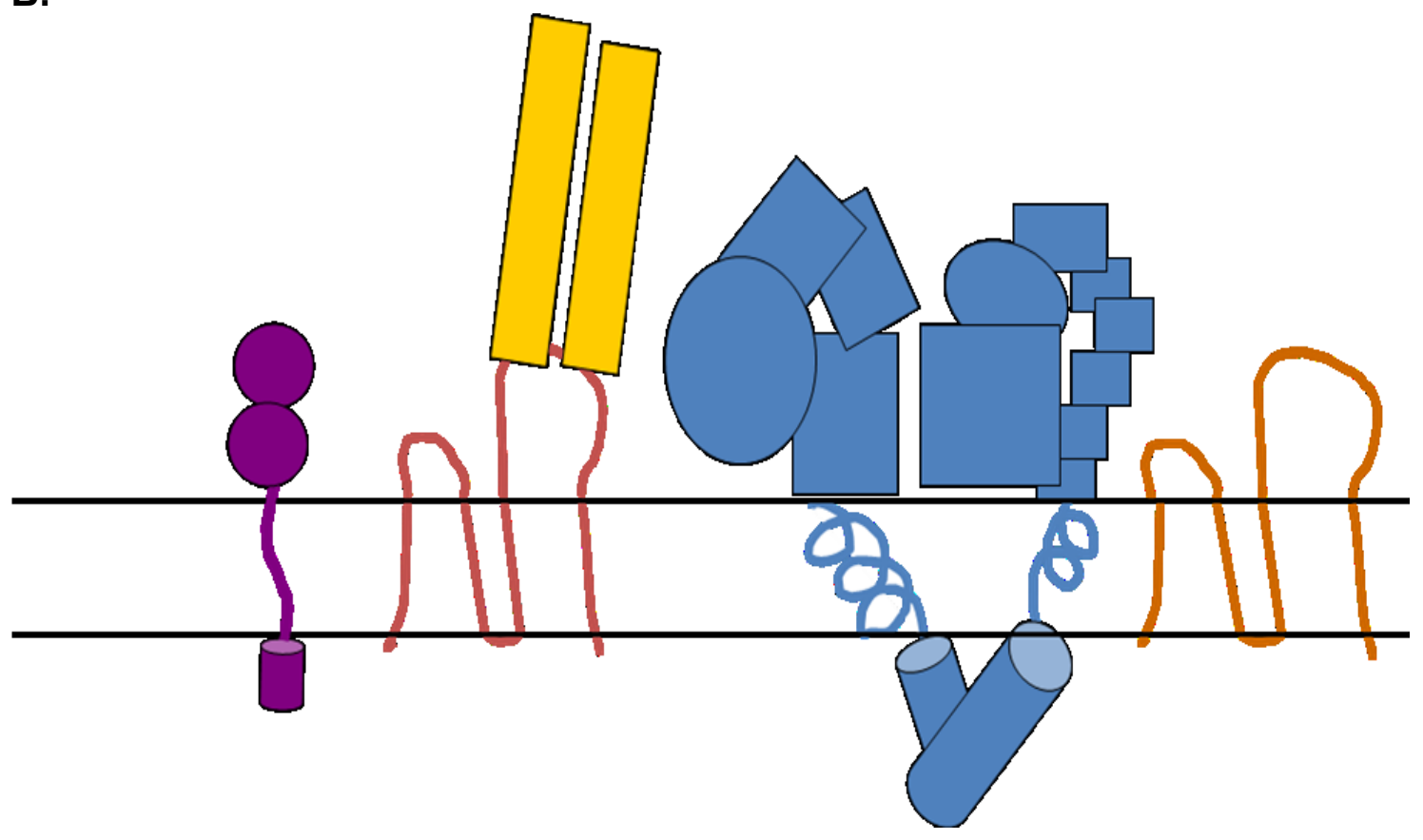


C.

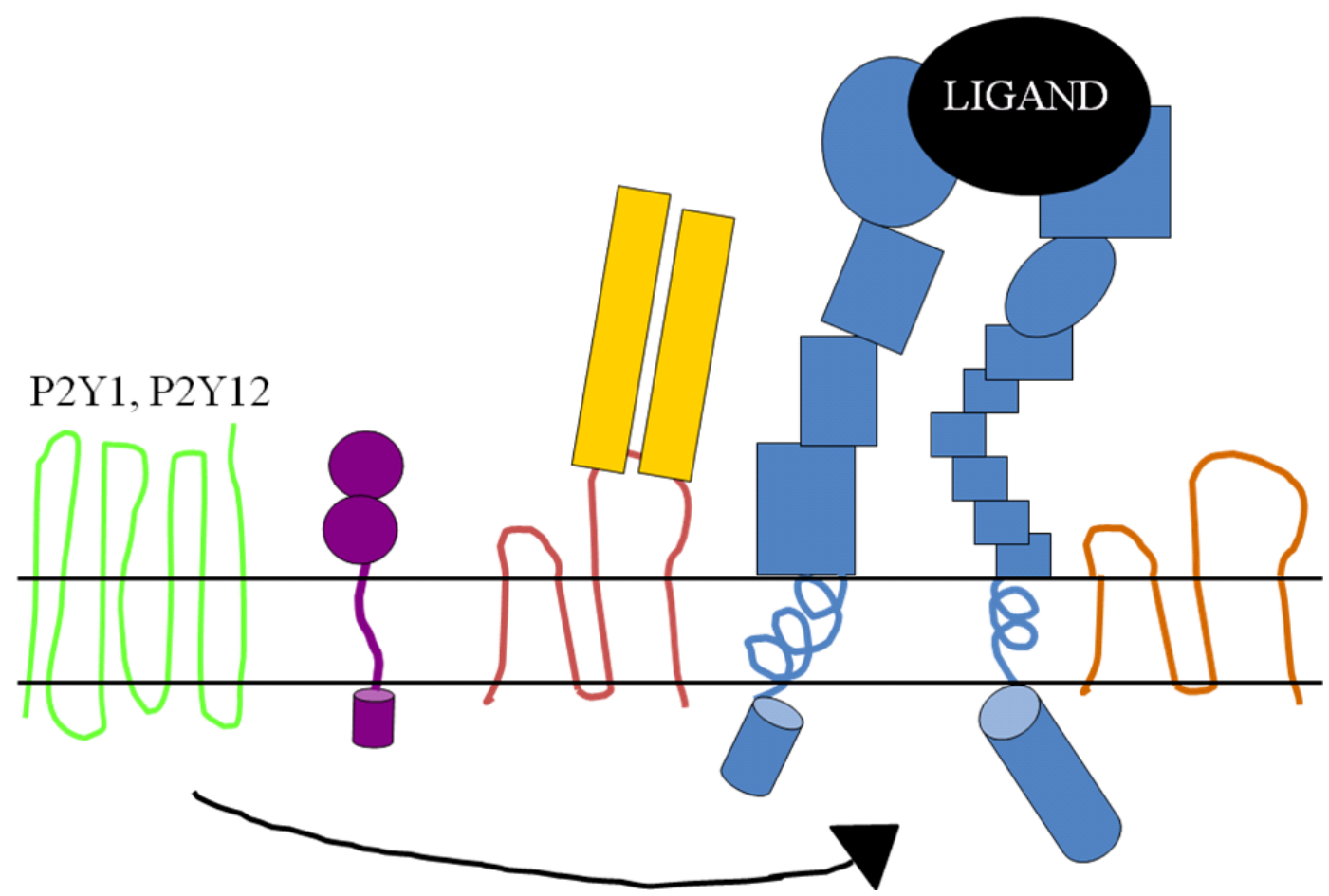

D.

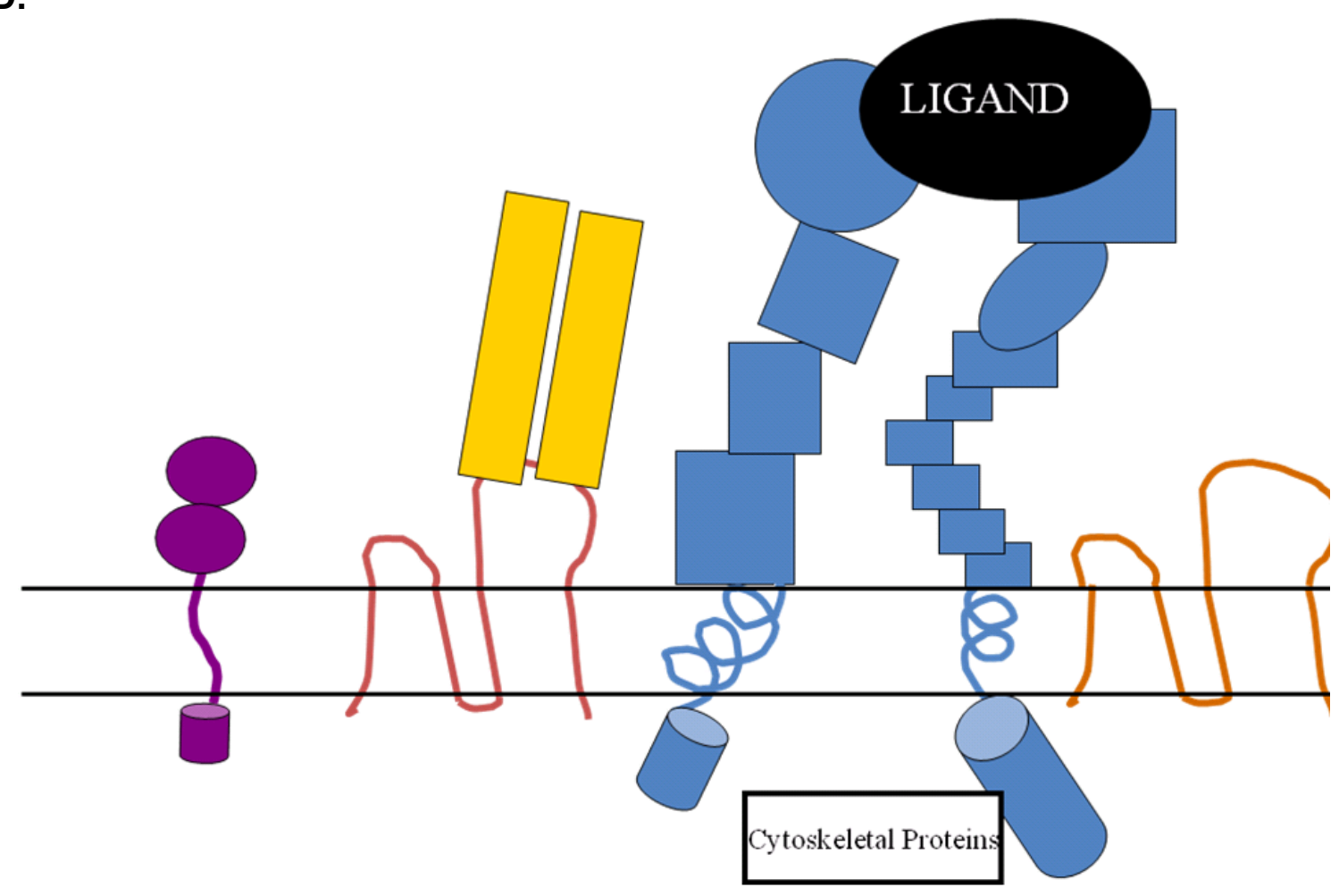

Figure 5.1 (continued) 
The increase in GPIlb-IIla activation caused by agonist in conjunction with CD9 alteration then leads to increased linkage of integrin to the cytoskeleton and increased stability of platelet agonists (Fig 5.1D).

\subsection{Recommendations for Future Study}

Further characterization of the mFab7-CD9 interaction will need to be carried out. It is unknown at this time whether mFab7 ligation is performing an activating or blocking role. It is possible that $\mathrm{mFab7}$ ligation is activating a signal cascade, which when combined with low-dose agonist, serves to encourage the active conformation of GPIIb-IIla. It is also possible that mFab7 is shifting the conformation of CD9, leading to a direct change in the CD9-GPIlbllla interaction, whether through large extracellular loop or the fourth transmembrane domain. It could also be altering the association of CD9 with other tetraspanins (such as CD151 or CD63) or with a ligand (such as FN). It is even plausible that mFab7 is affecting CD9 function in trans, altering a possible extracellular interaction between CD9 and GPIIb-IIla on nearby platelets. In light of other experiments involving CD9 function in platelets-such as the finding that platelet incubation with CD9 EC2 recombinant peptides inhibit platelet aggregation (J Kotha, unpublished data), or that decreased expression of CD9 is correlated with increased platelet aggregation in human patients (Vrelust 2007) -it is possible that CD9 encourages GPIIb-IIla to maintain an inactive conformation, in balance with the tetraspanins CD151 and CD63 which seem to support activation. Treatment with mFab7 would then be blocking CD9 inhibition on GPIIb-IIla, resulting in platelet activation in response to agonist, similarly to patients with reduced CD9 expression. Further characterization will shed light on this issue.

Further research using the $\mathrm{mFab} 7$ here created can also yield additional insight. It remains unclear what signaling cascades may be involved, and under what circumstances they may be modulated. Further characterization of the tetraspanin web, and the impact of CD9 modulation by mFab7, will also be valuable. This will provide vital information for characterizing the role of CD9 in modulating platelet function. More specific analysis of the exact sequence of CD9 involved in mFab7 binding, as well as an analysis of the impact on its association with GPIlb-Illa, will be insightful. Studies involving CD9 EC2 recombinant peptides may be a useful tool in characterizing the extracellular association between CD9 and GPIIb-IIla, although the possibility that mFab7 treatment could also alter the transmembrane associations between CD9 and GPIIb-IIla cannot be ruled out at this point.

The CD9 knock-out mouse will also provide additional insight. At present, it is unknown what effect disruption of CD9 expression has on the expression levels of other tetraspanins and integrins on the platelet surface. Increased availability of antibodies against these murine proteins will allow expression levels to be quantified. Additionally, while the most obvious phenotype of these 
mice is reduced fertility in the females (LaNaour 2000), careful studies of platelet function may reveal differences - which may involve increased aggregation and activation, rather than the inhibition seen with other tetraspanin knock-out mice. It is most likely that any change in platelet function will be seen using low concentrations of agonists.

I propose that CD9 is involved in modulating the activation state of GPIlbIIla. The addition of $\mathrm{mFab} 7$ to platelets, in the presence of ADP, reduces the CD9 EC2 interaction with GPIIb-IIla, allowing GPIIb-IIla to retain an active, extended conformation rather than a bent, inactive conformation. It will be interesting to see if patients expressing reduced levels of CD9 are more at risk for thrombotic events; therapies targeting increased surface expression of CD9 may become clinically relevant in the future. 


\section{LIST OF REFERENCES}

Adair BD, Yeager M. Three-dimensional model of the human platelet integrin alpha llb beta 3 based on electron cryomicroscopy and x-ray crystallography. Proc Nat Acad Sci USA. 2002; 99: 14059-14064.

Adell T, Gamulin V, Perovic-Ottstadt S, Wiens M, Korzhev M, Muller IM, Muller WE. Evolution of metazoan cell junction proteins: the scaffold protein MAGI and the transmembrane receptor tetraspanin in the desmosponge Suberites domuncula. J Mol Evol. 2004; 59: 1-50.

Andrews RK, Gardiner EE, Shen Y, Whisstock JC, Berndt MC. Glycoprotein IbIX-V. Int J Biochem Cell Biol. 2003; 35 (8): 1170-1174.

Andrews RK, Lopez JA, Berndt MC. Molecular mechanisms of platelet adhesion and activation. International Journal of Biochemistry and Cell Biology. 1997; 29: 91-105.

Arias-Salgado EG, Lizano S, Shattil SJ, Ginsberg MH. Specification of the direction of adhesive signaling by the integrin beta cytoplasmic domain. $J$ Biol Chem. 2005; 280: 29699-29707.

Arthur JF, Gardiner EE, Matzaris M, Taylor SG, Wijeyewickrema L, Ozaki Y, Kahn ML, Andrews RK, Berndt MC. Glycoprotein VI is associated with GPIb-IX-V on the membrane of resting and activated platelets. Thromb Haemost. 2005; 93: 716-723.

Atkinson BJG, Watson SP. Activation of GPVI by collagen is regulated by alpha2beta1 and secondary mediators. J Thromb Haemost. 2003; 1 : 1278-1287.

Banerjee SA, Hadjiargyrou M, Patterson PH. An antibody to the tetraspan membrane protein CD9 promotes neurite formation in a partially alpha3beta1 integrin-dependent manner. J Neurosci. 1997; 17: 27562765.

Banga HS, Simons ER, Brass LF, Rittenhouse SE. Activation of phospholipases $A$ and $C$ in human platelets exposed to epinephrine: role of glycoproteins Ilb/llla and dual role of epinephrine. Proc Natl Acad Sci USA. 1986; 83: 9197-9201.

Barreiro O, Yanez-Mo M, Sala-Valdez M, Gutierrez-Lopez MD, Ovalle S, Higginbottom A, Monk PN, Cabanas C, Sanchez-Madrid F. Endothelial tetraspanin microdomains regulate leukocyte firm adhesion during extravasation. Blood. 2005; 105: 2852-2861. 
Bennett JS, Chan C, Vilaire G, Mousa S, DeGrado WF. Agonist-activated alphav beta3 on platelets and lymphocytes binds to the matrix protein osteopontin. J Biol Chem. 1997; 272: 8137-8140.

Bennett JS. Structure and function of the platelet integrin $\alpha$ llb $\beta 3 . J$ Clin Invest. 2005; 115: 3363-3369.

Benoit P, Gross MS, Frachet P, Frezal J, Uzan G, Boucheix C, Nguyen VC. Assignment of the human CD9 gene to chromosome 12 (region P13) by use of human specific DNA probes. Hum Genet 1991; 86: 268-272.

Berditchevski F, Odintsova E. Characterization of integrin-tetraspanin adhesion complexes: role of tetraspanins in integrin signaling. J Cell Biol. 1999; 146 (2): 477-492.

Berditchevski F, Odintsova E, Sawada S, Gilbert E. Expression of the palmitoylation-deficient CD151 weakens the association of alpha3beta1 integrin with the tetraspanin-enriched microdomains and affects integrindependent signaling. J Biol Chem. 2002; 277: 36991-37000.

Berditchevski F, Tolias KF, Wong K, Carpenter CL, Hemler ME. A novel link between integrins, transmembrane-4 superfamily proteins (CD63 and CD81), and phosphatidylinositol 4-kinase. J Biol Chem. 1997; 272: 25952598.

Berditchevski F. Complexes of integrins with tetraspanins: more than meets the eye. J Cell Science, 2001; 114 (23): 4143-4151.

Bergmeier W, Piffath CL, Cheng G, Dole VS, Zhang Y, von Andrian UH, Wagner DD. Tumor necrosis factor-alpha-converting enzyme (ADAM17) mediates GPIbalpha shedding from platelets in vitro and in vivo. Circ Res. 2004; 95 (7): 677-683.

Bergmeier W, Piffath CL, Goerge T, Cifuni SM, Ruggeri ZM, Ware J, Wagner DD. The role of platelet adhesion receptor GPIb $\alpha$ far exceeds that of its main ligand, von Willebrand factor, in arterial thrombosis. Proc Natl Acad Sci USA. 2006; 103: 16900-16905.

Bergmeier W, Rackebrandt K, Schroder W, Zirngibl H, Nieswandt B. Structural and functional characterization of the mouse von Willebrand factor receptor GPIb-IX with novel monoclonal antibodies. Blood. 2000; 95: 886893.

Berlanga O, Bobe R, Murphy G, Leduc M, Bon C, Barry FA, Gibins JM, Garcia P, Frampton J, Watson SP. Expression of the collagen receptor glycoprotein VI during megakaryocyte differentiation. Blood. 2000; 96: 2740-2745. 
Berndt MC, Shen Y, Dopheide SM, Gardiner EE, Andrews RK. The vascular biology of the glycoprotein Ib-IX-V complex. Thomb Haemost. 2001; 86: 178-188.

Bienstock RJ, Barrett JC. KAl1, a prostate metastasis suppressor: prediction of solvated structure and interactions with binding partners; integrins, cadherins, and cell-surface receptor proteins. Mol Carcinog. 2001; 32 (3): 139-153.

Bodnar RJ, Gu M, Li Z, Englund GD, Du X. The cytoplasmic domain of platelet GPIba is phosphorylated at serine-609. J Bio Chem. 1999; 274: 3347433479 .

Booth JW. Phosphoinositides in FC gamma receptor signaling. Front Biosci. 2006; 11: 1264-1274.

Boucheix C, Benoit P. CD9 antigen: will platelet physiology help to explain the function of a surface molecule during hemopoietic differentiation? Nouv Rev Fr Hematol. 1988; 30: 201-202.

Boucheix C, Rubinstein E. Tetraspanins. Cell Mol Life Sci, 2001; 58 (9): 11891205.

Branehog I, Ridell B, Swolin B, Weinfeld A. Megakaryocyte quantifications in relation to thrombokinetics in primary thrombocythaemia and allied diseases. J Clin Pharm. 1975; 15: 321-332.

Breton-Gorius J, Reyes F. Ultrastructure of human bone marrow cell maturation. International Review of Cytology. 1976; 46: 251-321.

Brisson C, Azorsa DO, Jennings LK, Moog S, Cazenave JP, Lanza F. Colocalization of CD9 and GPIllb-Illa (alpha Ilb beta 3 integrin) on activated platelet pseudopods and alpha-granule membranes. Histochem J. 1997; 29 (2): 153-165.

Burridge K, Chrzanowska-Wodnicka M. Focal adhesions, contractility, and signaling. Annu Rev Cell Dev Biol. 1996; 12: 463-518.

Carroll RC, Worthington RE, Boucheix C. Stimulus-response coupling in human platelets activated by monoclonal antibodies to the CD9 antigen, a $24 \mathrm{kDa}$ surface-membrane glycoprotein. Biochem J, 1990; 266: 527-535.

Cattaneo M. The P2 receptors and congenital platelet function defects. Semin Thromb Hemost. 2005; 31 (2): 168-173. 
Chang JC, Chang HH, Lin CT, Lo SJ. The integrin alpha6beta1 modulation of $\mathrm{PI} 3 \mathrm{~K}$ and $\mathrm{Cdc} 42$ activities induces dynamic filopodium formation in human platelets. J Biomed Sci. 2005; 12: 881-898.

Charrin S, Manie S, Oualid M, Billard M, Boucheix C, Rubinstein E. Differential stability of tetraspanin/tetraspanin interactions: role of palmitoylation. FEBS Lett. 2002; 516: 139-144.

Chen MS, Tung KS, Coonrod SA, Takahashi Y, Bigler D, Chang A, Yamashita Y, Kincad PW, Herr JC, White, JM. Role of the integrin-associated protein CD9 in binding between sperm ADAM 2 and the egg integrin alpha6beta1: implications for murine fertilization. Proc Nat Acad Sci USA. 1999; 96: 11830-11835.

Chen YP, O'Toole TE, Ylanne J, Rosa JP, Ginsberg MH. A point mutation in the integrin beta 3 cytoplasmic domain $(\mathrm{S} 752 \rightarrow \mathrm{P})$ impairs bidirectional signaling through alpha IIb and beta 3 (platelet glycoprotein Ilb-IIla). Blood. 1994; 84: 1857-1865.

Choi ES, Nichol JL, Hokom MM, Hornkohl AC, Hunt P. Platelets generated in vitro from proplatelet-displaying human megakaryocytes are functional. Blood. 1995; 85: 402-413.

Claas C, Stipp CS, Hemler ME. Evaluation of prototype transmembrane 4 superfamily protein complexes and their relation to lipid rafts. J Biol Chem. 2001; 276 (11): 7974-7984.

Clay D, Rubinstein E, Mishal Z, Anjo A, Prenant M, Jasmin C, Boucheix C, Le Bousse-Kerdiles MC. CD9 and megakaryocyte differentiation. Blood. 2001; 97 (7): 1982-1989.

Clemetson KJ, Clemetson JM. Platelet collagen receptors. Thromb Haemost. 2001; 86: 189-197.

Coleman LG Jr, Polanowska-Grabowska RK, Marcinkiewicz M, Gear AR. LDL oxidized by hypochlorous acid causes irreversible platelet aggregation when combined with low levels of ADP, thrombin, epinephrine, or macrophage-derived chemokine (CCL22). Blood. 2004; 104: 380-389.

Connell G, Bascom R, Molday L, Reid D, Mclnnes RR, Molday RS. Photoreceptor peripherin is the normal product of the gene responsible for retinal degeneration in the rds mouse. Proc Nat Acad Sci USA. 1991; 88: 723-726. 
Cook GA, Longhurst C, Grgurevich S, Cholera S, Crossno JT Jr, Jennings LK. Identification of CD9 extracellular domains important in regulation of $\mathrm{CHO}$ cell adhesion to fibronectin and fibronectin pericellular matrix assembly. Blood. 2002; 100 (13): 4502-4511.

Cook GA, Wilkinson DA, Crossno JT Jr, Raghow R, Jennings LK. The tetraspanin CD9 influences the adhesion, spreading, and pericellular fibronectin matrix assembly of Chinese hamster ovary cells on human plasma fibronectin. Exp Cell Research. 1999; 251: 356-371.

Corbett SA, Wilson CL, Schwarzbauer JE. Changes in cell spreading and cytoskeletal organization are induced by adhesion to a fibronectin-fibrin matrix. Blood. 1996; 88: 158-166.

Coughlin SR. Protease-activated receptors in hemostasis, thrombosis, and vascular biology. J Thromb Haemost. 2005; 3: 1800-1814.

Cramer EM, Berger G, Berndt MC. Platelet $\alpha$-granule and plasma membrane share two new components: CD9 and PECAM-1. Blood. 1994; 84 (6):1722-1730.

Dempsey PW, Allison ME, Akkaraju S, Goodnow CC, Fearon DT. C3d of complement as a molecular adjuvant: bridging innate and acquired immunity. Science. 1996; 271: 348-350.

Deng CT, Terasaki PI, Iwaki Y, Hofman FM, Koeffler P, Cahan L, El Awar N, Billing R. A monoclonal antibody cross-reactive with human platelets, megakaryocytes, and common acute lymphocytic leukemia cells. Blood. 1983; 61: 759-764.

Deng J, Yeung VP, Tsitoura D, De Kruyff RH, Umetsu DT, Levy S. Allergeninduced airway hyperreactivity is diminished in CD81-deficient mice. $J$. Immunol. 2000; 165: 5054-5061.

Denis CV, Wagner DD. Platelet adhesion receptors and their ligands in mouse models of thrombosis. Arterioscler Thromb Vasc Biol. 2007; 27 (4): 729739.

Deutsch VR, Tomer A. Megakaryocyte development and platelet production. Brit J Haematology. 2006; 134: 453-466.

Di Giovine M, Salone B, Martina Y, Amati V, Zambruno G, Cundari E, Failla CM, Saggio I. Binding properties, cell delivery, and gene transfer of adenoviral penton base displaying bacteriophage. Virology. 2001; 282: 102-112. 
Dong JF, Berndt MC, Schade A, McIntire LV, Andrews RK, Lopez JA. Ristocetinbut not botrocetin-dependent binding of von Willebrand factor to the platelet membrane GPIb-IX-V complex correlates with shear-dependent interactions. Blood. 2001; 97: 162-168.

Emsley J, King SL, Bergelson JM, Liddington RC. Crystal structure of the I domain from integrin alpha2beta1. J Biol Chem. 1997; 272: 28512-28517.

Escola JM, Kleijmeer MJ, Stoorvogel W, Griffith JM, Yoshie O, Geuze HJ. Selective enrichment of tetraspan proteins on the internal vesicles of multivesicular endosomes and on exosomes secreted by human Blymphocytes. J Biol Chem. 1998; 273: 20121-20127.

Falet $\mathrm{H}$, Chang $\mathrm{G}$, Brohard-Bohn B, Rendu F, Hartwig JH. Integrin alpha(Ilb)beta3 signals lead cofilin to accelerate platelet actin dynamics. Am J Physiol Cell Physiol. 2005; 289 (4): C819-825.

Fernvik E, Hallden G, Hed J, Lundahl J. Intracellular and surface distribution of CD9 in human eosinophils. Apmis. 1995; 103: 699-706.

Focosi D. Physiology of adult homo sapiens_-blood (haemotology: plasma, blood cells, coagulation, and lymph). 2007.

Fodor S, Jakus Z, Mocsai A. ITAM-based signaling beyond the adaptive immune response. Immunol Lett. 2006; 104 (1-2): 29-37.

Foster LJ. Unbiased quantitative proteomics of lipid rafts reveals high specificity for signaling factors. Proc Nat Acad Sci USA. 2003; 100: 5813-5818.

Fritzsching B, Schwer B, Kartenbeck J, Pedal A, Horejsi V, Ott M. Release and intercellular transfer of cell surface CD81 via microparticles. J Immunol. 2002; 169: 5531-5537.

Fukudome K, Furuse M, Imai , Nishimura M, Takagi S. Identification of membrane antigen $\mathrm{C} 33$ recognized by monoclonal antibodies inhibitory to human T-cell leukemia virus type 1 (HTLV-1)-induced syncytium formation: altered glycosylation of C33 antigen in HTLV-1-positive cells. $J$ Virol. 1992; 66: 1394-1401.

Fureder W, Agis H, Sperr WR, Lechner K, Valent P. The surface membrane antigen phenotype of human blood basophils. Allergy. 1994; 49: 861-865.

Gachet C, Leon C, Hechler B. The platelet P2 receptors in arterial thrombosis. Blood Cell Mol Dis. 2006; 36: 223-227. 
Gachet C. Regulation of platelet functions by P2 receptors. Ann Rev Pharmacol Toxicol. 2006; 26: 277-300.

Garcia AJ, Huber F, Boettiger D. Force required to break alpha5beta1 integrinfibronectin bonds in intact adherent cells is sensitive to integrin activation state. J Biol Chem. 1998; 273: 10988-10993.

Geisert EE Jr, Williams R, Geisert GR, Fan L, Asbury AM, Maecker HT, Deng J, Levy $S$. Increased brain size and glial cell number in CD81-null mice. $J$ Comp Neurol. 2002; 453: 22-32.

Gertler FB, Niebuhr K, Reinhard M, Wehland J, Soriano P. Mena, a relative of VASP and Drosophila Enabled, is implicated in the control of microfilament dynamics. Cell. 1996; 87: 227-239.

Gordon-Elonso M, Yanex M, Barreiro O, Alvarez S, Munoz-Fernandez MA, Valenzuela-Fernandez A, Sanchez-Madrid F. Tetraspanins CD9 and CD81 modulate HIV-1-induced membrane fusion. J Immunol. 2006; 100: 2094-2101.

Goschnick MW, Jackson DE. Tetraspanins-structural and signalling scaffolds that regulate platelet function. Mini Rev Med Chem. 2007; 7: 1248-1254.

Goschnick MW, Lau LM, Wee JL, Liu LS, Hogarth PM, Robb LM, Hickey MJ, Wright MD, Jackson DE. Impaired "outside-in" integrin alphallbbeta3 signaling and thrombus stability in TSSC-6 deficient mice. Blood. 2006; 108: 1911-1918.

Gottschalk KE. A coiled-coil structure of the alphallbbeta3 integrin transmembrane and cytoplasmic domains in its resting state. Structure. 2005; 13: 703-712.

Gourgues M, Clergeot PH, Venault C, Cots J, Sibuet S, Brunet-Simon A, Levis C, Langin T, Lebrun MH. A new class of tetraspanins in fungi. Biochem Biophys Res Commun. 2002; 297: 197-1204.

Griffith L, Slupsky J, Seehafer J, Boshkov L, Shaw ARE. Platelet activation by immobilized monoclonal antibody: evidence for a CD9 proximal signal. Blood. 1991; 78 (7): 1753-1759.

Gross O, Gewies A, Finger K, Schafer M, Sparwasser T, Peschel C, Forster I, Ruland J. Card9 controls a non-TLR signaling pathway for innate antifungal immunity. Nature. 2006; 442: 651-656. 
Gu M, Xi X, Englund GD, Berndt MC, Du X. Analysis of the roles of 14-3-3 in the platelet GPIb-IX-mediated activation of integrin $\alpha \mathrm{llb} \beta 3$ using a reconstituted mammalian cell expression model. J Cell Biol. 1999; 147: 1085-1096.

Haas TA, Plow EF. The cytoplasmic domain of allb $\beta 3$ : a ternary complex of the integrin $\alpha$ and $\beta$ subunits and a divalent cation. J Biol Chem. 1996; 271: 6017-6026.

Han J, Lim CJ, Watanabe N, Soriani A, Ratnikov B, Calderwood D, PuzonMcLaughlin W, Lafuente EM, Boussiotis VA, Shattil SJ, Ginsberg MH. Reconstructing and deconstructing agonist-induced activation of integrin alphallbbeta3. Curr Biol. 2006; 16: 1796-1806.

Harker LA, Finch CA. Thrombokinetics in man. J Clin Invest. 1969; 48: 963-964.

Hartwig JH. The platelet: form and function. Seminars in hematology. 2006; 43 (1 Suppl 1): S94-S100.

Helluin O, Chan C, Ilaire G, Mousa S, DeGrado WF, Bennett JS. The activation state of alpha $v$ beta 3 regulates platelet and lymphocyte adhesion to intact and thrombin-cleaved osteopontin. J Biol Chem. 2000; 272: 81378140.

Hemler ME. Specific tetraspanin functions. J Cell Biol. 2001; 155 (7): 1103-1108.

Hemler ME. Tetraspanin functions and associated microdomains. Nature Rev Mol Cell Biol. 2005; 6: 801-811.

Hemler ME. Tetraspanin proteins mediate cellular penetration, invasion, and fusion events and define a novel type of membrane microdomain. Annu Rev Cell Dev Biol. 2003; 19: 397-422.

Ho S-H, Martin F, Higginbottom A, Partridge LJ, Parthasarathy V, Moseley GW, Lopez P, Cheng-Mayer C, Monk PN. Recombinant extracellular domains of tetraspanin proteins are potent inhibitors of the infection of macrophages by human immunodeficiency virus type 1. J Virol. 2006; 80 (13): 6487-6496.

Horvath G, Serru V, Clay D, Billard M, Boucheix C, Rubinstein E. CD19 is linked to the integrin-associated tetraspans CD9, CD81, and CD82. J Biol Chem. 1998; 273 (46): 30537-30543.

Huang CL, Ueno M, Liu D, Masuya D, Nakano J, Yokomise H, Nakagawa T, Miyake M. MRP-1/CD9 gene transduction regulates the actin cytoskeleton through the downregulation of WAVE2. Oncogene. 2006; 25: 6480-6488. 
Huizinga EG, Tsuji S, Romijn RAP, Schiphorst ME, de Groot PG, Sixma JJ, Gros P. Structures of GPIb $\alpha$ and its complex with the vWF-A1-domain. Science. 2002; 297: 1176-1179.

Humphries MJ. Integrin structure. Biochem. Soc. Trans. 2000; 28 (4): 311-339.

Inoue O, Suzuki-Inoue K, Dean WL, Frampton J, Watson SP. Integrin alpha2beta1 mediates outside-in regulation of platelet spreading on collagen through activation of Src kinases and PLCgamma2. J Cell Biol. 2003; 160: 769-780.

Inui S, Higashiyama S, Hashimoto K, Higashiyama M, Yoshikawa K, Taniguchi N. Possible role of coexpression of CD9 with membrane-anchored heparin-binding EGF-like growth factor and amphiregulin in cultured human keratinocyte growth. J Cell Physiol. 1997; 171: 291-298.

Israels SJ, McMillan-Ward EM. CD63 modulates spreading and tyrosine phosphorylation of platelets on immobilized fibrinogen. Thromb Haemost. 2005; 93: 311-318.

Israels SJ, McMillan-Ward EM. Platelet tetraspanin complexes and their association with lipid rafts. Thromb Haemost. 2007; 98: 1081-1087.

Italiano J, Bergmeier W, Tiwari S, Falet $\mathrm{H}$, Hartwig JH, Hoffmeister KM. Mechanisms and implications of platelet discoid shape. Blood. 2003; 101: 4789-4796.

Italiano J, Lecine P, Shivdasani RA, Hartwig JH. Blood platelets are assembled principally at the ends of proplatelet processes produced by differentiated megakaryocytes. J Cell Biol. 1999; 147: 1299-1312.

Jackson DE, Kupcho KR, Newman PJ. Characterization of phosphotyrosine binding motifs in the cytoplasmic domain of platelet/endothelial cell adhesion molecule-1 (PECAM-1) that are required for the cellular association and activation of the protein tyrosine phosphatase, SHP-2. J Biol Chem. 1997; 272: 24868-24875.

Jennings LK, Crossno JT Jr, Fox CF, White MM, Green CA. Platelet p24/CD9, a member of the tetraspanin family of proteins. Ann NY Acad Sci. 1994; 714: $175-184$.

Jennings LK, Fox CF, Kouns WC, McKay CP, Ballou LR, Schultz HE. The activation of human platelets mediated by anti-human platelet p24/CD9 monoclonal antibodies. J Bio Chem. 1990; 265 (7): 3815-3822. 
Jennings LK, White MM. Platelet protocols: research and clinical laboratory procedures. Academic Press, 1999.

Jung SM, Moroi M. Signal-transducing mechanisms involved in activation of the platelet collagen receptor integrin alpha(2)-beta(1). J Biol Chem. 2000; 275: 8016-8026.

Jurk K, Clemetson KJ, de Groot PG, de Brodde MF, Steiner M, Savion N, Varon $D$, Sixma JJ, van Aken H, Kehrel BE. Thrombospondin-1 mediates platelet adhesion at high shear via glycoprotein Ib (GPIb): an alternative/backup mechanism to on Willebrand factor. FASEB J. 2003; 17: 1490-1492.

Kahner BN, Shankar H, Murugappan S, Prasad GL, Kunapuli SP. Nucleotide receptor signaling in platelets. J Thromb Haemost. 2006; 4 (11): 23172326.

Kaji K, Oda S, Shikano T, Ohnuki T, Uematsu Y, Sakagami J, Tada N, Miyazaki $\mathrm{S}$, Kudo A. The gamete fusion process is defective in eggs of Cd9deficient mice. Nat Genet. 2000; 24: 279-282.

Kasarov AR, Yang X, Stipp CS, Sehgal B, Hemler ME. An extracellular site on tetraspanin CD151 determines $\alpha 3$ and $\alpha 6$ integrin-dependent cellular morphology. J Cell Biol. 2002; 158: 1299-1309.

Kasirer-Friede A, Kahn ML, Shattil SJ. Platelet integrins and immunoreceptors. Immunol Rev. 2007; 218: 247-264.

Kehrel B. Platelet-collagen interactions. Semin Thromb Hemost. 1995; 21: 123129.

Kelic S, Levy S, Suarez C, Weinstein DE. CD81 regulates neuron-induced astrocyte cell-cycle exit. Mol Cell Neurosci. 2001; 17: 551-560.

Kitadokoro K, Bordo D, Galli G, Petracca R, Falugi F, Abrighani S, Grandi G, Bolognesi M. CD81 extracellular domain 3D structure: insight into the tetraspanin superfamily structural motifs. EMBO J. 2001; 20: 12-18.

Klein-Soyer C, Azorsa DO, Cazenave JP, Lanza F. CD9 participates in endothelial cell migration during in vitro wound repair. Arterioscler Thromb Vasc Biol. 2000; 20: 360-369.

Ko EM, Lee IY, Cheon IS, Kim J, Choi JS, Hwang JY, Cho JS, Lee DH, Kang D, Kim SH, Choe J. Monoclonal antibody to CD9 inhibits platelet-induced human endothelial cell proliferation. Mol Cells. 2006; 22 (1): 70-77. 
Kohl S, Giddings I, Besch D, Apfelstedt-Sylla E, Zrenner E, Wissinger B. The role of the peripherin/RDS gene in retinal dystrophies. Acta Anat. 1998; 162: $75-84$.

Kotha J, Longhurst C, Appling W, Jennings LK. Tetraspanin CD9 regulates beta1 integrin activation and enhances cell motility to fibronectin via a PI-3 kinase-dependent pathway. Exp Cell Res. 2008; 314 (8): 1811-1822.

Kouns WC, Fox CF, Lamoreaux WJ, Coons LB, Jennings LK. The effect of glycoprotein Ilb-Illa receptor occupancy on the cytoskeleton of resting and activated platelets. J Biol Chem. 1991; 266: 13891-13900.

Kovalenko OV, Metcalf DG, DeGrado WF, Hemler ME. Structural organization and interactions of transmembrane domains in tetraspanin proteins. $B M C$ Structural Bio. 2005; 5: 11.

Kugelgen IV. Pharmacological profiles of cloned mammalian P2Y-receptor subtypes. Pharmacol and Therap. 2006; 110: 415-432.

Kuruda K, Ozaki Y, Qi R. Fc gamma II receptor-mediated platelet activation induced by anti-CD9 monoclonal antibody opens $\mathrm{Ca}^{2+}$ channels that are distinct from those associated with $\mathrm{Ca}^{2+}$ store depletion. J Immunol. 1995; 155: $4427-4436$.

Lagaudriere-Gesbert C, LaNaour F, Lebel-Binay S, Billard M, Lemichez E, Boquet $\mathrm{P}$, Boucheix $\mathrm{C}$, Conjeaud $\mathrm{H}$, Rubinstein $\mathrm{E}$. Functional analysis of four tetraspans, CD9, CD53, C81, and CD82, suggests a common role in costimulation, cell adhesion, and migration: only CD9 upregulates HBEGF activity. Cell Immunol. 1997; 182: 105-112.

Lammerding J, Kazarov AR, Huang H, Lee RT, Hemler ME. Tetraspanin CD151 regulates $\alpha 6 \beta 1$ integrin adhesion strengthening. Proc Nat Acad Sci USA. 2003; 100: 7616-7621.

LaNaour F, Rubinstein F, Jasmin C, Penant M, Boucheix C. Severely reduced female fertility in CD9-deficient mice. Science. 2000; 287: 319-321.

Lanza F, Wolf D, Fox CF, Kieffer N, Seyer JM, Fried VA, Coughlin SR, Philips DR, Jennings LK. CDNA cloning and expression of platelet p24/CD9. Evidence for a new family of multiple membrane-spanning proteins. J Biol Chem. 1991; 266: 10638-10645.

Lau LM, Wee JL, Wright MD, Moseley GW, Hogarth PM, Ashman LK, Jackson $D E$. The tetraspanin superfamily member CD151 regulates outside-in alphallbbeta3 signaling and platelet function. Blood. 2004; 104: 23682375. 
Lecine P, Italiano JE, Kim SW, Villeval JL, Shivdasani RA. Hematopoieticspecific B1 tubulin participates in a pathway of platelet biogenesis dependent on the transcription factor NF-E2. Blood. 2000; 96: 1366-1373.

Levy S, Shoham T. Protein-protein interactions in the tetraspanin web. Physiology. 2005; 20: 218-224.

Little KD, Hemler ME, Stipp CS. Dynamic regulation of a GPCR-tetraspanin-G protein complex on intact cells: central role of CD81 in facilitating GPR56Galpha $_{\mathrm{q} / 11}$ association. Mol Biol Cell. 2004; 15: 2375-2387.

Long MW, Williams N, McDonald TP. Immature megakaryocytes in the mouse: in vitro relationship to megakaryocyte progenitor cells and mature megakaryocytes. J Cell Physiology. 1988; 112: 339-344.

Longhurst CM, Jacobs JD, White MM, Crossno JT Jr, Fitzgerald DA, Bao J, Fitzgerald TJ, Raghow R, Jennings LK. Chinese hamster ovary cell motility to fibronectin is modulated by the second extracellular loop of CD9. Identification of a putative fibronectin binding site. J Biol Chem. 2002; 277 (36): 32445-32452.

Longhurst CM, White MM, Wilkinson DA, Jennings LK. A CD9, $\alpha$ llb $\beta 3$, integrinassociated protein, and GPIb/V/IX complex on the surface of human platelets is influenced by allb $\beta 3$ conformational states. Eur J Biochem. 1999; 263: 104-111.

Lopez JA, Andrews RK, Afshar-Kharghan B, Berndt MC. Bernard-Soulier syndrome. Blood. 1998; 91: 4397-4418.

Ma YQ, Qin J, Plow EF. Platelet integrin allbß3: activation mechanisms. J Thromb Haem. 2007; 5: 1345-1352.

Ma YQ, Yang J, Pesho MM, Vinogradova O, Qin J, Plow EF. Regulation of integrin alpha (llb)beta(3) activation by distinct regions of its cytoplasmic tails. Biochemistry. 2006; 45: 6656-6662.

Maecker HT, Todd SC, Levy S. The tetraspanin superfamily: molecular facilitators. FASEB J. 1997; 11: 428-442.

Matsukova J, Chauhan AK, Cambien B, Astrof S, Dole VS, Piffath CL, Hynes $\mathrm{RO}$, Wagner DD. Decreased plasma fibronectin leads to delayed thrombus growth in injured arterioles. Arterioscler Thromb Vasc Biol. 2006; 26: 1391-1396.

Matsuoka Y, Li X, Bennet V. Aducin: structure, function, and regulation. Cell Mol Life Sci. 2000; 57: 884-895. 
McCarty OJ, Zhao Y, Andrew N, Machesky LM, Staunton D, Frampton J, Watson SP. Evaluation of the role of platelet integrins in fibronectin-dependent spreading and adhesion. J Thromb Haemost. 2004; 2: 1823-1833.

Mejillano MR, Kojima S, Applewhite DA, Gertler FB, Svitkina TM, Borisy GG. Lamellipodial versus filopodial mode of the actin nanomachinery: pivotal role of the filament barbed end. Cell. 2004; 118: 363-373.

Metzlaar MJ, Wingaard PLJ, Peters PJ. CD63 antigen, a novel lysosomal membrane glycoprotein cloned by a screening procedure for intracellular antigens in eukaryotic cells. J Biol Chem. 1991; 266: 3239-3245.

Miao WM, Vasile E, Lane WS, Lawler J. CD36 associates with CD9 and integrins on human blood platelets. Blood. 2001; 97 (6): 1689-1696.

Miller BJ, Georges-Labouesse E, Primakoff P, Myles DG. Normal fertilization occurs with eggs lacking the integrin alpha6beta1 and is CD9-dependent. J Cell Biol. 2000; 149: 1289-1296.

Miller JL, Kupenski JW, Hustad KO. Characterization of a platelet membrane protein of low molecular weight associated with platelet activation following binding by monoclonal antibody. Blood. 1986; 68: 743-751.

Miyado K, Yamada G, Yamada S, Hauwa H, Naamua Y, Ryu F, Suzuki K, Kosai K, Inoue K, Ogura A, Okabe M, Mekada E. Requirement of CD9 on the egg plasma membrane for fertilization. Science. 2000; 287: 321-324.

Miyazaki T, Muller U, Campbell KS. Normal development but differentially altered proliferative responses of lymphocytes in mice lacking CD81. EMBO J. 1997; 16: 4217-4225.

Mori M, Tsuchiyama J, Okada S. Proliferation, migration, and platelet release by megakaryocytes in long-term bone marrow culture in collagen gel. Cell Structure and Function. 1993; 18: 409-417.

Moribe H, Yochem J, Yamada H, Tabuse Y, Fujimoto T, Mekada E. Tetraspanin protein (TSP-15) is required for epidermal integrity in Caenorhabditis elegans. J Cell Sci. 2004; 117: 5209-5220.

Moseley GW. Tetraspanin-Fc receptor interactions. Platelets. 2005; 16 (1): 3-12.

Murugappan S, Kunapuli SP. The role of ADP receptors in platelet function. Front Biosci. 2006; 11: 1977-1986. 
Murugappan S, Shankar H, Kunapuli SP. Platelet receptors for adenine nucleotides and thromboxane A2. Semin Thromb Hemost. 2004; 30 (4): 411-418.

Nakamura K, Iwamoto R, Mekada E. Membrane-anchored heparin-binding EGFlike growth factor (HB-EGF) and diphtheria toxin receptor-associated protein (DRAP-27)/CD9 forms a complex with integrin $\alpha 3 \beta 1$ at cell-cell contact sites. J Cell Bio. 1995; 129 (6): 1691-1705.

Nakamura K, Mitamura T, Takahashi T, Kobayashi T, Mekada E. Importance of the major extracellular domain of CD9 and the epidermal growth factor (EGF)-like domain of the heparin-binding EGF-like growth factor for upregulation of binding and activity. J Biol Chem. 2000; 275: 18284-18290.

Nanda N, Andra P, Bao M, Clauser K, Deguzman F, Howie D, Conley PB, Terhorst C, Phillips DR. Platelet aggregation induces platelet aggregate stability via SLAM family receptor signaling. Blood. 2005; 106: 3028-3034.

$\mathrm{Ni} \mathrm{H}$, Denis CV, Subbarao S, Dgen JL, Sato TN, Hynes RO, Wagner DD. Persistence of platelet thrombus formation in arterioles of mice lacking both von Willebrand factor and fibrinogen. J Clin Invest. 2000; 106: 385392.

$\mathrm{Ni} \mathrm{H,} \mathrm{Yuen} \mathrm{PS,} \mathrm{Papalia} \mathrm{JM,} \mathrm{Trevithick} \mathrm{JE,} \mathrm{Sakai} \mathrm{T,} \mathrm{Fassler} \mathrm{R,} \mathrm{Hynes} \mathrm{RO,}$ Wagner DD. Plasma fibronectin promotes thrombus growth and stability in injured arterioles. Proc Natl Acad Sci USA. 2003; 100: 2415-2419.

Nieswandt B, Bergmeier W, Schulte V, Rackebrandt K, Gessner JE, Zirngibl H. Expression and function of the mouse collagen receptor glycoprotein $\mathrm{VI}$ is strictly dependent on its association with the FcR gamma chain. J Biol Chem. 2000; 275: 23998-24002.

Nieuwenhuis HK, Akkerman JW, Houdijk WP, Sixma JJ. Human blood platelets showing no response to collagen fail to express surface glycoprotein la. Nature. 1985; 318: 470-472.

Nigatu A, Sime W, Gorfu G, Geberhiwot T, Anduren I, Ingerpuu S, Tryggyason K, Hjemdahl P, Patarroyo M. Megakaryocytic cells synthesize and platelets secrete alpha5-laminins, and the endothelial laminin isoform laminin 10 (alpha5beta1gamma1) strongly promotes adhesion but not activation of platelets. Thromb Haemost. 2006; 95: 85-93.

Nurden AT. Qualitative disorders of platelets and megakaryocytes. J Thromb Haemost. 2005; 3: 1773-1782. 
Offermans S. Activation of platelet function through $\mathrm{G}$ protein-coupled receptors. Circ Research. 2006; 99: 1293-1304.

O'Toole TE, Ylanne J, Culley BM. Regulation of integrin affinity states through an NPXY motif in the $\beta$ subunit cytoplasmic domain. J Biol Chem. 1995; 270: 8553-8558.

Parise LV. Integrin allbß3 signaling in platelet adhesion and aggregation. Curr Opin Cell Biol. 1999; 11(5): 597-601.

Patel SR, Hartwig JH, Italiano JE. The biogenesis of platelets from megakaryocyte proplatelets. J Clin Invest. 2005; 115: 3348-3434.

Penas PF, Garcia-Diez A, Sanchez-Madrid F, Yanez-Mo M. Tetraspanins are localized at motility-related structures and involved in normal human keratinocyte wound healing migration. J Invest Dermatol. 2000; 114: 11261135.

Phillips DR, Prasad KS, Manganello J, Bao M, Nannizzi-Alaimo L. Integrin tyrosine phosphorylation in platelet signaling. Curr Opin Cell Biol. 2001; 13: $546-554$.

Pitchford SC, Momi S, Giannini S, Casali L, Spina D, Page CP, Gresele P. Platelet $\mathrm{P}$-selectin is required for pulmonary eosinophil and lymphocyte recruitment in a murine model of allergic inflammation. Blood. 2005; 105: 2074-2081.

Platelets, Second Edition. Burlington, Massachusetts: Academic Press, 2007.

Pozgajova M, Sachs UJ, Hein L, Nieswandt B. Reduced thrombus stability in mice lacking the $\alpha 2 A$-adrenergic receptor. Blood. 2006; 108: 510-514.

Qi R, Ozaki Y, Kuruda K. Differential activation of human platelets induced by Fc gamma receptor II cross-linking and by anti-CD9 monoclonal antibody. $J$ Immunol. 1996; 157: 5638-5645.

Rees DJ, Ades SE, Singer SJ, Hynes RO. Sequence and domain structure of talin. Nature. 1990; 347: 685-689.

Reth M. Antigen receptor tail clue. Nature. 1989; 338: 383-384.

Rubinstein E, Boucheix C, Worthington RE, Carroll RC. Anti-platelet antibody interactions with Fc gamma receptor. Semin Thromb Hemost. 1995; 21 (1): 10-22. 
Rubinstein E, LeNaour F, Lagaudriere-Gesbert C, Billard M, Conjeaud $\mathrm{H}$, Bouchiex C. CD9, CD63, CD81, and CD82 are components of a surface tetraspan network connected to HLA-DR and VLA integrins. Eur $\mathrm{J}$ Immunol. 1996; 26: 2657-2665.

Rubinstein E, Ziyyat A, Prenant M, Wrobel E, Wolf JP, Levy S, LaNaour F, Boucheix C. Reduced fertility of female mice lacking CD81. Dev Biol. 2006; 290: 351-358.

Ruggeri ZM, Mendolicchio GL. Adhesion mechanisms in platelet function. Circ Research. 2007; 100: 1673-1685.

Ruggeri ZM. Von Willebrand factor. Curr Opin Hematol. 2003; 10: 142-149.

Saito Y, Tachibana I, Takeda Y, Yamane H, He P, Suzuki M, Minami S, Kijima T, Yoshida M, Kumagai T, Osaki T, Kawase I. Absence of CD9 enhances adhesion-dependent morphologic differentiation, survival, and matrix metalloproteinase-2 production in small cell lung cancer cells. Cancer Res. 2006; 66 (19): 9557-9565.

Sala-Valdez M, Ursa A, Charrin S, Rubinstein E, Hemler ME, Sanchez-Madrid F, Yanez-Mo M. EWI-2 and EWI-F link the tetraspanin web to the actin cytoskeleton through their direct association with ezrin-radixin-moesin proteins. JBC. 2006; 281 (28): 19665-19675.

Samaha FF, Kahn ML. Novel platelet and vascular roles for immunoreceptor signaling. Arterioscler Thromb Vasc Biol. 2006; 26: 2588-2593.

Savage B, Almus-Jacobs F, Ruggeri ZM. Specific synergy of multiple substratereceptor interactions in platelet thrombus formation under flow. Cell. 1998; 94: 657-666.

Sawada S, Yoshimoto M, Odintsova E, Hotchin NA, Berditchevski F. The tetraspanin CD151 functions as a negative regulator in the adhesiondependent activation of Ras. J Biol Chem. 2003; 278 (29): 26323-26326.

Scherberich A, Giannone G, Perennou E, Takeda K, Boucheix C, Rubinstein E, Lanza F, Beretz A. FAK-mediated inhibition of vascular smooth muscle cell migration by the tetraspanin CD9. Thromb Haemost. 2002; 87: 10431050.

Scherberich A, Moog S, Haan-Archipoff G, Azorsa DO, Lanza F, Beretz A. Tetraspanin CD9 is associated with very late-acting integrins in human vascular smooth muscle cells and modulates collagen matrix reorganization. Arteroscler Thromb Vasc Biol. 1998; 18: 1691-1697. 
Schwartz MA, Shattil SJ. Signaling networks linking integrins and Rho family GTPases. Trends Biochem Sci. 2000; 25: 388-391.

Schwartz-Albiez R, Dorken B, Hofmann W, Moldenhauer G. The B cellassociated CD37 antigen (gp40-52). Structure and subcellular expression of an extensively glycosylated glycoprotein. J Immunol. 1988; 140: 905914.

Seigneuret M, Delaguillaumie A, Lagaudriere-Gesbert C, Conjeaud H. Structure of the tetraspanin main extracellular domain. A partially conserved fold with a structurally variable domain insertion. J Biol Chem. 2001; 276: 40055-40064.

Senis YA, Tomlinson MG, Garcia A, Dumon S, Heath VL, Herbert J, Cobbold SP, Spalton JC, Ayman S, Antrobus R, Zitzmann M, Bicknell R, Frampton J, Authi K, Martin A, Wakelam MJ, Watson SP. A comprehensive proteomics and genomics analysis reveals novel transmembrane proteins in human platelets and mouse megakaryocytes including G6b-B, a novel immunoreceptor tyrosine-based inhibitory motif protein. Mol Cell Proteomics. 2007; 6 (3): 548-564.

Serru V, LaNaour F, Billard M, Azorsa DO, Lanza F, Boucheix C, Rubinstein E. Selective tetraspan-integrin complexes (CD81/alpha4beta1, CD151/alpha3beta1, CD151/alpha6beta1) under conditions disrupting tetraspanin interactions. Biochem J. 1999; 34091: 103-111.

Shattil SJ, Newman PJ. Integrins: dynamic scaffolds for adhesion and signaling in platelets. Blood. 2004; 13: 546-554.

Shen Y, Romo GM, Dong JF, Schade A, McIntire LV, Kenny D, Whisstock JC, Berndt MC, Lopez JA, Andrews RK. Requirement of leucine-rich repeats of GPIb $\alpha$ for shear-dependent and static binding of VWF to the platelet membrane GPIb-IX-V complex. Blood. 2000; 95: 903-910.

Shi W, Fan H, Shum L, Derynck R. The tetraspanin CD9 associates with transmembrane TGF-alpha and regulates TGF-alpha-induced EF receptor activation and cell proliferation. $J$ Cell Biol. 2000; 148: 591-602.

Slupsky JR, Seehafer JG, Tang SC, Masellis-Smith A, Shaw ARE. Evidence that monoclonal antibodies against CD9 antigen induce specific association between CD9 and the platelet glycoprotein Ilb-Illa complex. J Biol Chem. 1989; 264: 12289-12293.

Smith CW. Adhesion molecules and receptors. J All Clin Immunol. 2008; 121 (2): S375-S379. 
Sonnenberg A, Gehlsen KR, Aumailley M, Timpl R. Isolation of alpha 6 beta 1 integrins from platelets and adherent cells by affinity chromatography on mouse laminin fragment E8 and human laminin pepsin fragment. Exp Cell Res. 1991; 197: 234-244.

Sonnenberg A, Modderman PW, Hogervorst F. Laminin receptor on platelets is the integrin VLA-6. Nature. 1988; 336: 487-489.

Sperandion M. Selectins and glycosyltransferases in leukocyte rolling in vivo. FEBS J. 2006; 273: 4377-4389.

Stipp CS, Orlicky D, Hemler ME. FPRP, a major, highly stoichiometric, highly specific CD81- and CD9-associated protein. J Biol Chem. 2001; 276 (1): 4853-4862.

Suzuki S, Argraves WS, Pytela R, Arai H, Krusius T, Pierschblacher MD, Ruoslahti E. cDNA and amino acid sequences of the cell adhesion protein receptor recognizing vitronectin reveal a transmembrane domain and homologies with other adhesion protein receptors. Proc Natl Acad Sci USA. 1986; 83: 8614-8618.

Suzuki-Inoue K, Hughes CE, Inoue O, Kaneko M, Cuyun-Lira O, Takafuta T, Watson SP, Ozaki Y. Involvement of Src kinases and PLCY2 in clot retraction. Thromb Res. 2007; 120 (2): 251-258.

Tadokoro S, Shattil SJ, Eto K, Tai V, Liddington RC, de Pereda JM, Ginsberg $\mathrm{MH}$, Calderwood DA. Talin binding to integrin beta tails: a final common step in integrin activation. Science. 2003; 302: 103-106.

Tait AS, Dong JF, Dawes IW, Chong BH. Site-directed mutagenesis of platelet GPIb $\alpha$ demonstrating residues involved in the sulfation of tyrosines 276 , 278, and 279. Blood. 2002; 99: 4422-4427.

Takagi J, Petre BM, Walz T, Springer TA. Global conformational rearrangements in integrin extracellular domains in outside-in and inside-out signaling. Cell. 2002; 10: 599-611.

Takeda T, Hattori N, Tokuhara T, Nishimura Y, Yokoyama M, Miyake M. Adenoviral transduction of MRP-1/CD9 and KAI-1/CD82 inhibits lymph node metastasis in orthotopic lung cancer model. Cancer Res. 2007; 67 (4): 1744-1749.

Tarrant JM, Groom J, Metcalf D, Li R, Borobokas B. The absence of Tssc6, a member of the tetraspanin superfamily, does not affect lymphoid development but enhances in vitro T-cell proliferative responses. Mol Cell Biol. 2002; 22 (14): 5006-5018. 
Thomas DW, Mannon RB, Mannon PJ, Latour A, Oliver JA, Hoffman M, Smithies $\mathrm{O}$, Koller BH, Coffman TM. Coagulation defects and altered hemodynamic responses in mice lacking receptors for thromboxane A2. J Clin Invest. 1998; 102: 1994-2001.

Thomas W. For catch bonds, it all hinges on the interdomain region. $J$ Cell Biol. 2006; 174: 911-913.

Tomer A, Harker LA, Burstein SA. Flow cytometric analysis of normal human megakaryocytes. Blood. 1988; 71: 1244-1252.

Tomlinson MG, Heath VL, Fitzpatrick-Ellis KA, Dumon S, Berditchevski F, Hemler MA, Niewswandt B, Frampton J, Watson SP. The role of tetraspanin superfamily proteins in platelets and megakaryocytes. 2004. http://www.ukpg.bham.ac.uk/templates/Oxford/oxfordprog g00000f.pdf. Accessed 8 April 2008.

Travis GH, Sutcliffe JG, Bok D. The retinal degeneration slow (rds) gene product is a photoreceptor disc membrane-associated glycoprotein. Neuron. 1991; 6: 61-70.

Uff S, Clemetson JM, Harrison T, Clemetson KJ, Emsley J. Crystal structure of the platelet GPIb $\propto \mathrm{N}$-terminal domain reveals an unmasking mechanism for receptor activation. J Bio Chem. 2002; 277: 35657-35663.

Unternaehrer JJ, Chow A, Pypaert M, Inaba K, Mellman I. The tetraspanin CD9 mediates lateral association of $\mathrm{MHC}$ class II molecules on the dendritic cell surface. PNAS. 2007; 104 (1): 234-239.

Van der Geer P, Pawson T. The PTP domain: a new protein module implicated in signal transduction. TIBS. 1995; 20: 277-280.

Vinogradova O, Velyvis A, Velyviene A, Hu B, Haas T, Plow E, Qin J. A structural mechanism of integrin alpha(lllb)beta(3) "inside-out" activation as regulated by its cytoplasmic face. Cell. 2002; 110: 599-611.

Voss B, McLaughlin JN, Holinstat M, Zent R, Hamm HE. PAR1, but not PAR4, activates human platelets through a Gi/o/phosphoinosite-3 kinase signaling axis. Molec Pharmacol. 2007; 71 (5): 1399-1406.

Vrelust I, Vangenechten I, Vertessen F, Van der Planken M, Gadisseur AP. Increased platelet aggregation after DDAVP administration may be explained by decreased expression of the tetraspanin CD9. Abstract presented to International Society on Thrombosis and Haemostasis, 2007; Geneva Switzerland. 
Walz T, Haner M, Wu XR, Henn C, Engel A, Sunn TT, Aebi U. Towards the molecular architecture of the asymmetric unit membrane of the mammalian urinary bladder epithelium: a closed "twisted ribbon" structure. J Mol Biol. 1995; 248: 887-900.

Wang XQ, Alfaro ML, Evans GF, Zuckerman SH. Histone deacetylase inhibition results in decreased macrophage CD9 expression. Biochem Biophys Res Comm. 2002; 294 (3): 660-666.

Waterhouse R, Ha C, Dveksler GS. Murine CD9 is the receptor for pregnancyspecific glycoprotein 17. J Exp Med. 2002; 195: 277-282.

Watson SP, Auger JM, McCarty OJT, Pearce AC. GPVI and integrin allbß3 signaling in platelets. J Thromb Haemost. 2005; 3 (8): 1752-1762.

Weimin L, Yujing C, Jing L, Zeng H, Ping Z, Enkui D. The expression of CD9 in the peri-implantation mouse uterus is upregulated in an ovarian steroid hormone-dependent manner. Fertility and Sterility. 2007; 87 (3): 664-670.

Weljie AM, Hwang PM, Vogel H. Solution structures of the cytoplasmic tail complex from platelet integrin allb- and $\beta 3$ - subunits. Proc Nat Acad Sci USA. 2002; 99: 5878-5883.

White $M$, Jennings L. Laboratory evaluation of platelet function. In: Platelet Protocols. San Diego, CA: Academic Press, 1999: 39-40.

Willet B, Hosie M, Shaw A, Neil J. Inhibition of feline immunodeficiency virus infection by CD9 antibody operates after virus entry and is independent of virus tropism. J Gen Virol. 1997; 78: 611-618.

Won WJ, Kearney JF. CD9 is a unique marker for marginal zone B cells, B1 cells, and plasma cells in mice. J Immunol. 2002; 168: 5605-5611.

Worthington RE, Carroll RC, Boucheix C. Platelet activation by CD9 monoclonal antibodies is mediated by the Fc gamma II receptor. Br J Haematol. 1990; 74 (2): $216-222$.

Wright MD, Henkle KJ, Mitchell GF. An immunogenic Mr 23,000 integral membrane protein of Schistosoma mansoni worms that closely resembles a human tumor-associated antigen. J Biol Chem. 1990; 144: 3195-3200.

Wright MD, Mosely GW, van Spriel AB. Tetraspanin microdomains in immune cell signaling and malignant disease. Tissue Antigens. 2004; 64: 533-542. 
Wu H, Li J, Peng L. Anti-human tetraspanin (CD9) monoclonal antibodies induce platelet integrin alphallbbeta3 activation in a Fc receptor independent fashion. Chin Med Sci J. 2000; 15: 145-149.

Wu Y, Suzuki-Inoue K, Satoh K, Asazuma N, Yatomi Y, Berndt MC, Ozaki Y. Role of Fc receptor gamma-chain in platelet glycoprotein lb-mediated signaling. Blood. 2001; 97: 3836-3845.

Xiong JP, Stehle T, Diefenbach B, Zhang R, Dunker R, Scott DL, Joachimiak A, Goodman SL, Arnaout MA. Crystal structure of the extracellular segment of integrin alpha $V$ beta 3. Science. 2001; 294: 339-345.

Yanez-Mo M, Alfranca A, Cabanas C, Marazuela M, Tejedor R, Ursa MA, Ashman LK, de Landazuri MO, Sanchez-Madrid F. Regulation of endothelial cell motility by complexes of tetraspan molecules CD81/TAPA1 and CD151/PETA-3 with alpha3 beta1 integrin localized at endothelial lateral junctions. J Biol Chem. 1998; 141 (3): 791-804.

Yang XH, Claas C, Kraeft SK, Chen LB, Want Z, Kreidberg JA, Hemler ME. Palmitoylation of tetraspanin proteins: modulation of CD151 lateral interactions, subcellular distribution, and integrin-dependent cell morphology. Mol Biol Cell. 2002; 13: 767-781.

Yang XH, Kovalenko OV, Kolesnikova TV, Andzelm MM, Rubinstein E, Strominger JL, Hemler ME. Contrasting effects of EWI proteins, integrins, and protein palmitoylation on cell surface CD9 organization. JBC. 2006; 281 (18): 12976-12985.

Yang XH, Kovalenko OV, Tang W, Claas C, Stipp CS, Hemler ME. Palmitoylation supports assembly and function of integrin-tetraspanin complexes. J Cell Biol . 2004; 167: 1231-1240.

Yauch RL, Berditchevski F, Harler MB, Reichner J, Hemler ME. Highly stoichiometric, stable, and specific association of integrin $\alpha 2 \beta 1$ with CD151 provides a major link to phosphatidylinositol 4-kinase, and may regulate cell migration. Mol Biol Cell. 1998; 9: 2751-2765.

Yi TG, Kim HJ, Cho JY, Woo KM, Ryoo HM, Kim GS, Baek JW. Tetraspanin CD9 regulates osteoclastogenesis via regulation of p44/42 MAPK activity. Biochem Biophys Res Comm. 2006; 347: 178-184.

Yunta M, Lazo PA. Tetraspanin proteins as organizers of membrane microdomains and signaling complexes. Cell Signaling. 2002; 15: 559564. 
Zarbock A, Polanowska-Grabowska RK, Ley K. Platelet-neutrophil-interactions: linking hemostasis and inflammation. Blood Rev. 2006; 21: 99-111.

Zhang XA, Bontrager AL, Hemler ME. Transmembrane-4 superfamily proteins associate with activated protein kinase $\mathrm{C}$ (PKC) and link PKC to specific $\beta 1$ integrins. J Biol Chem. 2001; 276: 25005-25013.

Zhu GZ, Miller BJ, Boucheix C, Rubinstein E, Liu CC, Hynes RO, Myles DG, Primakoff P. Residues SFQ (173-175) in the large extracellular loop of CD9 are required for gamete fusion. Development. 2002; 129: 1995-2002.

Ziyyat A, Rubinstein E, Monier-Gavelle F, Barraud V, Kulski O, Prenant M, Boucheix C, Bomsel M, Wolf JP. CD9 controls the formation of clusters that contain tetraspanins and the integrin $\alpha 6 \beta 1$, which are involved in human and mouse gamete fusion. J Cell Science. 2006; 119: 416-424.

Zucker-Franklin D, Petursson S. Thrombocytopoiesis—analysis by membrane tracer and freeze-fracture studies on fresh human and cultured mouse megakaryocytes. J Cell Biol. 1984; 9: 390-402.

Zvieriev V, Wang JC, Chevrett M. Over-expression of CD9 does not affect in vivo tumorigenic or metastatic properties of human prostate cancer cells. Biochem Biophys Res Comm. 2005; 337: 498-504. 


\section{VITA}

Sarah Kathleen Hill was born in 1980 in Fort Lewis, Washington. She received her Associate of Science degree with a major in Microbiology from Ricks College, Rexburg, Idaho, in 2001. She received her Bachelor of Science degree with a major in Microbiology from Brigham Young University, Provo, Utah in 2003. She joined The University of Tennessee Health Science Center in 2003, where she was a member of the Department of Molecular Science and of the Vascular Biology Center of Excellence. 